\title{
Measuring solar reflectance - Part I: defining a metric that accurately predicts solar heat gain
}

\author{
Ronnen Levinson \\ Hashem Akbari* \\ Paul Berdahl \\ Heat Island Group \\ Lawrence Berkeley National Laboratory
}

April 28, 2010

\begin{abstract}
Solar reflectance can vary with the spectral and angular distributions of incident sunlight, which in turn depend on surface orientation, solar position and atmospheric conditions. A widely used solar reflectance metric based on the ASTM Standard E891 beam-normal solar spectral irradiance underestimates the solar heat gain of a spectrally selective "cool colored" surface because this irradiance contains a greater fraction of near-infrared light than typically found in ordinary (unconcentrated) global sunlight. At mainland U.S. latitudes, this metric $R_{\mathrm{E} 891 \mathrm{BN}}$ can underestimate the annual peak solar heat gain of a typical roof or pavement (slope $\left.\leq 5: 12\left[23^{\circ}\right]\right)$ by as much as $89 \mathrm{~W} \mathrm{~m}^{-2}$, and underestimate its peak surface temperature by up to $5 \mathrm{~K}$. Using $R_{\mathrm{E} 891 \mathrm{BN}}$ to characterize roofs in a building energy simulation can exaggerate the economic value $N$ of annual cool-roof net energy savings by as much as $23 \%$.

We define clear-sky air mass one global horizontal ("AM1GH") solar reflectance $R_{\mathrm{g}, 0}$, a simple and easily measured property that more accurately predicts solar heat gain. $R_{\mathrm{g}, 0}$ predicts the annual peak solar heat gain of a roof or pavement to within $2 \mathrm{~W} \mathrm{~m}^{-2}$, and overestimates $N$ by no more than $3 \% . R_{\mathrm{g}, 0}$ is well suited to rating the solar reflectances of roofs, pavements and walls. We show in Part II that $R_{\mathrm{g}, 0}$ can be easily and accurately measured with a pyranometer, a solar spectrophotometer or version 6 of the Solar Spectrum Reflectometer.
\end{abstract}

\footnotetext{
*Akbari's current address: Department of Building, Civil and Environmental Engineering, Concordia University, Montreal, Quebec, Canada.
} 


\section{Introduction}

Absorption of sunlight warms the exterior surfaces of buildings and vehicles, increasing demand for space cooling energy in summer and reducing use of space heating energy in winter $[1,2]$. Solar absorption by these and other outdoor surfaces, such as pavements, tends to raise the outside air temperature, further augmenting the need for summer cooling energy and decreasing the need for winter heating energy $[3,4]$. Solar heat gain also increases a surface's peak daily temperature. This widens the surface's diurnal temperature range - daytime high minus nighttime low — and can aggravate material stresses that result from thermal expansion and contraction [5].

It is generally easier to measure the fraction of incident sunlight that is reflected than to measure the fraction of incident sunlight that is absorbed. Therefore, the solar absorptance of an opaque surface is usually determined by subtracting its solar reflectance from unity. The goal of this twopart study is to develop an easily measured solar reflectance metric that accurately predicts solar heat gain. In Part I, we consider the variation of solar irradiance and solar reflectance with surface orientation, solar position and atmospheric conditions, then evaluate the errors that result from using constant value of solar reflectance to compute instantaneous, peak and mean solar heat gains. In Part II, we review practical methods for measuring solar reflectance.

We propose a simple and easily measured solar reflectance metric from which one can estimate the solar heat gain of common surfaces, especially roofs and pavements. This metric will be shown to predict the peak and mean solar heat gains of a spectrally selective surface, such as a "cool color," more accurately than another metric in wide use.

The fraction of incident beam light of wavelength $\lambda$ reflected by a flat surface into the hemisphere of origin is its beam-hemispherical spectral reflectance, $r_{\mathrm{b}}(\lambda)$. Painted metals, pigmented plastics and other smooth surfaces often appear glossy, reflecting images only when viewed obliquely. If a surface is glossy, the variation with incidence angle $\theta$ of $r_{\mathrm{b}}(\lambda)$ can be estimated from the Fresnel equations [6]. For a rough surface like a granule-covered roofing shingle, the dependence of $r_{\mathrm{b}}(\lambda)$ on $\theta$ is often governed by "shading" and "masking," the obstruction of incident or reflected light by surface features $[7,8,9]$. Shading and masking effects are quite complex and not addressed here. Instead, we assume that a rough surface has a "matte" spectral reflectance such that $r_{\mathrm{b}}(\lambda)$ is independent of $\theta$. 
An unshaded outdoor surface is exposed to both diffuse and beam (a.k.a. direct) sunlight, while a shaded outdoor surface receives only diffuse sunlight. Global solar irradiance $I_{\mathrm{g}}$ is the solar power per unit surface area incident on a surface from all directions; global solar reflectance $R_{\mathrm{g}}$ is the fraction of this irradiance that is reflected. We use the Gueymard SMARTS (Simple Model of the Atmospheric Radiative Transfer of Sunshine) 2.9.5 algorithm [10] to estimate global, beam and diffuse solar spectral irradiances as a function of solar position, surface orientation and atmospheric turbidity.

Under the atmospheric and ground conditions used to generate ASTM Standard G197-08 (Standard Table for Reference Solar Spectral Distributions: Direct and Diffuse on $20^{\circ}$ Tilted and Vertical Surfaces) [11] (Table 1), a SMARTS simulation of global horizontal irradiance indicates that over $99 \%$ of the sunlight incident on an unshaded horizontal surface illuminated by a zenith sun arrives at wavelengths between 300 and $2500 \mathrm{~nm}$, with about $48 \%$ in the near-infrared (NIR) range of 700 to $2500 \mathrm{~nm}$. This solar irradiance contains about $89 \%$ normal-incidence beam sunlight and $11 \%$ diffuse sunlight. A horizontal surface shaded from the zenith sun receives only diffuse sunlight, of which $17 \%$ is near-infrared (Figure 1).

$R_{\mathrm{g}}$ can depend on the spectral and/or angular distributions of incident sunlight. We illustrate this variation with four examples of flat, horizontal surfaces moved from sun to shade when the sky is clear and the sun is near zenith. In these examples, the surface's normal-incidence beamhemispherical spectral reflectance $r_{\mathrm{b}, \mathrm{n}}(\lambda)$ is assigned value $r_{\mathrm{V}}$ in the $\mathrm{UV}$ and visible spectra (300 $700 \mathrm{~nm})$ and value $r_{\mathrm{N}}$ in the NIR spectrum $(700-2500 \mathrm{~nm})$. Computation details are deferred to $\S 5$.

1. Glossy nonselective black surface. $R_{\mathrm{g}}$ of a glossy surface with constant $r_{\mathrm{b}, \mathrm{n}}(\lambda)$ depends only on the angular distribution of incident light. A glossy nonselective surface of real refractive index 1.5 whose reflectance is due solely to the air-surface interface will exhibit $r_{\mathrm{b}, \mathrm{n}}(\lambda)=0.04$. Moving from sun to shade increases the fraction of sunlight incident at large angles. This raises $R_{\mathrm{g}}$ from 0.05 to 0.09 , for a gain of 0.04 .

2. Glossy selective black surface. $R_{\mathrm{g}}$ of a glossy surface with variable $r_{\mathrm{b}, \mathrm{n}}(\lambda)$ depends on both the angular and spectral distributions of incident sunlight. Consider a glossy selective black surface with $r_{\mathrm{V}}=0.04$ and $r_{\mathrm{N}}=0.90$. Moving from sun to shade increases the fraction of 
sunlight incident at large angles but reduces the NIR fraction. The net effect is to lower $R_{\mathrm{g}}$ from 0.46 to 0.23 , for a loss of 0.23 .

3. Matte nonselective black surface. $R_{\mathrm{g}}$ of a matte nonselective surface is constant.

4. Matte selective black surface. $R_{\mathrm{g}}$ of a matte surface with variable $r_{\mathrm{b}, \mathrm{n}}(\lambda)$ depends only on the spectral distribution of incident sunlight. Consider a matte selective black surface with $r_{\mathrm{V}}=0.04$ and $r_{\mathrm{N}}=0.90$. Moving from sun to shade reduces the portion of sunlight incident in the NIR spectrum. This lowers $R_{\mathrm{g}}$ from 0.46 to 0.19 , for a loss of 0.27 .

\section{Choice of solar reflectance metric}

Solar reflectance is often used to predict solar heat gain, the solar power absorbed per unit surface area. The solar heat gain of an opaque surface is $Q=I_{\mathrm{g}}\left(1-R_{\mathrm{g}}\right) . R_{\mathrm{g}}$ can vary with time of day and day of year as the angular and spectral distributions of sunlight change with solar position and sky conditions.

Building-energy simulation and climate models that compute $Q$ may assign a constant solar reflectance $R$ to each surface regardless of its orientation or the position of the sun. No single value can accurately represent solar reflectance under all conditions unless the surface's reflectance is independent of both incidence angle and wavelength. Thus, we consider two criteria when choosing a solar reflectance metric. First, how well does it estimate solar heat gain? Second, how easily and accurately can it be measured? The following discussion focuses on horizontal surfaces because most pavements and large roofs are approximately horizontal. We will later show that a solar reflectance metric optimized for a horizontal surface will also apply well to moderately pitched roofs with slopes up to $5: 12\left[23^{\circ}\right]$.

\subsection{Approach A: select metric based on an existing standard solar spectral irradiance}

One option is to measure solar reflectance under conditions matching those used to generate a widely used standard solar spectral irradiance, such as one specified in ASTM Standard G173-03 (Standard Tables for Reference Solar Spectral Irradiances: Direct Normal and Hemispherical on 
$37^{\circ}$ Tilted Surface) [12] or G197-08. Table 2 summarizes 10 solar spectral irradiances, including seven published by ASTM and three more simulated in the current study. The air mass (AM) 1.5 and AM2 beam-normal irradiances in ASTM Standards E891-87(1992) [13], G173-03 and E42471(2007) [14] are not suited to roofs and pavements because they exclude diffuse sunlight. The AM1.5 global irradiances in ASTM Standards E892-87(1992) [15], G173-03 and G197-08 describe a sun-facing surface tilted 20 to $90^{\circ}$, rather than a horizontal surface. The global irradiance on a sun-facing tilted surface tends to be richer in NIR radiation than that on a surface that is horizontal or tilted facing away from the sun. For example, the AM1.5 global irradiance on a surface tilted $37^{\circ}$ from horizontal is $51.8 \%$ NIR when faced toward the sun, but only $37.1 \%$ NIR when faced away away from the sun. Thus, none of the existing standard irradiances are ideal for horizontal surfaces exposed to both beam and diffuse sunlight.

Although ASTM Standard E891-87(1992) was withdrawn in 1999, it deserves special attention because the E891BN (E891 Beam Normal) spectral irradiance is widely used for the calculation of terrestrial solar reflectance in ASTM Standard E903-96 (Standard Test Method for Solar Absorptance, Reflectance, and Transmittance of Materials Using Integrating Spheres) [16]. It is also incorporated into ASTM Standard C1549-04 (Standard Test Method for Determination of Solar Reflectance Near Ambient Temperature Using a Portable Solar Reflectometer) [17], because the spectral response of the AM1.5 output of the Devices \& Services Solar Spectrum Reflectometer [18] is designed to mimic the E891BN spectral irradiance. The Solar Spectrum Reflectometer is further detailed in Part II of this study.

E891BN models only beam-normal radiation because it was intended to characterize sunlight incident on a solar concentrator. Its air mass of 1.5 was selected by determining that in many U.S. locations, about half of the annual beam-normal solar energy is delivered when the air mass is less than or equal 1.5. The large atmospheric aerosol optical depth (0.270 at $500 \mathrm{~nm})$ represents a hazy sky. It was selected as an average for the continental United States [19], though the accuracy of this assessment has been questioned [20].

ASTM Standard E903-06 was withdrawn in 2005, but is still referenced by the Cool Roof Rating Council (CRRC) [21], the U.S. EPA Energy Star program [22], ASHRAE Standard 90.1-2007 (Energy Standard for Buildings Except Low-Rise Residential Buildings) [23] and ASHRAE Standard 90.2-2007 (Energy Efficient Design of Low-Rise Residential Buildings) [24] as a test method 
for measuring the solar reflectance of roofs. The current version (3.0) of the U.S. Green Building Council's Leadership in Energy and Environmental Design (LEED) Green Building Rating System [25] references E903 as a method to measure the solar reflectances of both roofs and pavements, and California's 2008 Title 24 (Building Energy Efficiency Standards for Residential and Nonresidential Buildings) [26] references CRRC labels for roof solar reflectance. These standards and rating program also accept C1549 as a test method for rating the solar reflectance of roofs and/or pavements. The CRRC explicitly specifies the use of the reflectometer's AM1.5 output for C1549 solar reflectance measurement. Thus, the E891BN irradiance is currently used in essentially all laboratory measurements of roof solar reflectance in the U.S.

The E891BN solar reflectance $R_{\mathrm{E} 891 \mathrm{BN}}$ measured via E903 or C1549 tends to overestimate the global horizontal solar reflectance of a spectrally selective "cool color" because the NIR fraction of the E891BN irradiance (58.1\%) substantially exceeds than that of global horizontal irradiance (48.7\% at AM1; 49.1\% at AM1.5). Figure 2 illustrates the influence of NIR fraction on the solar reflectance of a selective black surface $\left(r_{\mathrm{V}}=0.04, r_{\mathrm{N}}=0.90\right)$ exposed to the various solar spectral irradiances shown in Figure 3. The E891BN reflectance of this selective black is 0.08 higher than its AM1.5 or AM1 global horizontal solar reflectance.

\subsection{Approach B: select metric that best predicts annual mean solar heat gain}

A second option is to measure solar reflectance under conditions that best predict annual mean solar heat gain. For example, we will show that if the sky is always clear, the solar reflectance property that best predicts the annual mean solar heat gain of a horizontal surface at the U.S. mainland average latitude of $37^{\circ} \mathrm{N}$ is global horizontal solar reflectance measured at a solar zenith angle $z$ of about $56^{\circ}$ (AM1.8). We will show that it is challenging to accurately measure global horizontal solar reflectance with a pyranometer at large solar zenith angles, and that the two other instruments commonly used to measure solar reflectances - the solar spectrophotometer and the Solar Spectrum Reflectometer - are not ordinarily designed to measure reflectance at large incidence angles (here, $\theta=z=56^{\circ}$ ). The difficulties associated with large zenith and/or incidence angles apply also to pyranometer, spectrophotometer and reflectometer measurement of global horizontal solar reflectance at $\operatorname{AM1.5}\left(\theta=z=48.2^{\circ}\right)$. 


\subsection{Approach C: select metric that best predicts annual peak solar heat gain}

A third option is to measure solar reflectance under conditions that best predict annual peak solar heat gain. This is helpful because building air conditioning systems are typically sized to meet annual peak cooling load, rather than annual mean cooling load. Also, a solar reflectance metric $R$ that underestimates $R_{\mathrm{g}}$ by $\Delta R$ will overestimate $Q$ by $\Delta Q=I_{\mathrm{g}} \Delta R$. Defining $R$ to equal $R_{\mathrm{g}}$ at or near peak $I_{\mathrm{g}}$ tends to limit $|\Delta Q|$ by making $\Delta R$ small when $I_{\mathrm{g}}$ is large.

Most pavements and large roofs are approximately horizontal, and therefore tend to be most strongly illuminated when the sun is high and the sky is clear. A zenith sun (AM1) reasonably approximates the solar position of annual peak global horizontal solar irradiance in the mainland U.S., which occurs at $z=1.6^{\circ}(\mathrm{AM} 1.00)$ at $25^{\circ} \mathrm{N}, z=13.6^{\circ}(\mathrm{AM} 1.03)$ at $37^{\circ} \mathrm{N}$, and $z=25.6^{\circ}$ (AM1.11) at $49^{\circ} \mathrm{N}$ (Figure 4). We refer to this clear-sky solar irradiance as "AM1GH," an initialism for Air Mass 1 Global Horizontal. The fraction of sunlight reflected in this configuration is the surface's AM1GH solar reflectance, denoted $R_{\mathrm{g}, 0}$. Later we will show that solar heat gain computed using $R_{\mathrm{g}, 0}$ approximates the annual peak solar heat gain of a horizontal surface in the mainland U.S.to within $2 \mathrm{~W} \mathrm{~m}^{-2}$, and also approximates the solar heat gain of a horizontal surface within $10 \mathrm{~W} \mathrm{~m}^{-2}$ at air masses up to 1.5 . We will also show that $R_{\mathrm{g}, 0}$ predicts the peak global solar heat gain $Q_{\text {peak }}$ of a selective surface much more accurately than does $R_{\mathrm{E} 891 \mathrm{BN}}$.

Daytime mean solar heat gains in winter and summer can be used to estimate the extent to which the absorption of sunlight reduces annual space heating load and/or increases annual space cooling load. Let $\bar{Q}$ represent the daytime mean solar heat gain of a surface. We will show that if a surface is matte, the variation of $R_{\mathrm{g}}$ with solar position is generally small enough to accurately calculate $\bar{Q}$ from $R_{\mathrm{g}, 0}$. However, if a surface is glossy, its spectral reflectance will increase with $\theta$. This tends to make $R_{\mathrm{g}, 0}$ underestimate $R_{\mathrm{g}}$ and overestimate $\bar{Q}$. These errors are most pronounced for horizontal surfaces in winter, when $\theta=z$ remains large even at noon.

If we define the daytime mean solar reflectance $\bar{R}$ as the ratio of reflected solar energy to incident solar energy, it follows that $\bar{R}>R_{\mathrm{g}, 0}$ for a glossy nonselective surface. There will exist for each interval (e.g., summer, winter or year) some incidence angle $\hat{\theta}$ at which $\bar{R}=R_{\mathrm{g}}(\hat{\theta})$. We show that at mainland U.S. latitudes, $\hat{\theta}$ is quite large-about $50^{\circ}$ to $70^{\circ}$.

Finally, we will show in Part II that AM1GH solar reflectance is readily measured with a 
pyranometer, a spectrophotometer, or a solar spectrum reflectometer.

\section{Practical considerations for solar reflectance measurement}

Solar reflectance is typically measured with a pyranometer, a spectrophotometer or a reflectometer. We briefly review why each instrument is well suited to measure $R_{\mathrm{g}, 0}$, but not solar reflectance at a large zenith or incidence angle. These measurement techniques are fully detailed in Part II.

\subsection{Pyranometer measurements}

ASTM E1918-06 (Standard Test Method for Measuring Solar Reflectance of Horizontal and LowSloped Surfaces in the Field) [27] details the use of a pyranometer to measure the clear-sky global solar reflectance of a horizontal or near-horizontal surface (pitch $\leq 2: 12\left[9.5^{\circ}\right]$ ) when $\theta<45^{\circ} . R_{\mathrm{g}, 0}$ is convenient to evaluate with a pyranometer because $R_{\mathrm{g}}$ of a horizontal surface rises by not more than 0.01 as $\theta=z$ increases from 0 to $45^{\circ}$. In summer, the time window during which $z \leq 45^{\circ}$ can be quite wide. For example, on June 21 (the summer solstice), $z \leq 45^{\circ}$ from about 09:00 to 15:00 local standard time (LST) at a mainland-U.S. middle latitude of $37^{\circ} \mathrm{N}$ (Figure 5).

Angular sensitivity narrows the interval during which one can use a pyranometer to accurately measure $R_{\mathrm{g}}$ at large $\theta$. For example, consider the measurement at $z=60^{\circ}$ of the air mass two global horizontal (AM2GH) solar reflectance of a nonselective black glossy surface, such as a conventional black membrane roof. At latitude $37^{\circ} \mathrm{N}$ on June $21, z=60^{\circ}$ and $R_{\mathrm{g}}=0.09$ at about 16:40 LST. After 10 minutes, $z$ increases to $62^{\circ}$ and $R_{\mathrm{g}}$ rises to 0.10 . This indicates that there is roughly a 20-minute window in the morning and a 20-minute window in the afternoon during which one can measure the AM2GH solar reflectance of this surface to within 0.01. Similar analysis shows that there is an 80-minute window in the morning and an 80-minute window in the afternoon during which one can measure the AM1.5GH solar reflectance $\left(R_{\mathrm{g}}=0.06\right.$ at $\left.z=48^{\circ}\right)$ of this surface to within 0.01 .

A related concern is that the pyranometer may be imperfectly leveled, especially in field measurements with portable equipment. If a nominally horizontal pyranometer is tilted $10^{\circ}$ from horizontal and faces away from the sun, $\theta$ will be $70^{\circ}$ when $z=60^{\circ}$. Neglecting shadow and background errors, the surface's AM2GH solar reflectance will be measured as 0.15 , or 0.06 higher than 
its true value of 0.09. Similarly, the surface's AM1.5GH solar reflectance would be measured as 0.083 , or 0.023 higher than its true value of 0.060 , if a $10^{\circ}$ tilt from horizontal increases $\theta$ to $58^{\circ}$ from $48^{\circ}$.

We note that installed roofs and pavements are immovable and can not be tilted toward the sun to reduce solar incidence angle.

\subsection{Spectrophotometer and reflectometer measurements}

The two other instruments commonly used to determine solar reflectance, the solar spectrophotometer and the Solar Spectrum Reflectometer, each measure reflectance at $\theta \leq 20^{\circ}$. They are unable to measure solar reflectance at large $\theta$ because the angles of their optics are fixed. For example, regardless of choice of solar spectral irradiance, both E903 and C1549 will measure the solar reflectance of a nonselective black glossy surface as 0.04. This is just 0.005 lower than its AM1GH solar reflectance of 0.045 , but 0.02 below its AM1.5GH solar reflectance of 0.06 , and 0.05 less than its AM2GH solar reflectance of 0.09 .

We will show that weighting a spectrophotometer measurement of solar spectral reflectance with AM1GH solar spectral irradiance $i_{\mathrm{g}, 0}(\lambda)$ will yield a solar reflectance $R_{\mathrm{g}, 0}^{*}$ that agrees with $R_{\mathrm{g}, 0}$ to within 0.006 (neglecting error in measurement of solar spectral reflectance). We will also show in Part II that the AM1GH output of a new version of the Solar Spectrum Reflectometer (version 6) agrees with $R_{\mathrm{g}, 0}^{*}$ to within 0.01 .

\section{Theory}

Here we formally define $R_{\mathrm{g}}$ and model how it varies with solar position and surface orientation. Roofs, walls and pavements are represented by axisymmetric shapes whose solar reflectances are easy to compute. We define the errors in peak solar heat gain that result from evaluating this property using each of two candidate solar reflectance metrics. We then define annual, winter and summer daytime mean values of global solar reflectance and solar heat gain, and consider the errors in mean solar heat gain that result from replacing a daytime mean value of $R_{\mathrm{g}}$ with each candidate metric. 


\subsection{Definitions of spectral and solar irradiances and reflectances}

Let irradiance $I$ denote incident power per unit surface area and spectral irradiance $i(\lambda)$ represent incident power per unit surface area per unit wavelength. Consider a flat surface that for incident light of wavelength $\lambda$ reflects into the hemisphere of origin a fraction $r_{\mathrm{b}}(\lambda)$ of beam solar spectral irradiance $i_{\mathrm{b}}(\lambda)$ and a fraction $r_{\mathrm{d}}(\lambda)$ of diffuse solar spectral irradiance $i_{\mathrm{d}}(\lambda)$. The fractions of beam solar irradiance

$$
I_{\mathrm{b}} \equiv \int_{\mathcal{S}} i_{\mathrm{b}}(\lambda) d \lambda
$$

and diffuse solar irradiance

$$
I_{\mathrm{d}} \equiv \int_{\mathcal{S}} i_{\mathrm{d}}(\lambda) d \lambda
$$

reflected into the hemisphere of origin will be

$$
R_{\mathrm{b}} \equiv I_{\mathrm{b}}^{-1} \int_{\mathcal{S}} i_{\mathrm{b}}(\lambda) r_{\mathrm{b}}(\lambda) d \lambda
$$

and

$$
R_{\mathrm{d}} \equiv I_{\mathrm{d}}^{-1} \int_{\mathcal{S}} i_{\mathrm{d}}(\lambda) r_{\mathrm{d}}(\lambda) d \lambda
$$

respectively, where $\mathcal{S}$ denotes the solar spectrum. Note that diffuse solar irradiance includes all light scattered out of the solar beam and/or reflected from neighboring surfaces, and is not limited to the subset of this radiation that is isotropic.

Let global spectral irradiance

$$
i_{\mathrm{g}}(\lambda) \equiv i_{\mathrm{b}}(\lambda)+i_{\mathrm{d}}(\lambda)
$$

represent the sum of the beam and diffuse spectral irradiances. The fraction of $i_{\mathrm{g}}(\lambda)$ reflected into the hemisphere of origin will be

$$
r_{\mathrm{g}}(\lambda)=\frac{i_{\mathrm{b}}(\lambda) r_{\mathrm{b}}(\lambda)+i_{\mathrm{d}}(\lambda) r_{\mathrm{d}}(\lambda)}{i_{\mathrm{g}}(\lambda)}=\left[(1-\phi(\lambda)] r_{\mathrm{b}}(\lambda)+\phi(\lambda) r_{\mathrm{d}}(\lambda)\right.
$$

where

$$
\phi(\lambda) \equiv i_{\mathrm{d}}(\lambda) / i_{\mathrm{g}}(\lambda)
$$


is the fraction of $i_{\mathrm{g}}(\lambda)$ that is diffuse. Similarly, the fraction of global solar irradiance

$$
I_{\mathrm{g}} \equiv I_{\mathrm{b}}+I_{\mathrm{d}}
$$

reflected into the hemisphere of origin will be

$$
R_{\mathrm{g}} \equiv I_{\mathrm{g}}^{-1}\left(I_{\mathrm{b}} R_{\mathrm{b}}+I_{\mathrm{d}} R_{\mathrm{d}}\right)=(1-\Phi) R_{\mathrm{b}}+\Phi R_{\mathrm{d}}
$$

where

$$
\Phi \equiv I_{\mathrm{d}} / I_{\mathrm{g}}
$$

is the fraction of $I_{\mathrm{g}}$ that is diffuse. Formally, the properties $r_{\mathrm{b}}(\lambda), R_{\mathrm{b}}, r_{\mathrm{d}}(\lambda), R_{\mathrm{d}}, r_{\mathrm{g}}(\lambda)$ and $R_{\mathrm{g}}$ are the surface's beam-hemispherical spectral reflectance, beam-hemispherical solar reflectance, diffusehemispherical spectral reflectance, diffuse-hemispherical solar reflectance, global-hemispherical spectral reflectance and global-hemispherical solar reflectance, respectively.

Over $99 \%$ of AM1GH sunlight arrives in the solar spectrum $\mathcal{S}=300-2500 \mathrm{~nm}$. We define the ultraviolet, visible and near-infrared (NIR) subranges of the solar spectrum as $\mathcal{U}=300-400$ $\mathrm{nm}, \mathcal{V}=400-700 \mathrm{~nm}$ and $\mathcal{N}=700-2500 \mathrm{~nm}$, respectively. Since "cool colored" spectrally selective surfaces are characterized by low reflectance in the ultraviolet and visible spectra and high reflectance in the near-infrared spectrum, the NIR fraction of $I_{\mathrm{g}}$

$$
f_{\mathrm{g}} \equiv I_{\mathrm{g}}^{-1} \int_{\mathcal{N}} i_{\mathrm{g}}(\lambda) d \lambda
$$

is a helpful indicator of the spectral distribution of sunlight. For example, $R_{\mathrm{g}}$ of a selective black surface is nearly proportional to $f_{\mathrm{g}}$.

\subsection{Variation of spectral irradiance}

Under given atmospheric conditions, the beam solar spectral irradiance $i_{\mathrm{b}}(\lambda ; \theta, z, \gamma)$ depends on beam incidence angle $\theta$, solar zenith angle $z$ and surface solar azimuth angle $\gamma$, where

$$
\cos \theta=\sin (z) \cos (\gamma) \sin (\Sigma)+\cos (z) \cos (\Sigma)
$$


and

$$
\gamma \equiv \xi-\psi
$$

are in turn functions of $z$, solar azimuth angle $\xi$, surface tilt angle $\Sigma$ and/or surface azimuth angle $\psi$. The diffuse solar spectral irradiance $i_{\mathrm{d}}(\lambda ; z, \gamma, \Sigma)$ incident from the sky and ground will also depend on $z, \gamma$ and $\Sigma$.

A spectral irradiance model can be used to simulate beam and diffuse solar spectral irradiances for each specific combination of surface orientation, solar position and atmospheric condition.

\subsection{Simple models of angular spectral reflectance}

Consider a smooth surface that when illuminated by beam light incident from a medium of equal real refractive index exhibits Lambertian reflectance, meaning that the spectral intensity (power per unit wavelength per unit solid angle per unit area normal to the direction of reflection) of reflected light is independent of both incidence direction and reflectance direction. Beam light incident from air will undergo a specular reflectance at the air-surface interface whose magnitude depends on the beam incidence angle, $\theta$; the real refractive index of the surface, $n_{\mathrm{s}}$; and the real refractive index of air, $n_{\mathrm{a}}$. This is a simple model of $r_{\mathrm{b}}(\lambda ; \theta)$ for a "glossy" surface that reflects an image that is easily seen only when viewed obliquely.

We assume that all diffuse solar irradiance is isotropic, and use subscript ' $\mathrm{n}$ ' to denote normal incidence of beam radiation $(\theta=0)$. The beam-hemispherical spectral reflectance $r_{\mathrm{b}}(\lambda)$ and diffusehemispherical spectral reflectance $r_{\mathrm{d}}(\lambda)$ of this glossy surface are related to $r_{\mathrm{b}, \mathrm{n}}(\lambda)$ by

$$
r_{\mathrm{b}}(\lambda ; \theta)=r_{\mathrm{b}, \mathrm{n}}(\lambda)+e_{\mathrm{b}}\left(\theta ; n_{\mathrm{s}}, n_{\mathrm{a}}\right)\left[1-r_{\mathrm{b}, \mathrm{n}}(\lambda)\right]
$$

and

$$
r_{\mathrm{d}}(\lambda)=r_{\mathrm{b}, \mathrm{n}}(\lambda)+e_{\mathrm{d}}\left(n_{\mathrm{s}}, n_{\mathrm{a}}\right)\left[1-r_{\mathrm{b}, \mathrm{n}}(\lambda)\right]
$$

respectively. The "interface reflection" functions $e_{\mathrm{b}}\left(\theta ; n_{\mathrm{s}}, n_{\mathrm{a}}\right)$ and $e_{\mathrm{d}}\left(n_{\mathrm{s}}, n_{\mathrm{a}}\right)$ are derived in Appendix $\mathrm{A}$, and values for light passing from air $\left(n_{\mathrm{a}}=1\right)$ to a surface of real refractive index $n_{\mathrm{s}}=1.5$ are plotted in Figure 6. Note that the influences of the specular interface reflection on $r_{\mathrm{b}}(\lambda)$ and $r_{\mathrm{d}}(\lambda)$ are greatest when $r_{\mathrm{b}, \mathrm{n}}(\lambda)$ approaches zero, and least when $r_{\mathrm{b}, \mathrm{n}}(\lambda)$ approaches unity. 
If the surface is rough in a manner that makes $r_{\mathrm{b}}(\lambda)$ independent of $\theta$ when light is incident from air, then $r_{\mathrm{b}}(\lambda ; \theta)=r_{\mathrm{d}}(\lambda)=r_{\mathrm{b}, \mathrm{n}}(\lambda)$. This is a simple "matte" ( $\theta$-invariant) model of beamhemispherical spectral reflectance of light from air.

\subsection{Simple geometric representations of common exterior surfaces}

A horizontal surface well approximates the geometry of a low-sloped roof or pavement, but not that of a pitched roof or a closed vertical wall. We consider three simple surfaces: (1) a low-sloped roof or pavement; (2) a pitched roof composed of outwardly facing planes that share a common slope and exhibit no preferred azimuthal direction; and (3) a closed wall formed of vertical surfaces that exhibit no preferred azimuthal direction. Each of these ideal surfaces can be approximated by an axisymmetric surface of constant tilt angle $\Sigma$. Modeling a roof, pavement, or closed wall in this manner greatly simplifies computation of $R_{\mathrm{g}}$ and $Q$ by making incident and reflected global solar irradiances independent of solar azimuth angle $\xi$.

The low-sloped roof or pavement is represented by a horizontal plane $(\Sigma=0)$; a pitched roof, by the curved wall of a right circular cone or truncated cone $\left(0<\Sigma<90^{\circ}\right)$; and a closed wall, by the curved wall of a right circular cylinder $\left(\Sigma=90^{\circ}\right)$. A roof or closed wall that does not take one of these forms can still be modeled as a constant-tilt axisymmetric surface if its planes (flat surfaces) share a common slope but face different directions. This approximation improves when applied to a large population of roof or exterior wall surfaces - e.g., all roofing planes in a typical suburban residential development - that share the same tilt and do not exhibit a preferred azimuthal orientation (Figure 7).

Eq. (12) indicates that $\theta$ is symmetric about $\gamma=0$; i.e., $\theta(z,-\gamma, \Sigma)=\theta(z, \gamma, \Sigma)$. Assume that $i_{\mathrm{b}}(\lambda)$ and $i_{\mathrm{d}}(\lambda)$ are also each symmetric about $\gamma=0$. The spatial mean global solar irradiance and spatial mean solar reflectance of an axisymmetric surface of constant tilt angle $\Sigma$ and spatially uniform $r_{\mathrm{b}, \mathrm{n}}(\lambda)$ are then

$$
I_{\mathrm{g}, \operatorname{axi}}(z, \Sigma)=\pi^{-1} \int_{0}^{\pi} I_{\mathrm{g}}(z, \gamma, \Sigma) d \gamma
$$

and

$$
R_{\mathrm{g}, \operatorname{axi}}(z, \Sigma)=\frac{\int_{0}^{\pi} I_{\mathrm{g}}(z, \gamma, \Sigma) R_{\mathrm{g}}(\theta[(z, \gamma, \Sigma)]) d \gamma}{\int_{0}^{\pi} I_{\mathrm{g}}(z, \gamma, \Sigma) d \gamma}
$$

respectively. 


\subsection{Time-averaged values of global solar reflectance and solar heat gain}

Let an overhead bar denote evaluation of mean value over the daytime hours of a season or year. The daytime mean solar heat gain $\bar{Q}$ (absorbed power per unit surface area) of a solar-opaque surface can be written in terms of its daytime mean global solar irradiance $\bar{I}$ and its daytime mean global solar reflectance $\bar{R}$ :

$$
\bar{Q} \equiv \tau_{\text {day }}^{-1} \int_{\tau_{\text {day }}} I_{\mathrm{g}}(t)\left[1-R_{\mathrm{g}}(t)\right] d t=\bar{I}[1-\bar{R}]
$$

where

$$
\bar{I} \equiv \tau_{\text {day }}^{-1} \int_{\tau_{\text {day }}} I_{\mathrm{g}}(t) d t
$$

and

$$
\bar{R} \equiv \frac{\int_{\tau_{\text {day }}} I_{\mathrm{g}}(t) R_{\mathrm{g}}(t) d t}{\int_{\tau_{\text {day }}} I_{\mathrm{g}}(t) d t} .
$$

Here $\tau_{\text {day }}$ is the portion of the interval for which $I_{\mathrm{g}}(t)>0 . \bar{I}$ and $\bar{R}$ of an axisymmetric surface can be computed by substituting $I_{\mathrm{g}, \text { axi }}(t)$ for $I_{\mathrm{g}}(t)$ and $R_{\mathrm{g}, \text { axi }}(t)$ for $R_{\mathrm{g}}(t)$ in Eqs. (19) and (20).

Evaluation of $\bar{R}$ requires either (a) measuring time series of incident and reflected irradiances $I_{\mathrm{g}}(t)$ and $I_{\mathrm{g}}(t) R_{\mathrm{g}}(t)$ with a pyranometer; or $(\mathrm{b})$ measuring $r_{\mathrm{b}, \mathrm{n}}(\lambda)$ with a solar spectrophotometer, then simulating time series of $I_{\mathrm{g}}(t)$ and $R_{\mathrm{g}}(t)$ from knowledge of solar position, surface orientation and atmospheric conditions. We take the latter approach. Note that since the noon sun is higher in summer than in winter, $\bar{R}_{\text {summer }}$ can differ from $\bar{R}_{\text {winter }}$ and $\bar{R}_{\text {annual }}$.

\subsection{Errors in global solar reflectance and solar heat gain}

A building-energy or climate simulation model might approximate the instantaneous global solar reflectance of an axisymmetric surface $R_{\mathrm{g}}(z)$ by some fixed value $R_{j}$. Substituting $R_{j}$ for $R_{\mathrm{g}}(z)$ will underestimate $R_{\mathrm{g}}(z)$ by

$$
\Delta R_{j}(z) \equiv R_{\mathrm{g}}(z)-R_{j}
$$

and overestimate instantaneous solar heat gain $Q(z)$ by

$$
\Delta Q_{j}(z) \equiv I_{\mathrm{g}}(z) \Delta R_{j}(z) .
$$


If a surface experiences peak $Q$ at $z=\tilde{z}$, substituting $R_{j}$ for $R_{\mathrm{g}}(\tilde{z})$ will overestimate $Q_{\text {peak }}$ by

$$
\Delta Q_{\text {peak }, j} \equiv I_{\mathrm{g}}(\tilde{z}) \Delta R_{j}(\tilde{z})
$$

Similarly, replacing $\bar{R}$ by $R_{j}$ will underestimate $\bar{R}$ by

$$
\Delta \bar{R}_{j} \equiv \bar{R}-R_{j}
$$

and overestimate $\bar{Q}$ by

$$
\Delta \bar{Q}_{j} \equiv \bar{I} \Delta \bar{R}_{j}
$$

We show in Appendix $\mathrm{C}$ that under typical convective and radiative conditions, each $10 \mathrm{~W} \mathrm{~m}^{-2}$ overestimation of solar heat gain will overestimate surface temperature by no more than $0.6 \mathrm{~K}$.

\subsection{Overestimation of building energy savings}

Increasing the solar reflectance of a building's roof can reduce annual cooling energy use and/or increase annual heating energy use. Building energy simulation tools that do not adjust the solar reflectance of a building's roof for surface orientation or solar position may inaccurately estimate solar heat gains in the cooling and heating seasons. Consider a building whose conditioning energy use is modeled first with a roof of low solar reflectance, and then again with a roof of high solar reflectance. If each roof is assigned a fixed solar reflectance $R_{j}$ (e.g., $R_{1}=R_{\mathrm{E} 891 \mathrm{BN}}$ or $R_{2}=R_{\mathrm{g}, 0}$ ), the simulated heating energy penalty and cooling energy savings will each be proportional to the assumed increase in the roof's solar reflectance, $\delta R_{j}[28]$.

In climates where cooling is required primarily in summer and heating is required primarily in winter, it may be more realistic to assume that the cooling energy savings will be proportional to the increase in summer daytime mean global solar reflectance, $\delta \bar{R}_{\text {summer }}$, and that the heating energy penalty will be proportional to the increase in winter daytime mean global solar reflectance, $\delta \bar{R}_{\text {winter. }}$. In such climates, the fraction by which the simulation results overestimate the cooling energy savings is that by which $\delta R_{j}$ overestimates $\delta \bar{R}_{\text {summer }}$ :

$$
F_{\text {summer }, j}=\left(\delta R_{j}-\delta \bar{R}_{\text {summer }}\right) / \delta \bar{R}_{\text {summer }} .
$$


Similarly, the fraction by which the simulation results overestimate the heating energy penalty is that by which $\delta R_{j}$ overestimates $\delta \bar{R}_{\text {winter: }}$

$$
F_{\text {winter }, j}=\left(\delta R_{j}-\delta \bar{R}_{\text {winter }}\right) / \delta \bar{R}_{\text {winter }}
$$

The annual analog

$$
F_{\text {annual }, j}=\left(\delta R_{j}-\delta \bar{R}_{\text {annual }}\right) / \delta \bar{R}_{\text {annual }}
$$

can be applied to buildings that require either year-round cooling or year-round heating.

The net economic value of the building's annual conditioning energy savings is $N=C-H$, where $C$ and $H$ are the nonnegative economic values of the annual cooling energy savings and annual heating energy penalty, respectively. If a simulation overestimates $C$ by fraction $F_{\text {summer }}$ and overestimates $H$ by fraction $F_{\text {winter }}$, the fraction by which it overestimates $N$ is

$$
\mathcal{F}_{\text {net }}=\left(F_{\text {summer }} C-F_{\text {winter }} H\right) /(C-H) \text {. }
$$

If $F_{\text {winter }} \geq F_{\text {summer }}$, it follows that

$$
\mathcal{F}_{\text {net }} \leq F_{\text {summer }}
$$

This is a helpful result because it will be shown that $F_{\text {winter }}$ is typically greater than $F_{\text {summer }}$ for

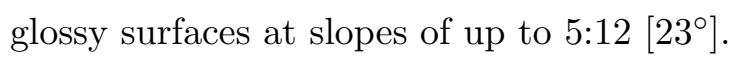

\subsection{Solar reflectance metrics}

Here we define three solar reflectance metrics. The first, E891BN solar reflectance $R_{\mathrm{E} 891 \mathrm{BN}}$, characterizes a solar concentrator. The second, AM1GH solar reflectance $R_{\mathrm{g}, 0}$, is designed to predict the solar heat gain of a surface exposed to ordinary (unconcentrated) sunlight. The third, E903_AM1GH solar reflectance $R_{\mathrm{g}, 0}^{*}$, is a close approximation to $R_{\mathrm{g}, 0}$ that can be measured with a solar spectrophotometer.

A surface's E891BN solar reflectance $R_{\mathrm{E} 891 \mathrm{BN}}$ is defined as

$$
R_{\mathrm{E} 891 \mathrm{BN}} \equiv I_{\mathrm{E} 891 \mathrm{BN}}^{-1} \int_{\mathcal{S}} i_{\mathrm{E} 891 \mathrm{BN}}(\lambda) r_{\mathrm{b}, \mathrm{n}}(\lambda) d \lambda
$$


where E891BN solar irradiance $I_{\mathrm{E} 891 \mathrm{BN}} \equiv \int_{\mathcal{S}} i_{\mathrm{E} 891 \mathrm{BN}}(\lambda) d \lambda$. A solar spectrophotometer equipped with an integrating sphere measures near-normal beam-hemispherical spectral reflectance $r_{\mathrm{b}, \mathrm{nn}}(\lambda)$ rather than $r_{\mathrm{b}, \mathrm{n}}(\lambda)$. However, substituting $r_{\mathrm{b}, \mathrm{nn}}(\lambda)$ for $r_{\mathrm{b}, \mathrm{n}}(\lambda)$ in Eq. (31) induces negligible error because $r_{\mathrm{b}, \mathrm{nn}}(\lambda)$ exceeds $r_{\mathrm{b}, \mathrm{n}}(\lambda)$ by less than $10^{-3}$ for a surface of real refractive index 1.5 (Appendix B).

Let the subscript 0 indicate that the sky is clear, the surface is horizontal and the sun is at zenith $(z=0)$. The material's AM1GH solar reflectance $R_{\mathrm{g}, 0}$ is defined as

$$
R_{\mathrm{g}, 0} \equiv I_{\mathrm{g}, 0}^{-1} \int_{\mathcal{S}} i_{\mathrm{g}, 0}(\lambda) r_{\mathrm{g}, 0}(\lambda) d \lambda
$$

where AM1GH solar irradiance $I_{\mathrm{g}, 0} \equiv \int_{\mathcal{S}} i_{\mathrm{g}, 0}(\lambda) d \lambda$.

Spectrophotometer measurements of $r_{\mathrm{b}, \mathrm{nn}}(\lambda)$ can be used to estimate AM1GH solar reflectance by substituting $r_{\mathrm{b}, \mathrm{nn}}(\lambda)$ for $r_{\mathrm{g}, 0}(\lambda)$ in Eq. $(32)$. We show in Appendix B that this "E903_AM1GH" solar reflectance

$$
R_{\mathrm{g}, 0}^{*} \equiv I_{\mathrm{g}, 0}^{-1} \int_{\mathcal{S}} i_{\mathrm{g}, 0}(\lambda) r_{\mathrm{b}, \mathrm{n}}(\lambda) d \lambda
$$

underestimates $R_{\mathrm{g}, 0}$ by no more than 0.006 .

We model simplified surfaces whose $r_{\mathrm{b}, \mathrm{n}}(\lambda)$ has value $r_{\mathrm{V}}$ in the UV and visible spectra (300 $700 \mathrm{~nm})$ and value $r_{\mathrm{N}}$ in the NIR spectrum $(700-2500 \mathrm{~nm})$. The E891BN and E903_AM1GH solar reflectances of such a surface are

$$
R_{\mathrm{E} 891 \mathrm{BN}}=\left(1-f_{\mathrm{E} 891 \mathrm{BN}}\right) r_{\mathrm{V}}+\left(f_{\mathrm{E} 891 \mathrm{BN}}\right) r_{\mathrm{N}}
$$

and

$$
R_{\mathrm{g}, 0}^{*}=\left(1-f_{\mathrm{AM} 1 \mathrm{GH}}\right) r_{\mathrm{V}}+\left(f_{\mathrm{AM} 1 \mathrm{GH}}\right) r_{\mathrm{N}}
$$

respectively. Here $f_{\mathrm{E} 891 \mathrm{BN}}=0.581$ and $f_{\mathrm{AM} 1 \mathrm{GH}}=0.485$ are the NIR fractions of the E891BN and AM1GH solar irradiances. It also follows from Eqs. (32), (33), (6) and (15) that for such surfaces

$$
R_{\mathrm{g}, 0}=R_{\mathrm{g}, 0}^{*}+e_{\mathrm{d}}\left(n_{\mathrm{s}}, n_{\mathrm{a}}\right) \Phi_{\mathrm{AM} 1 \mathrm{GH}}\left[\left(1-f_{\mathrm{AM} 1 \mathrm{DH}}\right)\left(1-r_{\mathrm{V}}\right)+\left(f_{\mathrm{AM} 1 \mathrm{DH}}\right)\left(1-r_{\mathrm{N}}\right)\right]
$$


where $\Phi_{\mathrm{AM} 1 \mathrm{GH}}=0.106$ is the diffuse fraction of the AM1GH solar irradiance, $f_{\mathrm{AM} 1 \mathrm{DH}}=0.173$ is the NIR fraction of the air mass 1 diffuse horizontal (AM1DH) solar irradiance, and interface diffuse reflection function $e_{\mathrm{d}}\left(n_{\mathrm{s}}, n_{\mathrm{a}}\right)=0.0539$ for a surface of $n_{\mathrm{s}}=1.5$.

\section{Simulations}

We employ a solar irradiance simulation tool to estimate for a wide range of solar positions the solar spectral irradiances incident on surfaces of various orientations. A second tool is used to compute the annual solar trajectory at several mainland U.S. latitudes. We calculate the E891BN and AM1GH solar reflectances of a variety of materials. We then compute at tilts ranging from horizontal to vertical the errors in solar heat gain and simulated cool-roof net energy savings that result from using each solar reflectance metric.

\subsection{Solar spectral irradiances}

Beam and diffuse solar spectral irradiances incident on unshaded surfaces were simulated with version 2.9.5 of the SMARTS algorithm [10]. Spectral irradiances were calculated at a $5 \mathrm{~nm}$ interval from 300 to $2500 \mathrm{~nm}$ for all combinations of 10 surface slopes, 49 solar zenith angles and 37 surface solar azimuth angles (Table 3). The domain of surface solar azimuth angle $\gamma$ was restricted to 0 $180^{\circ}$ because the beam and diffuse spectral irradiances predicted by the simulation model are each symmetric about $\gamma=0$.

Each irradiance was computed twice: once for the clear-sky (low turbidity) atmospheric conditions used in the active ASTM Standards G173-03 and G197-08, and again for hazy-sky (high turbidity) atmospheric conditions referenced in the withdrawn ASTM Standards E891-87(1992), E892-87(1992) and G159-98. The only difference between these two conditions was the assignment of greater atmospheric turbidity to the latter (Table 1). When the sun is at zenith, the clear-sky and hazy-sky $I_{\mathrm{g}}$ incident on a horizontal surface are quite similar (Figure 8).

We note that these simulations do not account for other factors that can influence solar irradiance, such as clouds and snow cover. 


\subsection{Spectral reflectances}

We considered both glossy and matte materials with each of six solar spectral reflectances designated "nonselective black," "nonselective gray," "nonselective white," "selective black," "selective gray" and "selective white" (Table 4). Nonselective black, gray and white represent conventionally colored materials, and were assigned a uniform $r_{\mathrm{b}, \mathrm{n}}(\lambda)$ of $0.04,0.20$ or 0.90 , respectively. Selective black and gray represent materials designed to offer both dark appearance and high NIR reflectance through use of colorants that weakly absorb and/or strongly backscatter near-infrared light. These "cool colored" surfaces can be used to reduce the solar heat gain of nonwhite roofs. The selective black was assigned $r_{\mathrm{b}, \mathrm{n}}(\lambda)$ values of $r_{\mathrm{V}}=0.04$ in the $\mathrm{UV}$ and visible spectra $(300-700 \mathrm{~nm})$ and $r_{\mathrm{N}}=0.90$ in the NIR spectrum $(700-2500 \mathrm{~nm})$. The selective gray was assigned $r_{\mathrm{V}}=0.20$ and $r_{\mathrm{N}}=0.90$.

The complement of a selective black is a selective white, a material with a high $\mathrm{UV} /$ visible spectral reflectance $r_{\mathrm{V}}=0.90$ and a minimal NIR spectral reflectance $r_{\mathrm{N}}=0.04$. The selective white is largely hypothetical because visible reflectance rarely exceeds NIR reflectance by more than about 0.2 . There are two reasons for this. First, colorants typically exhibit stronger absorption in the UV and visible spectra than in the NIR. Second, while the common white pigment titanium dioxide rutile backscatters more strongly in the visible spectrum than in the NIR spectrum, this spectral variation in backscattering is insufficient to create simultaneous high visible reflectance and low near-infrared reflectance $[6,29,30]$. Thus while the selective white material was included for completeness, it is not a case of practical significance.

\subsection{Instantaneous and peak solar heat gains}

$R_{\mathrm{E} 891 \mathrm{BN}}, R_{\mathrm{g}, 0}^{*}$ and $R_{\mathrm{g}, 0}$ of each of the 12 materials ( 2 reflectance models $\times 6$ spectral reflectances) were computed from Eqs. (34) - (36). Each material was then considered in constant-tilt axisymmetric surfaces of 10 slopes ranging from horizontal to vertical (Table 3$)$. Variations with $z$ (0 to $\left.89.9^{\circ}\right)$ of $I_{\mathrm{b}}(z), I_{\mathrm{d}}(z)$ and $I_{\mathrm{g}}(z) ; \Phi(z)$ and $f_{\mathrm{g}}(z) ; R_{\mathrm{g}}(z) ; \Delta R_{1}(z)$ and $\Delta R_{2}(z) ;$ and $\Delta Q_{1}(z)$ and $\Delta Q_{2}(z)$ were evaluated using Eqs. (1) - (4), (9), (10), (16), (17), (21), (22) and (A.1) - (A.10). $\Delta Q_{\text {peak }, j}$ was calculated from Eq. (23). All values for the 120 axisymmetric surfaces (12 materials $\times 10$ tilts) were computed under both clear-sky and hazy-sky atmospheric conditions. 


\subsection{Mean solar heat gains}

Two errors in daytime mean solar heat gain $-\Delta \bar{Q}_{1}$, induced by substituting $R_{\mathrm{E} 891 \mathrm{BN}}$ for winter, summer or annual mean solar reflectance $\bar{R}$; and $\Delta \bar{Q}_{2}$, yielded by substituting $R_{\mathrm{g}, 0}$ for $\bar{R}$-were computed using Eqs. (24) and (25). The annual interval was represented by the 21st day of each month; winter, by the 21st days of December, January and February; and summer, by the 21st days of June, July and August.

Each $\Delta \bar{Q}_{j}$ was evaluated under both clear-sky and hazy-sky atmospheric conditions at latitudes of $25^{\circ} \mathrm{N}, 37^{\circ} \mathrm{N}$ and $49^{\circ} \mathrm{N}$. This range of latitudes spans the continental U.S. Version 2.0 of the NREL SOLPOS (SOLar POSition) calculator [31] was used to compute $z$ and $\xi$ at each latitude every 15 minutes over the course of a year.

\subsection{Cool-roof net energy savings}

We considered four upgrades from a conventional roof to a cool roof: (a) nonselective black to nonselective white; (b) nonselective gray to nonselective white; (c) nonselective black to selective black; and (d) nonselective gray to selective gray. The first two upgrades represent the installation of a light-colored cool roof; the third and fourth represent the installation of a dark-colored cool roof. Overestimations of the resulting cooling energy savings in summer, heating energy penalty in winter, or annual energy savings in a climate that requires year-round cooling or year-round heating were approximated by calculating $F_{\text {summer }, j}, F_{\text {winter, } j}$ and $F_{\text {annual, } j}$ from Eqs. (26) - (28). Each $F_{j}$ was evaluated under both a clear sky and a hazy sky using $R_{1}=R_{\mathrm{E} 891 \mathrm{BN}}$ and $R_{2}=R_{\mathrm{g}, 0}$.

\section{$6 \quad$ Results}

Here we explore trends in solar irradiance; compare the values of several solar reflectance metrics; and evaluate the accuracy with which each metric predicts instantaneous, peak and mean solar heat gains, as well as cool-roof net energy savings.

\subsection{Solar irradiance trends}

We begin by considering trends in solar irradiance that influence $R_{\mathrm{g}}$. Figure 9 shows for three axisymmetric surfaces $I_{\mathrm{g}}(z), I_{\mathrm{b}}(z)$ and $I_{\mathrm{d}}(z)$ under both clear and hazy skies. Also drawn are the 
diffuse fraction $\Phi(z)$ and NIR fraction $f_{\mathrm{g}}(z)$ of $I_{\mathrm{g}}(z)$. The horizontal surface represents a low-sloped roof or pavement; the medium-slope $\left(5: 12\left[23^{\circ}\right]\right)$ surface, a pitched roof; and the vertical surface, a wall.

Since the effective $\theta$ of isotropically diffuse light is about $60^{\circ}$ [32], increasing $\Phi$ tends to augment $R_{\mathrm{g}}$ of a glossy surface when $\theta<60^{\circ}$. Haziness increases $\Phi$. For example, a horizontal surface under a zenith sun receives about $11 \%$ diffuse light when the sky is clear, and $19 \%$ diffuse light when the sky is hazy. Sunlight incident on the horizontal and medium-slope surfaces also tends to grow more diffuse as the air mass - roughly equal to $1 / \cos (z)$ - and thus the atmospheric path length available for scattering increase. Note, however, that at $z<85^{\circ}$, the global sunlight received by an axisymmetric vertical surface actually grows less diffuse as air mass increases because a vertical surface receives no beam light when the sun is directly overhead (Table 5).

Increases in $f_{\mathrm{g}}$ will tend to augment $R_{\mathrm{g}}$ of a spectrally selective "cool colored" surface. Haze has little effect on $f_{\mathrm{g}}$. For example, a horizontal surface under a zenith sun receives $48.5 \%$ diffuse light when the sky is clear, and $48.8 \%$ NIR light when the sky is hazy. At $z \leq 60^{\circ}, f_{\mathrm{g}}$ increases very slowly with $z$ for horizontal and medium-slope surfaces, but increases rapidly with $z$ for a vertical surface (Table 6).

While the sunlight incident on a horizontal or medium-slope surface becomes more diffuse and NIR-rich as $z$ increases, the rise in $f_{\mathrm{g}}$ between $z=0$ and $z=60^{\circ}$ is less than 0.01 under a clear sky. This suggests that as air mass increases from 1 to 2 , any changes to $R_{\mathrm{g}}$ of a horizontal or medium-slope selective glossy surface under a clear sky will result almost entirely from increases in $\Phi$.

\subsection{Solar reflectance metrics}

Here we compare the values of solar reflectance metrics $R_{\mathrm{E} 891 \mathrm{BN}}, R_{\mathrm{g}, 0}$ and $R_{\mathrm{g}, 0}^{*}$. Table 4 shows $r_{\mathrm{b}, \mathrm{n}}(\lambda), R_{\mathrm{E} 891 \mathrm{BN}}, R_{\mathrm{g}, 0}$ and $R_{\mathrm{g}, 0}^{*}$ of each of the 12 materials $(2$ reflectance models $\times 6$ spectral reflectances). $R_{\mathrm{g}, 0}^{*}$ equals $R_{\mathrm{g}, 0}$ for matte materials because the spectral reflectance of a matte surface is assumed not to vary with incidence angle. If a surface is glossy, $R_{\mathrm{g}, 0}^{*}$ slightly underestimates $R_{\mathrm{g}, 0}$ because about $11 \%$ of the AM1GH solar spectral irradiance is diffuse and therefore arrives at non-normal incidence. The difference $R_{\mathrm{g}, 0}-R_{\mathrm{g}, 0}^{*}$ ranges from 0.001 to 0.005 for the six glossy materials. 
$R_{\mathrm{E} 891 \mathrm{BN}}$ equals $R_{\mathrm{g}, 0}^{*}$ for each nonselective surface because both metrics assume normally incident light. However, $R_{\mathrm{E} 891 \mathrm{BN}}$ of each selective surface exceeds $R_{\mathrm{g}, 0}$ by about -0.08 (selective white) to +0.08 (selective black) because $f_{\mathrm{E} 891 \mathrm{BN}}-f_{\mathrm{AM} 1 \mathrm{GH}}=0.10$.

To summarize, $R_{\mathrm{E} 891 \mathrm{BN}}, R_{\mathrm{g}, 0}$ and $R_{\mathrm{g}, 0}^{*}$ all agree to within 0.006 for each nonselective material, but $R_{\mathrm{E} 891 \mathrm{BN}}$ differs from $R_{\mathrm{g}, 0}$ and $R_{\mathrm{g}, 0}^{*}$ by as much as 0.08 for each selective material.

\subsection{Instantaneous solar heat gains}

Here we consider the accuracy with which $R_{1}=R_{\mathrm{E} 891 \mathrm{BN}}$ and $R_{2}=R_{\mathrm{g}, 0}$ each predict $Q(z)$. All figures presented hereafter characterize surfaces under a clear sky. Hazy-sky outcomes are very similar to those shown for a clear sky, and are therefore omitted to save space.

Figures 10 and 11 show for horizontal, medium-slope $\left(5: 12\left[23^{\circ}\right]\right)$ and vertical axisymmetric glossy surfaces the errors $\Delta R_{j}(z)$ and $\Delta Q_{j}(z)$ that result from replacing $R_{\mathrm{g}}(z)$ by $R_{1}$ or $R_{2}$. Tables 7 and 8 present for axisymmetric surfaces at all 10 simulated tilts the minimum and maximum values of each error $\Delta R_{j}(z)$ and $\Delta Q_{j}(z)$. Clear-sky and hazy-sky errors are shown for the "practical" subset of materials that excludes the hypothetical selective white. For glossy surfaces, the ranges of $\Delta R_{j}(z)$ for both solar reflectance metrics were comparable. However, because selective glossy surfaces exhibit high $\left|\Delta R_{1}(z)\right|$ when $I(z)$ is at or near its peak value, the range of $\Delta Q_{1}(z)$ was roughly twice that of $\Delta Q_{2}(z)$. Note that some of the limiting errors in $Q(z)$ occur at tilts not shown in Figures 10 and 11.

Figures 12 and 13 show errors $\Delta R_{1}(z), \Delta Q_{1}(z), \Delta R_{2}(z)$ and $\Delta Q_{2}(z)$ for matte surfaces under a clear sky. Trends were similar to those observed for glossy surfaces, except that all errors vanish for nonselective matte surfaces. The range of $\Delta R_{1}(z)$ was comparable that of $\Delta R_{2}(z)$, but the range of $\Delta Q_{1}$ was nearly three times that of $\Delta Q_{2}$.

To summarize, using $R_{\mathrm{g}, 0}$ instead of $R_{\mathrm{E} 891 \mathrm{BN}}$ to predict $Q(z)$ reduces the range of instantaneous solar heat gain error $\Delta Q(z)$ by a factor of two to three.

\subsection{Peak solar heat gains}

Here we consider the accuracy with which $R_{1}=R_{\mathrm{E} 891 \mathrm{BN}}$ or $R_{2}=R_{\mathrm{g}, 0}$ each predict $Q_{\text {peak }}$. Table 9 and charts (a) - (b) of Figure 14 show for glossy surfaces at all simulated tilts the error $\Delta Q_{\text {peak, } j}$ that results from substituting $R_{1}$ or $R_{2}$ for $R_{\mathrm{g}}(\tilde{z})$, where $\tilde{z}$ is the solar zenith angle that yields $Q_{\text {peak }}$. 
$\Delta Q_{\text {peak }, 1}$ and $\Delta Q_{\text {peak }, 2}$ are comparable for nonselective glossy surfaces, but $\left|\Delta Q_{\text {peak }, 1}\right| \gg\left|\Delta Q_{\text {peak }, 2}\right|$ for selective glossy surfaces because $f_{\mathrm{g}}(\tilde{z})$ is typically much closer to $f_{\mathrm{AM} 1 \mathrm{GH}}$ than to $f_{\mathrm{E} 891 \mathrm{BN}}$.

Table 9 and charts (c) - (d) of Figure 14 show for matte surfaces the error $\Delta Q_{\text {peak }, j}$ that results from replacing $R_{\mathrm{g}}(\tilde{z})$ by $R_{1}$ or $R_{2}$. If the matte surface is nonselective, either metric will predict $Q_{\text {peak }}$ without error. However, if the matte surface is selective, $\left|\Delta Q_{\text {peak }, 1}\right| \gg\left|\Delta Q_{\text {peak,2 }}\right|$ at any tilt.

These results indicate that $R_{\mathrm{g}, 0}$ more accurately predicts $Q_{\text {peak }}$, especially for selective surfaces at slopes of up to $5: 12\left[23^{\circ}\right]$.

\subsection{Mean solar heat gains}

Here we consider the accuracy with which $R_{1}=R_{\mathrm{E} 891 \mathrm{BN}}$ and $R_{2}=R_{\mathrm{g}, 0}$ each predict $\bar{Q}$. Charts (a) and (b) of Figure 15 characterize for glossy surfaces at all simulated tilts the error $\Delta \bar{Q}_{j}$ induced by substituting $R_{1}=R_{\mathrm{E} 891 \mathrm{BN}}$ or $R_{2}=R_{\mathrm{g}, 0}$ for $\bar{R}$. Winter, annual and summer errors (left column to right column) were evaluated at latitudes of $25^{\circ} \mathrm{N}, 37^{\circ} \mathrm{N}$ and $49^{\circ} \mathrm{N}$ but are plotted only at $37^{\circ} \mathrm{N}$ to save space. For a nonselective glossy surface, $\Delta \bar{Q}_{1} \approx \Delta \bar{Q}_{2}$ because $R_{1} \approx R_{2}$. For a selective glossy surface, $\left|\Delta \bar{Q}_{1}\right| \gg\left|\Delta \bar{Q}_{2}\right|$ because $\left|\Delta Q_{1}(z)\right| \gg\left|\Delta Q_{2}(z)\right|$ over a wide range of $z$. Charts (c) and (d) show $\Delta \bar{Q}_{1}$ and $\Delta \bar{Q}_{2}$ for matte surfaces. Trends were close to those observed for glossy surfaces, except that all errors vanish for nonselective matte surfaces.

Tables 10 and 11 show the minimum and maximum values of $\Delta \bar{R}_{j}$ and $\Delta \bar{Q}_{j}$ over all 10 simulated tilts, all three intervals and all three latitudes. For glossy surfaces, the range of $\Delta \bar{R}_{1}$ was larger than that of $\Delta \bar{R}_{2}$, and the range of $\Delta \bar{Q}_{1}$ was more than twice that of $\Delta \bar{Q}_{2}$. For matte selective surfaces, the range of $\Delta \bar{Q}_{1}$ was nearly four times larger than that of $\Delta \bar{Q}_{2}$.

To summarize, using $R_{\mathrm{g}, 0}$ instead of $R_{\mathrm{E} 891 \mathrm{BN}}$ to predict $\bar{Q}$ reduces the range of mean solar heat gain error $\Delta \bar{Q}$ by a factor of two to four.

\subsection{Cool-roof net energy savings}

Here we consider the accuracy with which $R_{1}=R_{\mathrm{E} 891 \mathrm{BN}}$ and $R_{2}=R_{\mathrm{g}, 0}$ each predict the gain in $\bar{R}$ yielded when replacing a conventional roof by a cool roof. In climates where buildings are cooled in summer and heated in winter, we expect $C \propto \delta \bar{R}_{\text {summer }}$ and $H \propto \delta \bar{R}_{\text {winter. In climates where }}$ buildings require either year-round cooling or year-round heating, we expect either $C \propto \delta \bar{R}_{\text {annual }}$ or $H \propto \delta \bar{R}_{\text {annual }}$. 
Charts (a) and (b) of Figure 16 characterize for glossy surfaces under a clear sky the fractional overestimation $F_{j}$ of $\delta \bar{R}$ in a cool-roof upgrade when $R_{1}=R_{\mathrm{E} 891 \mathrm{BN}}$ or $R_{2}=R_{\mathrm{g}, 0}$ is substituted for $\bar{R}$. Winter, annual and summer errors (left column to right column) were evaluated at latitudes of $25^{\circ} \mathrm{N}, 37^{\circ} \mathrm{N}$ and $49^{\circ} \mathrm{N}$ but are plotted only at $37^{\circ} \mathrm{N}$ to save space.

When upgrading from one nonselective glossy surface to another, $F_{1} \approx F_{2}$. However, when upgrading from a nonselective glossy surface to a selective glossy surface, $\left|F_{1}\right|$ is at most tilts much greater than $\left|F_{2}\right|$. For example, if the surfaces are horizontal, $\left|F_{1}\right|>20 \%$ and $\left|F_{2}\right| \leq 5 \%$. For glossy surfaces at slopes of up to $5: 12\left[23^{\circ}\right], \mathcal{F}_{\text {net }, j} \leq F_{\text {summer }, j}$ because $F_{\text {winter }, j} \geq F_{\text {summer }, j}$ (c.f. $\S 4.7$ ); thus, $\mathcal{F}_{\text {net, } 1} \leq 23 \%$ and $\mathcal{F}_{\text {net }, 2} \leq 3 \%$. That is, while using $R_{\text {E891BN }}$ in simulations can overestimate the economic value $N$ of annual cool-roof net energy savings by up to $23 \%$, using $R_{\mathrm{g}, 0}$ will overestimate $N$ by no more than $3 \%$.

Charts $(\mathrm{c})$ and $(\mathrm{d})$ of Figure 16 show $F_{1}$ and $F_{2}$ for matte surfaces. When upgrading from one nonselective matte surface to another, $F_{1}=F_{2}=0$. When upgrading from a nonselective matte surface to a selective matte surface, $\left|F_{1}\right|$ is generally much greater than $\left|F_{2}\right|$. For example, if the surfaces are horizontal, $\left|F_{1}\right|>15 \%$ and $\left|F_{2}\right| \leq 3 \%$. Since $F_{\text {winter }, j}<F_{\text {summer }, j}$ for matte selective surfaces at slopes of up to $5: 12\left[23^{\circ}\right]$, there is no simple bound on $\mathcal{F}_{\text {net, }, j}$.

To summarize, using $R_{\mathrm{g}, 0}$ instead of $R_{\mathrm{E} 891 \mathrm{BN}}$ better predicts $N$ for glossy selective surfaces at slopes of up to $5: 12\left[23^{\circ}\right]$, bounding overestimation of $N$ at $3 \%$ instead of $23 \%$.

\section{Discussion}

The solar reflectance metrics $R_{\mathrm{E} 891 \mathrm{BN}}$ and $R_{\mathrm{g}, 0}$ have different purposes. $R_{\mathrm{E} 891 \mathrm{BN}}$ is intended to characterize the mean annual solar heat gain of a solar concentrator that receives almost exclusively normal-incidence beam sunlight, while $R_{\mathrm{g}, 0}$ is designed to predict the peak solar heat gain $Q_{\text {peak }}$ of a surface receiving ordinary (unconcentrated) sunlight. If a surface is nonselective, its E891BN and AM1GH solar reflectances $R_{\mathrm{E} 891 \mathrm{BN}}$ and $R_{\mathrm{g}, 0}$ agree to within 0.006 , and thus predict $Q_{\text {peak }}, \bar{Q}$ and the economic value of cool-roof net energy savings $N$ with comparable accuracy. The agreement is exact for matte reflectors.

If a surface is selective, $R_{\mathrm{E} 891 \mathrm{BN}}$ can exceed $R_{\mathrm{g}, 0}$ by as much as 0.08 , and its use can yield larger errors in solar heat gain. We illustrate with values for a glossy horizontal selective black 
surface - e.g., a cool black membrane on a low-sloped roof - that receives unconcentrated sunlight. At latitude $37^{\circ} \mathrm{N}, R_{\mathrm{E} 891 \mathrm{BN}}$ underestimates annual peak solar heat gain (at $z=13.6^{\circ}$ ) by $81 \mathrm{~W} \mathrm{~m}^{-2}$, while $R_{\mathrm{g}, 0}$ predicts this value to within $1 \mathrm{~W} \mathrm{~m}^{-2}$. $R_{\mathrm{E} 891 \mathrm{BN}}$ underestimates $\bar{Q}_{\text {annual }}$ by $28 \mathrm{~W} \mathrm{~m}^{-2}$, while $R_{\mathrm{g}, 0}$ overestimates $\bar{Q}_{\text {annual }}$ by $11 \mathrm{~W} \mathrm{~m}^{-2}$. Simulations of cool-roof net energy savings (nonselective black to selective black) based on $R_{\mathrm{E} 891 \mathrm{BN}}$ can overestimate $N$ by up to $23 \%$, while those based on $R_{\mathrm{g}, 0}$ will overestimate $N$ by no more than $3 \%$. These and similar results presented herein indicated that in ordinary sunlight, $R_{\mathrm{g}, 0}$ tends to predict the solar heat gain of a selective surface more accurately than does $R_{\mathrm{E} 891 \mathrm{BN}}$. $R_{\mathrm{g}, 0}$ performs better than $R_{\mathrm{E} 891 \mathrm{BN}}$ for this purpose mostly because the NIR fraction $f_{\mathrm{g}}$ of global solar irradiance tends to be much closer to $f_{\mathrm{AM} 1 \mathrm{GH}}$ than to $f_{\mathrm{E} 891 \mathrm{BN}}$.

\subsection{Rating the solar reflectances of roofs and pavements}

An important question is whether one should use $R_{\mathrm{E} 891 \mathrm{BN}}$ or $R_{\mathrm{g}, 0}$ to rate the solar reflectance of roofing and paving materials for compliance with energy efficiency standards and programs. Applications include but are not limited to Cool Roof Rating Council and Energy Star product labels, LEED 3.0 certification, and compliance with California Title 24, ASHRAE Standard 90.12007 and ASHRAE Standard 90.2-2007.

Low-sloped roofs (pitch $\leq 2: 12$ ), medium-sloped roofs (pitch 5:12) and low-sloped pavements

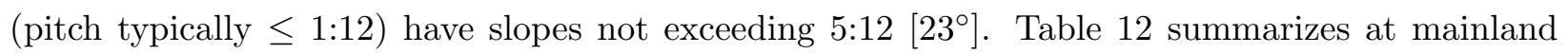
U.S. latitudes the extents to which $R_{\mathrm{E} 891 \mathrm{BN}}$ and $R_{\mathrm{g}, 0}$ each overestimate $Q_{\text {peak }}, \bar{Q}_{\text {annual }}, C, H$ and $N$ for practical glossy axisymmetric surfaces at slopes of up to 5:12. As expected, $R_{\mathrm{g}, 0}$ is much more accurate than $R_{\mathrm{E} 891 \mathrm{BN}}$, especially in prediction of $Q_{\text {peak }}$. $R_{\mathrm{g}, 0}$ conservatively predicts $N$, overestimating it by no more than $3 \%$. If the surfaces are matte, $R_{\mathrm{g}, 0}$ is much more accurate than $R_{\mathrm{E} 891 \mathrm{BN}}$ in prediction of $Q_{\text {peak }}$, and only slightly underestimates $C$ and $H$ (Table 13).

We recommend using $R_{\mathrm{g}, 0}$ to rate the solar reflectance of all roofing and paving materials. This metric is conceptually simple, an excellent predictor of $Q_{\text {peak }}$, and a conservative predictor of $N$ when used in a building energy simulation. 


\subsection{Rating the solar reflectances of walls}

Future energy efficiency standards and programs may rate the solar reflectance of wall materials. Table 14 summarizes at mainland U.S. latitudes the extents to which $R_{\mathrm{E} 891 \mathrm{BN}}$ and $R_{\mathrm{g}, 0}$ each overestimate $Q_{\text {peak }}, \bar{Q}_{\text {annual }}, C$ and $H$ for practical vertical axisymmetric surfaces. $R_{\mathrm{g}, 0}$ is more accurate than $R_{\mathrm{E} 891 \mathrm{BN}}$ for glossy surfaces. If the vertical surfaces are matte, $R_{\mathrm{g}, 0}$ is much more accurate than $R_{\mathrm{E} 891 \mathrm{BN}}$ in prediction of $Q_{\text {peak }}, \bar{Q}_{\text {annual }}$ and $C$, and underestimates $H$ by about the same extent that $R_{\mathrm{E} 891 \mathrm{BN}}$ overestimates $H$ (Table 15). Hence, we also recommend using $R_{\mathrm{g}, 0}$ for all walls.

\subsection{The case for measuring solar reflectance at air mass one}

The sun reaches zenith only in the tropics, and the daytime mean solar zenith angle at any latitude will always be greater than zero. This suggests that one might better predict winter, summer or annual values of $\bar{Q}$ replacing $R_{\mathrm{g}, 0}$ with a global solar reflectance measured at some nonzero solar zenith angle $\hat{z}$ where $R_{\mathrm{g}}(\hat{z})=\bar{R}$. The value of $\hat{z}$ varies with not only with interval-winter, summer or annual—but also with surface tilt and latitude. For a horizontal surface at U.S. mainland latitudes, $\hat{z} \approx 50^{\circ}-70^{\circ}$ (Table 16 ), a range centered approximately about air mass 2 . Yet another option would be to select an air mass of 1.5 to match the solar position used in solar irradiance standards ASTM G173-03 and G197-08. Here we compare the merits of measuring global horizontal solar reflectance at AM1 $\left(z=0^{\circ}\right)$, AM1.5 $\left(z=48.2^{\circ}\right)$, or AM2 $\left(z=60^{\circ}\right)$ based on prediction of annual peak solar heat gain, prediction of annual mean solar heat gain, and measurability.

First criterion: prediction of annual peak solar heat gain. The solar zenith angle of peak annual global horizontal irradiance ranges from $z=1.6^{\circ}(\mathrm{AM} 1.00)$ at latitude $25^{\circ} \mathrm{N}$ to $z=25.6^{\circ}$ (AM1.11) at latitude $49^{\circ} \mathrm{N}$ (Figure 4). AM1.11GH irradiance (48.8\% NIR, 10.9\% diffuse) is virtually identical to AM1GH irradiance (48.7\% NIR, 10.1\% diffuse), and the spectral reflectance of a glossy nonselective black surface at an incidence angle of $\theta=25.6^{\circ}$ is within 0.001 of that at $\theta=0^{\circ}$. Consequently, AM1GH solar reflectance matches the peak-irradiance solar reflectance of a horizontal surface in the mainland U.S. to within 0.001 .

AM1.5GH irradiance (49.1\% NIR, $14.0 \%$ diffuse) and AM2GH irradiance $(49.6 \%$ NIR, $17.4 \%$ diffuse) are each just slightly redder and more diffuse than AM1GH (or AM1.1GH) irradiance. 
However, the spectral reflectances of a glossy nonselective black surface at incidence angles of $\theta=48.2^{\circ}$ and $\theta=60^{\circ}$ are 0.015 and 0.049 higher, respectively, than those at normal incidence. The AM1.5GH and AM2GH solar reflectances of a glossy horizontal surface can therefore exceed its solar reflectance at peak annual solar irradiance by up to 0.015 and 0.044 , respectively. At a typical annual peak solar irradiance of $1 \mathrm{~kW} \mathrm{~m}^{-2}$, AM1GH, AM1.5GH, and AM2GH solar reflectances can underestimate the solar heat gain of a horizontal surface by as much as 1,15 , and $49 \mathrm{~W} \mathrm{~m}^{-2}$.

Second criterion: prediction of annual mean solar heat gain. For a glossy horizontal surface at the mean latitude of the mainland U.S. $\left(37^{\circ} \mathrm{N}\right)$, a global horizontal solar reflectance $R_{\mathrm{g}}(\hat{z})$ equal to its annual mean global horizontal solar reflectance $\bar{R}_{\text {annual }}$ is attained at $\hat{z} \approx 56^{\circ}$. The AM1GH, AM1.5GH and AM2GH solar reflectances of a glossy nonselective black horizontal surface will underestimate $\bar{R}_{\text {annual }}$ by $0.034,0.020$, and -0.010 , respectively, and overestimate its annual mean solar heat gain by 17,10 and $-5 \mathrm{~W} \mathrm{~m}^{-2}$. It is difficult to select a universal solar zenith angle $\hat{z}$ at which $R_{\mathrm{g}}(\hat{z})$ matches $\bar{R}_{\text {annual }}$ because (a) $\hat{z}$ ranges from about $53^{\circ}$ to $60^{\circ}$ within the mainland U.S. (Table 16), and (b) global horizontal solar reflectance can vary rapidly at $z>45^{\circ}$ (Figure 17 ). It is simpler to extrapolate $\bar{R}_{\text {annual }}$ from AM1GH solar reflectance using the glossy-surface reflectance model presented in this study (Appendix D).

Third criterion: measurability. Section 3 presented several practical reasons to measure global horizontal solar reflectance at AM1 rather than at AM1.5 or AM2. AM1GH solar reflectance can be measured easily with a pyranometer, a solar spectrophotometer, or reflectometer. However, AM1.5GH and AM2GH solar reflectances are difficult to measure accurately with a field-installed pyranometer - $\mathrm{a} 10^{\circ}$ tilt error can overestimate global horizontal solar reflectance by up to 0.02 at AM1.5, and by as much as 0.06 at AM2 - and can not be measured accurately with a typical solar spectrophotometer or reflectometer. For example, a pyranometer or reflectometer designed to measure near-normal reflectance will underestimate the AM1.5GH solar reflectance of a glossy nonselective black surface by 0.02 , and underestimate its AM2GH solar reflectance by 0.05 .

Based on these three criteria, we recommend evaluating global horizontal solar reflectance at air mass 1, rather than at air mass 1.5 or air mass 2. However, AM1GH solar reflectance is not intended to characterize sun-facing solar equipment, whose irradiances may be better represented by G197GT (photovoltaic panel parallel to roof), G173GT (photovoltaic panel at latitude tilt) or G173BN (receiver in solar concentrator). The G197GT, G173GT and G173BN irradiances are 
described in Table 2.

\subsection{Applicability of AM1GH solar reflectance outside the mainland U.S.}

Our analysis simulated irradiances at mainland U.S. latitudes $\left(25^{\circ} \mathrm{N}\right.$ to $\left.49^{\circ} \mathrm{N}\right)$ through a U.S. standard cloudless atmosphere (Table 1). However, other things being equal, the accuracy with which the AM1GH solar reflectance metric can be used to estimate annual peak and annual mean solar heat gains should improve as one approaches the equator and peak daily solar positions grow higher. Thus under atmospheric and ground conditions similar to those used to simulate the AM1GH solar spectral irradiance, the AM1GH solar reflectance metric should work well from $49^{\circ} \mathrm{S}$ to $49^{\circ} \mathrm{N}$.

\section{Conclusions}

The E891BN solar reflectance measured in the current versions of ASTM methods E903 and C1549 tends to overestimate the global solar reflectance of a cool colored surface because the high NIR fraction $(58 \%)$ of the E891BN solar irradiance is attained in global sunlight only when the sun is very low. At mainland U.S. latitudes, $R_{\mathrm{E} 891 \mathrm{BN}}$ can underestimate the annual peak solar heat gain of a typical roof or pavement (slope $\leq 5: 12\left[23^{\circ}\right]$ ) by as much as $89 \mathrm{~W} \mathrm{~m}^{-2}$. This can underestimate peak surface temperature by up to $5 \mathrm{~K}\left(10^{\circ} \mathrm{F}\right)$ at the rate of $0.6 \mathrm{~K}$ per $10 \mathrm{~W} \mathrm{~m}^{-2}$. It overestimates the daytime mean solar heat gain $\bar{Q}$ of such surfaces by -41 to $29 \mathrm{~W} \mathrm{~m}^{-2}$ if glossy, or by -50 to $2 \mathrm{~W} \mathrm{~m}^{-2}$ if matte. Using $R_{\mathrm{E} 891 \mathrm{BN}}$ to characterize glossy roofs in a building energy simulation can exaggerate the net economic value $N$ of annual cool-roof net energy savings by as much as $23 \%$.

We have introduced a simple solar reflectance metric, AM1GH solar reflectance $R_{\mathrm{g}, 0}$, to replace $R_{\mathrm{E} 891 \mathrm{BN}}$. Our analysis of the variation of solar reflectance with surface orientation, solar position, atmospheric condition and spectral reflectance indicates that it can estimate the annual peak solar heat gain of a typical roof or pavement to within $2 \mathrm{~W} \mathrm{~m}^{-2}$, accurately predicting peak surface

temperature. It overestimates $\bar{Q}$ of such surfaces by 1 to $28 \mathrm{~W} \mathrm{~m}^{-2}$ if glossy, or by 0 to $21 \mathrm{~W} \mathrm{~m}^{-2}$ if matte. $R_{\mathrm{g}, 0}$ overestimates $N$ by no more than $3 \%$ for glossy roofs. $R_{\mathrm{g}, 0}$ also predicts the peak and mean solar heat gains of walls better than does $R_{\mathrm{E} 891 \mathrm{BN}}$. Hence, we recommend using $R_{\mathrm{g}, 0}$ to rate the solar reflectances of roofs, pavements, walls and other surfaces (other than solar equipment) 
that receive unconcentrated sunlight.

We show in Part II that $R_{\mathrm{g}, 0}$ can be easily and accurately measured with pyranometer, a solar spectrophotometer or version 6 of the Solar Spectrum Reflectometer.

\section{Acknowledgements}

This work was supported by the California Energy Commission (CEC) through its Public Interest Energy Research Program (PIER) and by the Assistant Secretary for Renewable Energy under Contract No. DE-AC02-05CH11231. The authors wish to thank PIER manager Chris Scruton and former CEC Commissioner Arthur Rosenfeld for their support and advice. We thank Chris Gueymard of Solar Consulting Services (Colebrook, NH) and Daryl Myers of the National Renewable Energy Laboratory (Golden, CO) for guidance in the computation of solar spectral irradiance. We also thank Charlie Moore of Devices \& Services (Dallas, TX) for characterization of the Solar Spectrum Reflectometer.

\section{References}

[1] Ronnen Levinson and Hashem Akbari. Potential benefits of cool roofs on commercial buildings: conserving energy, saving money, and reducing emission of greenhouse gases and air pollutants. Energy Efficiency, 3(1):53-109, 2010.

[2] Ronnen Levinson, Hashem Akbari, Steve Konopacki, and Sarah Bretz. Inclusion of cool roofs in nonresidential Title 24 prescriptive requirements. Energy Policy, 33:151-170, 2005.

[3] Haider Taha. Meso-urban meteorological and photochemical modeling of heat island mitigation. Atmospheric Environment, 42(38):8795 - 8809, 2008.

[4] Haider Taha. Modeling the impacts of large-scale albedo changes on ozone air quality in the south coast air basin. Atmospheric Environment, 31(11):1667 - 1676, 1997.

[5] Paul Berdahl, Hashem Akbari, Ronnen Levinson, and William A. Miller. Weathering of roofing materials - an overview. Construction and Building Materials, 22(4):423-433, April 2008. 
[6] Ronnen Levinson, Paul Berdahl, and Hashem Akbari. Solar spectral optical properties of pigments-Part I: model for deriving scattering and absorption coefficients from transmittance and reflectance measurements. Solar Energy Materials $\& 3$ Solar Cells, 89:319-349, 2005.

[7] Bram van Ginneken, Marigo Stavridi, and Jan J. Koenderink. Diffuse and specular reflectance from rough surfaces. Applied Optics, 37(1):130-139, January 1998.

[8] C.L. Walthall, J.M. Norman, J.M. Welles, G. Campbell, and B.L. Blad. Simple equation to approximate the bidirectional reflectance from vegetative canopies and bare soil surfaces. Applied Optics, 24(3):383-387, February 1985.

[9] Jouni I. Peltonieme, Jukka Piironen, Jyri Näränen, Juha Suomalainen, Risto Kuittinen, Lauri Markelin, and Eija Honkavarra. Bidirectional reflectance spectometry of gravel at the Sjökulla test field. ISPRS Journal of Photogrammetry \& Remote Sensing, 62:434-446, 2007.

[10] Chris Gueymard. Simple Model of the Atmospheric Radiative Transfer of Sunshine (SMARTS) 2.9.5. Online at http://www.nrel.gov/rredc/smarts, 2006.

[11] ASTM. ASTM G197-08: Standard table for reference solar spectral distributions: direct and diffuse on $20^{\circ}$ tilted and vertical surfaces. Technical report, American Society for Testing and Materials, West Conshohocken, PA, 2008.

[12] ASTM. ASTM G173-03: Standard tables for reference solar spectral irradiances: direct normal and hemispherical on $37^{\circ}$ tilted surface. Technical report, American Society for Testing and Materials, West Conshohocken, PA, 2003. Spectra online at http://rredc.nrel.gov/solar/ spectra/am1.5.

[13] ASTM. ASTM E891-87 (1992): Tables for terrestrial direct normal solar spectral irradiance for air mass 1.5. Technical report, American Society for Testing and Materials, West Conshohocken, PA, 1987.

[14] ASTM. ASTM E424-71 (2007): Standard test methods for solar energy transmittance and reflectance (terrestrial) of sheet materials. Technical report, American Society for Testing and Materials, West Conshohocken, PA, 2007. 
[15] ASTM. ASTM E892-87 (1992): Tables for terrestrial solar spectral irradiance at air mass 1.5 for a $37^{\circ}$ tilted surface. Technical report, American Society for Testing and Materials, West Conshohocken, PA, 1987.

[16] ASTM. ASTM E903-96: Standard test method for solar absorptance, reflectance, and transmittance of materials using integrating spheres. Technical report, American Society for Testing and Materials, West Conshohocken, PA, 1996.

[17] ASTM. ASTM C1549-04: Standard test method for determination of solar reflectance near ambient temperature using a portable solar reflectometer. Technical report, American Society for Testing and Materials, West Conshohocken, PA, 2002.

[18] Devices \& Services. Devices \& Services Solar Spectrum Reflectometer. Online at http: //devicesandservices.com, 2010.

[19] K. Emery, D. Myers, and S. Kurtz. What is the appropriate reference spectrum for characterizing concentrator cells? In Conference Record of the Twenty-Ninth IEEE Photovoltaic Specialists Conference, pages 841-843, New Orleans, Louisiana, May 20 - 24 2002. Institute of Electrical and Electronics Engineers, Inc. (IEEE). Online at http://www.nrel.gov/docs/ fy02osti/32284.pdf.

[20] C. A. Gueymard, D. Myers, and K. Emery. Proposed reference irradiance spectra for solar energy systems testing. Solar Energy, 73(6):443 - 467, 2002.

[21] Cool Roof Rating Council. Product rating program. Online at http://coolroofs.org/ productratingprogram.html, 2010.

[22] U.S. Environmental Protection Agency. Energy Star. Online at http://www.energystar.gov, 2010 .

[23] ASHRAE. ASHRAE 90.1-2007: Energy Standard for Buildings Except Low-Rise Residential Buildings, SI Edition. American Society of Heating, Refrigerating, and Air-Conditioning Engineers, Atlanta, GA, 2007. 
[24] ASHRAE. ASHRAE 90.2-2007: Energy Efficient Design of Low-Rise Residential Buildings. American Society of Heating, Refrigerating, and Air-Conditioning Engineers, Atlanta, GA, 2007.

[25] USGBC. Leadership in Energy and Environmental Design Green Building Rating System for New Construction and Major Renovations (LEED-NC), Version 3.0. Technical report, U.S. Green Building Council, Washington, D.C., 2009.

[26] CEC. 2008 Building Energy Efficiency Standards for Residential and Nonresidential Buildings. Technical Report CEC-400-2008-001-CMF, California Energy Commission, Sacramento, CA, December 2008.

[27] ASTM. ASTM E1918-06: Standard test method for measuring solar reflectance of horizontal and low-sloped surfaces in the field. Technical report, American Society for Testing and Materials, West Conshohocken, PA, 2006.

[28] Steve Konopacki, Hashem Akbari, Melvin Pomerantz, Sasa Gabersek, and Lisa Gartland. Cooling energy savings potential of light-colored roofs for residential and commercial buildings in 11 U.S. metropolitan areas. Technical Report LBNL-39433, Lawrence Berkeley National Laboratory, Berkeley, CA, 1997.

[29] Ronnen Levinson, Paul Berdahl, and Hashem Akbari. Solar spectral optical properties of pigments-Part II: survey of common colorants. Solar Energy Materials and Solar Cells, 89(4):351 - 389, 2005.

[30] Ronnen Levinson, Paul Berdahl, Hashem Akbari, William Miller, Ingo Joedicke, Joseph Reilly, Yoshi Suzuki, and Michelle Vondran. Methods of creating solar-reflective nonwhite surfaces and their application to residential roofing materials. Solar Energy Materials and Solar Cells, 91(4):304-314, 2007.

[31] NREL MIDC. National Renewable Energy Laboratory Measurement and Instrumentation Data Center (NREL MIDC) Solar Position and Intensity (SOLPOS) Calculator. Online at http://www.nrel.gov/midc/solpos/solpos.html, 2010. 
[32] J.A. Duffie and W.A. Beckman. Solar Engineering of Thermal Processes. John Wiley \& Sons, 3rd edition, 2006.

[33] J.W. Ryde. The scattering of light by turbid media: Part I. Proceedings of the Royal Society of London: Series A, 131(817):451-464, May 1931.

[34] Gustav Kortum. Reflectance Spectroscopy: Principles, Methods, Applications. Springer, 1969.

[35] J.L. Saunderson. Calculation of the color of pigmented plastics. Journal of the Optical Society of America, 34(167):727-736, 1942.

[36] ASTM. ASTM E1980-01: Standard practice for calculating solar reflectance index of horizontal and low-sloped opaque surfaces. Technical report, American Society for Testing and Materials, West Conshohocken, PA, 2001.

[37] Paul Berdahl and Sarah E. Bretz. Preliminary survey of the solar reflectance of cool roofing materials. Energy and Buildings, 25(2):149 - 158, 1997.

[38] ASTM. ASTM G159-98: Standard tables for references solar spectral irradiance at air mass 1.5: direct normal and hemispherical for a $37^{\circ}$ tilted surface. Technical report, American Society for Testing and Materials, West Conshohocken, PA, 1998.

[39] Parry Moon. Proposed standard solar-radiation curves for engineering use. Journal of the Franklin Institute, 230(5):583 - 617, 1940.

\section{A Influence of interface reflection on spectral reflectance}

We model a flat, glossy surface as a smooth material of refractive index $n_{\mathrm{s}}>1$ that exhibits a Lambertian spectral reflectance $\hat{r}(\lambda)$ when illuminated by light incident from a medium of equal refractive index. The change in refractive index as beam light passes from air (a medium of lower refractive index $n_{\mathrm{a}}=1$ ) to the surface will induce a specular "interface" reflectance $\omega$ that varies with polar incidence angle $\theta$ :

$$
\omega_{\mathrm{b}, \mathrm{a} \rightarrow \mathrm{s}}(z)=\frac{1}{2}\left[\frac{\sin ^{2}(\theta-\beta)}{\sin ^{2}(\theta+\beta)}+\frac{\tan ^{2}(\theta-\beta)}{\tan ^{2}(\theta+\beta)}\right]
$$


where $\beta=\arcsin \left[\left(n_{\mathrm{a}} / n_{\mathrm{s}}\right) \sin \theta\right]$.

Diffuse light passing from air to surface or surface to air will also be partially reflected by the change in refractive index. Define

$$
\begin{aligned}
\gamma(m) \equiv & \frac{1}{2}+\frac{(m-1)(3 m+1)}{6(m+1)^{2}}+\left[\frac{m^{2}\left(m^{2}-1\right)^{2}}{\left(m^{2}+1\right)^{3}}\right] \log \frac{m-1}{m+1} \\
& -\frac{2 m^{3}\left(m^{2}+2 m-1\right)}{\left(m^{2}+1\right)\left(m^{4}-1\right)}+\left[\frac{8 m^{4}\left(m^{4}+1\right)}{\left(m^{2}+1\right)\left(m^{4}-1\right)^{2}}\right] \log m .
\end{aligned}
$$

If the diffuse light has an isotropic angular distribution, the interface reflectances to diffuse light passing from air to surface $(\mathrm{a} \rightarrow \mathrm{s})$ and surface to air $(\mathrm{s} \rightarrow \mathrm{a})$

$$
\begin{aligned}
\omega_{\mathrm{d}, \mathrm{a} \rightarrow \mathrm{s}} & =\gamma\left(n_{\mathrm{s}} / n_{\mathrm{a}}\right) \\
\omega_{\mathrm{d}, \mathrm{s} \rightarrow \mathrm{a}} & =1-\left(n_{\mathrm{a}} / n_{\mathrm{s}}\right)^{2}\left[1-\gamma\left(n_{\mathrm{s}} / n_{\mathrm{a}}\right)\right]
\end{aligned}
$$

will be independent of $\theta[6,33,34]$.

Application of the "Saunderson correction" $[6,35]$ to $\hat{r}(\lambda)$ yields

$$
\begin{aligned}
r_{\mathrm{b}}(\lambda, \theta) & =\omega_{\mathrm{b}, \mathrm{a} \rightarrow \mathrm{s}}(\theta)+\frac{\left[1-\omega_{\mathrm{b}, \mathrm{a} \rightarrow \mathrm{s}}(\theta)\right]\left[1-\omega_{\mathrm{d}, \mathrm{s} \rightarrow \mathrm{a}}\right] \hat{r}(\lambda)}{1-\omega_{\mathrm{d}, \mathrm{s} \rightarrow \mathrm{a}} \hat{r}(\lambda)} \\
r_{\mathrm{d}}(\lambda) & =\omega_{\mathrm{d}, \mathrm{a} \rightarrow \mathrm{s}}+\frac{\left[1-\omega_{\mathrm{d}, \mathrm{a} \rightarrow \mathrm{s}}\right]\left[1-\omega_{\mathrm{d}, \mathrm{s} \rightarrow \mathrm{a}}\right] \hat{r}(\lambda)}{1-\omega_{\mathrm{d}, \mathrm{s} \rightarrow \mathrm{a}} \hat{r}(\lambda)}
\end{aligned}
$$

Let subscript 'n' denote normal incidence $(\theta=0)$. Solving Eq. (A.5) for $\hat{r}(\lambda)$ in terms of $r_{\mathrm{b}, \mathrm{n}}(\lambda)$ and substituting this result into Eqs. (A.5) and (A.6) relates $r_{\mathrm{b}}(\lambda, \theta)$ and $r_{\mathrm{d}}(\lambda)$ to $r_{\mathrm{b}, \mathrm{n}}(\lambda)$ :

$$
r_{\mathrm{b}}(\lambda ; \theta)=r_{\mathrm{b}, \mathrm{n}}(\lambda)+e_{\mathrm{b}}\left(\theta ; n_{\mathrm{s}}, n_{\mathrm{a}}\right)\left[1-r_{\mathrm{b}, \mathrm{n}}(\lambda)\right]
$$

and

$$
r_{\mathrm{d}}(\lambda)=r_{\mathrm{b}, \mathrm{n}}(\lambda)+e_{\mathrm{d}}\left(n_{\mathrm{s}}, n_{\mathrm{a}}\right)\left[1-r_{\mathrm{b}, \mathrm{n}}(\lambda)\right]
$$


where interface reflection functions

$$
\begin{aligned}
e_{\mathrm{b}}(\theta) & \equiv \frac{\omega_{\mathrm{b}, \mathrm{a} \rightarrow \mathrm{s}}(\theta)-\omega_{\mathrm{b}, \mathrm{a} \rightarrow \mathrm{s}, \mathrm{n}}}{1-\omega_{\mathrm{b}, \mathrm{a} \rightarrow \mathrm{s}, \mathrm{n}}} \\
e_{\mathrm{d}} & \equiv \frac{\omega_{\mathrm{d}, \mathrm{a} \rightarrow \mathrm{s}}-\omega_{\mathrm{b}, \mathrm{a} \rightarrow \mathrm{s}, \mathrm{n}}}{1-\omega_{\mathrm{b}, \mathrm{a} \rightarrow \mathrm{s}, \mathrm{n}}} .
\end{aligned}
$$

\section{B Estimation of AM1GH solar reflectance from near-normal beam- hemispherical spectral reflectance}

A spectrophotometer equipped with an integrating sphere typically measures beam-hemispherical global reflectance at a near-normal incidence angle $\theta_{\mathrm{nn}} \approx 8^{\circ}$. The beam-hemispherical spectral reflectance of a glossy surface at near-normal incidence $r_{\mathrm{b}, \mathrm{nn}}(\lambda)$ very slightly exceeds that at normal incidence, $r_{\mathrm{b}, \mathrm{n}}(\lambda)$. For a surface of real refractive index 1.5 , the difference is less than $10^{-5}$ at an incidence angle of $8^{\circ}$, and less than $10^{-3}$ for incidence angles up to $27^{\circ}$. Therefore, we can assume that $r_{\mathrm{b}, \mathrm{n}}(\lambda)=r_{\mathrm{b}, \mathrm{nn}}(\lambda)$.

It is convenient to approximate $\mathrm{AM} 1 \mathrm{GH}$ solar reflectance $R_{\mathrm{g}, 0}$ by substituting $r_{\mathrm{b}, \mathrm{n}}(\lambda)$ for AM1GH spectral reflectance $r_{\mathrm{g}, 0}(\lambda)$ in Eq. (32). We name this value "E903_AM1GH" after ASTM Standard E903, which details the measurement of solar spectral reflectance. E903_AM1GH solar reflectance

$$
R_{\mathrm{g}, 0}^{*} \equiv I_{\mathrm{g}, 0}^{-1} \int_{\mathcal{S}} i_{\mathrm{g}, 0}(\lambda) r_{\mathrm{b}, \mathrm{n}}(\lambda) d \lambda
$$

underestimates $R_{\mathrm{g}, 0}$ by

$$
\delta_{R_{\mathrm{g}, 0}^{*}} \equiv R_{\mathrm{g}, 0}-R_{\mathrm{g}, 0}^{*}=I_{\mathrm{g}, 0}^{-1} \int_{\mathcal{S}} i_{\mathrm{d}, 0}(\lambda) \delta_{r_{\mathrm{d}}}(\lambda) d \lambda
$$

where

$$
\delta_{r_{\mathrm{d}}}(\lambda) \equiv r_{\mathrm{d}}(\lambda)-r_{\mathrm{b}, \mathrm{n}}(\lambda)=e_{\mathrm{d}}\left(n_{\mathrm{s}}, n_{\mathrm{a}}\right)\left[1-r_{\mathrm{b}, \mathrm{n}}(\lambda)\right]
$$

where $\Phi_{\mathrm{AM} 1 \mathrm{GH}}=0.106$ is the diffuse fraction of AM1GH solar irradiance. $R_{\mathrm{g}, 0}^{*}$ Since $e_{\mathrm{d}}\left(n_{\mathrm{s}}, n_{\mathrm{a}}\right) \geq 0$, it follows that

$$
0 \leq \delta_{R_{\mathrm{g}, 0}^{*}} \leq e_{\mathrm{d}}\left(n_{\mathrm{s}}, n_{\mathrm{a}}\right)\left[1-r_{\mathrm{b}, \mathrm{n}}(\lambda)\right] \Phi_{\mathrm{AM} 1 \mathrm{GH}} \leq e_{\mathrm{d}}\left(n_{\mathrm{s}}, n_{\mathrm{a}}\right) \Phi_{\mathrm{AM} 1 \mathrm{GH}}
$$


For a glossy surface of real refractive index $1.5, e_{\mathrm{d}}\left(n_{\mathrm{s}}, n_{\mathrm{a}}\right) \Phi_{\mathrm{AM} 1 \mathrm{GH}}=0.006$, so $R_{\mathrm{g}, 0}^{*}$ underestimates $R_{\mathrm{g}, 0}$ by no more than 0.006 . For a matte surface, $R_{\mathrm{g}, 0}^{*}=R_{\mathrm{g}, 0}$ because $r_{\mathrm{b}}(\lambda)$ is assumed to be independent of incidence angle.

\section{Error in surface temperature resulting from error in solar heat gain}

If a surface with solar heat gain $Q$ convects heat to ambient air at absolute temperature $T_{\mathrm{a}}$, exchanges long-wave radiation with a surface at absolute temperature $T_{\mathrm{r}}$ and conducts heat into a conditioned space at temperature $T_{\mathrm{i}}$, its quasi-steady temperature $T$ is governed by the energy balance

$$
Q=h_{\mathrm{c}}\left(T-T_{\mathrm{a}}\right)+h_{\mathrm{r}}\left(T-T_{\mathrm{r}}\right)+h_{\mathrm{k}}\left(T-T_{\mathrm{i}}\right)
$$

Here $h_{\mathrm{c}}, h_{\mathrm{r}}$ and $h_{\mathrm{k}}$ are the coefficients of heat transfer by convection, radiation and conduction, respectively. Neglecting small errors associated with the temperature dependence of $h_{\mathrm{r}}$, increasing solar heat gain by $\Delta Q$ raises the surface temperature by

$$
\Delta T=\left[h_{\mathrm{c}}+h_{\mathrm{r}}+h_{\mathrm{k}}\right]^{-1} \Delta Q
$$

Other factors being equal, $\Delta T$ will be greatest for an adiabatic surface $\left(h_{\mathrm{k}}=0\right)$. If the adiabatic surface has typical heat transfer coefficients of $h_{\mathrm{c}}=12 \mathrm{~W} \mathrm{~m}^{-2} \mathrm{~K}^{-1}$ (medium wind speeds of 2 to $\left.6 \mathrm{~m} \mathrm{~s}^{-1}\right)[36]$ and $h_{\mathrm{r}}=5 \mathrm{~W} \mathrm{~m}^{-2} \mathrm{~K}^{-1}$ (300 $\mathrm{K}$ surface of thermal emittance 0.85), then

$$
\frac{\Delta T}{\Delta Q}=\left[h_{\mathrm{c}}+h_{\mathrm{r}}\right]^{-1}=0.06 \mathrm{~K} \mathrm{~W}^{-1} \mathrm{~m}^{2}
$$

Under these conditions each $10 \mathrm{~W} \mathrm{~m}^{-2}$ overestimation of solar heat gain will exaggerate surface temperature by about $0.6 \mathrm{~K}$.

The sensitivity of surface temperature to environmental parameters is further explored in reference [37]. 


\section{Effective global solar reflectance of a glossy surface}

As shown in Eq. (14), our model assumes that the amount by which a glossy surface's obliqueincidence beam-hemispherical spectral reflectance $r_{\mathrm{b}}(\lambda ; \theta>0)$ exceeds $r_{\mathrm{b}, \mathrm{n}}(\lambda)$ is proportional to $\left[1-r_{\mathrm{b}, \mathrm{n}}(\lambda)\right]$. This suggests that $\bar{R}$ could be approximated by a linear adjustment to $R_{\mathrm{g}, 0}$ of the form

$$
R_{\mathrm{g}}^{\prime} \equiv R_{\mathrm{g}, 0}+c\left(1-R_{\mathrm{g}, 0}\right)
$$

where $c$ is a coefficient obtained by fitting $R_{\mathrm{g}}^{\prime}$ to $\bar{R}$. We refer to $R_{\mathrm{g}}^{\prime}$ as a glossy surface's "effective" global solar reflectance. While the coefficient $c$ can vary with interval, latitude, surface orientation and spectral reflectance, the relationship between $R_{\mathrm{g}}^{\prime}$ and $R_{\mathrm{g}, 0}$ is easiest to use if there exists a fixed value of $c$ that yields acceptably small errors in $\bar{Q}$ over all cases of interest.

A coefficient $c=0.036$ relating $R_{\mathrm{g}}^{\prime}$ to $R_{\mathrm{g}, 0}$ in Eq. (D.1) was obtained by fitting $\bar{R}_{\text {annual }}$ to $R_{\mathrm{g}, 0}$ for a nonselective black glossy horizontal surface under a clear sky at latitude $37^{\circ} \mathrm{N}$. This value of $c$ was selected for three reasons. First, $R_{\mathrm{g}}$ of a nonselective black glossy surface exhibits maximum sensitivity to $\theta$. Second, $37^{\circ} \mathrm{N}$ is near the mean latitude of the mainland United States $\left(37^{\circ} \mathrm{N}\right)$. Third, $\bar{R}_{\text {annual }}$ is expected to lie between $\bar{R}_{\text {summer, }}$, evaluated when the daytime sun is relatively high, and $\bar{R}_{\text {winter }}$, evaluated when the daytime sun is relatively low.

By definition, $R_{\mathrm{g}}^{\prime}-R_{\mathrm{g}, 0}=c\left(1-R_{\mathrm{g}, 0}\right)$. Using $c=0.036$, this difference ranges from a minimum of 0.004 for a nonselective white with $R_{\mathrm{g}, 0}=0.90$ to a maximum of 0.034 for a nonselective black with $R_{\mathrm{g}, 0}=0.045$.

If a surface is glossy, substituting $R_{\mathrm{g}}^{\prime}$ for $R_{\mathrm{g}, 0}$ degrades prediction of $Q_{\text {peak }}$ to improve that of $\bar{Q}$. This is true of both selective and nonselective surfaces, but the effect is greatest for surfaces with low $R_{\mathrm{g}, 0}$. Consider a glossy horizontal nonselective black surface - e.g., a hot black membrane on a low-sloped roof - exposed to unconcentrated sunlight. At latitude $37^{\circ} \mathrm{N}, R_{\mathrm{g}}^{\prime}$ perfectly predicts $\bar{Q}_{\text {annual }}$ (by design), but underestimates $Q_{\text {peak }}$ by $36 \mathrm{~W} \mathrm{~m}^{-2}$. A simulation of cool-roof net energy savings (nonselective black to selective black) based on $R_{\mathrm{g}}^{\prime}$ will underestimate $N$ by up to $1 \%$. 


\section{Nomenclature}

\section{English symbols}

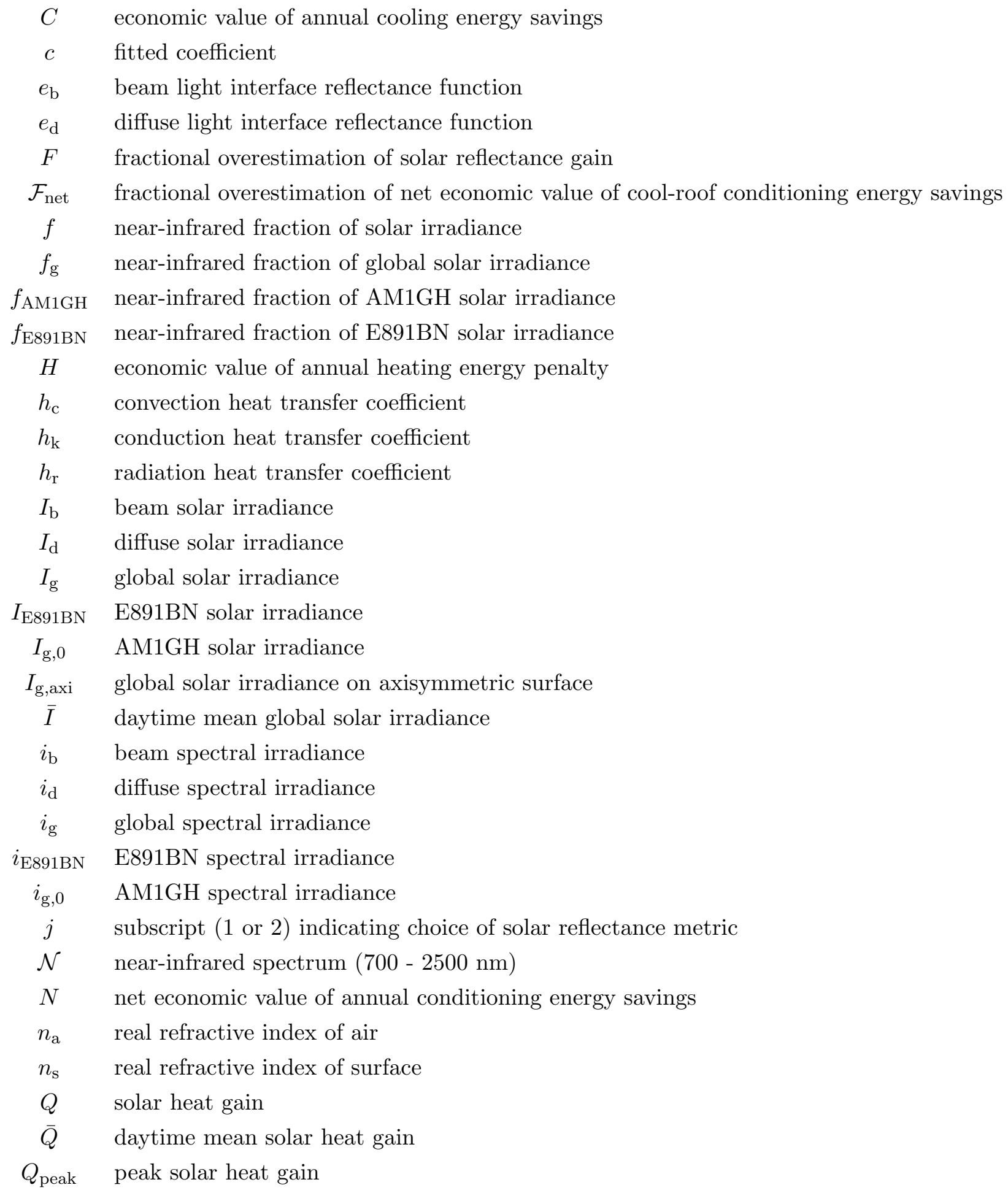




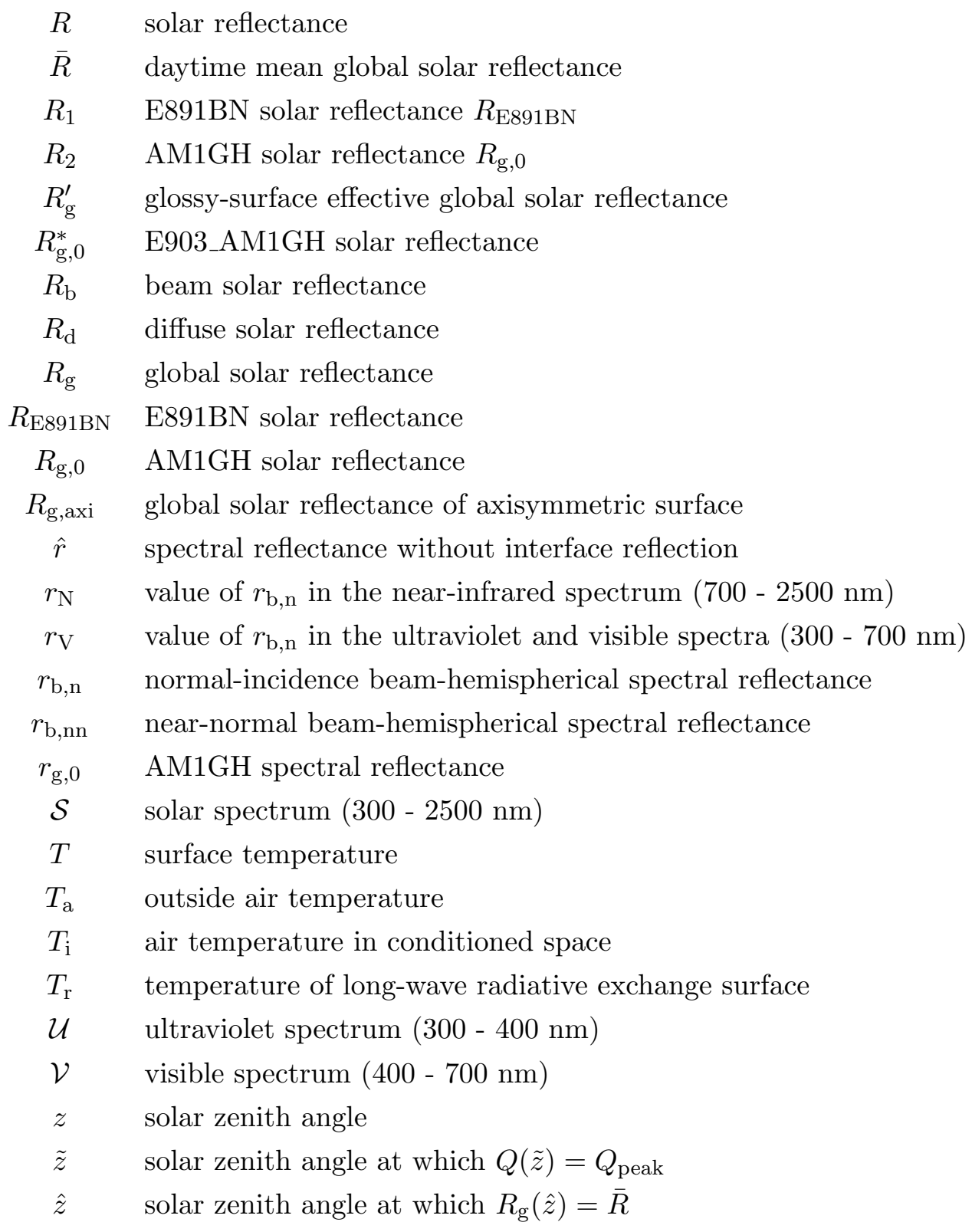




\section{Greek symbols}

$\beta \quad$ intermediate variable for computing interface reflectance

$\gamma \quad$ surface solar azimuth angle

$\gamma(m)$ intermediate function for computing interface reflectance

$\Delta Q$ increase in solar heat gain

$\Delta Q_{j} \quad$ overestimation of solar heat gain by solar reflectance metric $j$

$\Delta R_{j} \quad$ underestimation of global solar reflectance by solar reflectance metric $j$

$\Delta T$ surface temperature elevation

$\Delta \bar{Q}_{j} \quad$ underestimation of daytime mean solar heat gain using solar reflectance metric $j$

$\Delta \bar{R}_{j} \quad$ underestimation of daytime mean global solar reflectance using solar reflectance metric $j$

$\theta \quad$ incidence angle

$\hat{\theta} \quad$ incidence angle at which $R_{\mathrm{g}}(\hat{\theta})=\bar{R}$

$\lambda \quad$ wavelength

$\xi \quad$ solar azimuth angle

$\Sigma \quad$ surface tilt angle

$\tau_{\text {day }}$ daytime portion of winter, summer or annual interval

$\phi \quad$ diffuse fraction of global spectral irradiance

$\Phi$ diffuse fraction of global solar irradiance

$\psi \quad$ surface azimuth angle

$\omega_{\mathrm{b}}$ beam reflectance at interface

$\omega_{\mathrm{d}} \quad$ diffuse reflectance at interface

\section{Initialisms}

AM air mass

AM1DH (clear-sky) air mass 1 diffuse horizontal

AM1GH (clear-sky) air mass 1 global horizontal

E891BN (ASTM Standard) E891 beam normal

LST local standard time

NIR near infrared 
Table 1: Simulation parameters supplied to the SMARTS 2.9.5 solar spectral irradiance model. Values are based on those used in ASTM Standard G197-08 [11].

\begin{tabular}{|l|l|}
\hline parameter & value \\
\hline $\begin{array}{l}\text { atmospheric turbidity specified as } \\
\text { aerosol optical depth at } 500 \mathrm{~nm}\end{array}$ & 0.084 (clear sky) or 0.270 (hazy sky) \\
\hline site pressure $(\mathrm{mb})$ & 1013.25 \\
\hline altitude at ground $(\mathrm{km})$ & 0 \\
\hline height above ground $(\mathrm{km})$ & 0 \\
\hline atmosphere & U.S. Standard Atmosphere 1976 \\
\hline water vapor & calculate from reference atmosphere and altitude \\
\hline ozone & use default from reference atmosphere \\
\hline gaseous absorption and pollution & use defaults from selected atmosphere \\
\hline carbon dioxide $(\mathrm{ppmv})$ & 370 \\
\hline extraterrestrial spectrum & Gueymard 2004 \\
\hline aerosol model & Shettle and Fenn, rural \\
\hline regional albedo & dry soil \\
\hline tilt albedo & dry soil \\
\hline spectral range & $300-2500 \mathrm{~nm}$ \\
\hline solar constant $\left(\mathrm{W} \mathrm{m}^{-2}\right)$ & 1367.0 \\
\hline $\begin{array}{l}\text { solar constant distance correction } \\
\text { factor }\end{array}$ & 1.0 \\
\hline
\end{tabular}







Table 3: Surface slopes and solar positions for which solar spectral irradiances were simulated.

\begin{tabular}{|l|l|}
\hline surface slope (tilt angle) & horizontal $\left(0^{\circ}\right), 2: 12\left(9.5^{\circ}\right), 5: 12\left(22.6^{\circ}\right), 9: 12\left(36.9^{\circ}\right), 12: 12\left(45.0^{\circ}\right)$, \\
& $\begin{array}{l}24: 12\left(63.4^{\circ}\right), 48: 12\left(76.0^{\circ}\right), 96: 12\left(82.9^{\circ}\right), 192: 12\left(86.4^{\circ}\right), \text { vertical } \\
\left(90^{\circ}\right)\end{array}$ \\
\hline solar zenith angle $z$ & $0^{\circ}, 2^{\circ}, 4^{\circ}, \ldots, 84^{\circ}, 85^{\circ}, 86^{\circ}, 87^{\circ}, 88^{\circ}, 89^{\circ}, 89.9^{\circ}$ \\
\hline surface solar azimuth angle $\gamma$ & $0^{\circ}, 5^{\circ}, 10^{\circ}, \ldots, 180^{\circ}$ \\
\hline
\end{tabular}

\begin{tabular}{|l|l|l|l|l|l|l|}
\hline & $\begin{array}{l}\text { nonselective } \\
\text { black }\end{array}$ & $\begin{array}{l}\text { nonselective } \\
\text { gray }\end{array}$ & $\begin{array}{l}\text { nonselective } \\
\text { white }\end{array}$ & $\begin{array}{l}\text { selective } \\
\text { black }\end{array}$ & $\begin{array}{l}\text { selective } \\
\text { gray }\end{array}$ & $\begin{array}{l}\text { selective } \\
\text { white }\end{array}$ \\
\hline glossy or matte & & & & & & \\
$r_{\mathrm{V}}$ & 0.040 & 0.200 & 0.900 & 0.040 & 0.200 & 0.900 \\
$r_{\mathrm{N}}$ & 0.040 & 0.200 & 0.900 & 0.900 & 0.900 & 0.040 \\
glossy & & & & & & \\
$R_{\mathrm{E} 891 \mathrm{BN}}$ & 0.040 & 0.200 & 0.900 & 0.540 & 0.607 & 0.400 \\
$R_{\mathrm{g}, 0}^{*}$ & 0.040 & 0.200 & 0.900 & 0.459 & 0.541 & 0.481 \\
$R_{\mathrm{g}, 0}$ & 0.045 & 0.204 & 0.901 & 0.463 & 0.544 & 0.483 \\
matte $_{R_{\mathrm{E} 891 \mathrm{BN}}}$ & 0.040 & 0.200 & 0.900 & 0.540 & 0.607 & 0.400 \\
$R_{\mathrm{g}, 0}^{*}$ & 0.040 & 0.200 & 0.900 & 0.459 & 0.541 & 0.481 \\
$R_{\mathrm{g}, 0}$ & 0.040 & 0.200 & 0.900 & 0.459 & 0.541 & 0.481 \\
\hline
\end{tabular}

Table 4: Reflectance properties of six ideal materials with glossy and matte surfaces, including (a) normal-incidence beam-hemispherical spectral reflectance $r_{\mathrm{b}, \mathrm{n}}$ values $r_{\mathrm{V}}$ (UV and visible spectra, $300-700 \mathrm{~nm}$ ) and $r_{\mathrm{N}}$ (NIR spectrum, $700-2500 \mathrm{~nm}$ ); (b) E891BN solar reflectance $R_{\mathrm{E} 891 \mathrm{BN}}$; (c) E903_AM1GH solar reflectance $R_{\mathrm{g}, 0}^{*}$; and (d) AM1GH solar reflectance $R_{\mathrm{g}, 0}$.

\begin{tabular}{|c|c|c|c|c|}
\hline & $\mathrm{AM} 1\left(\mathrm{z}=0.0^{\circ}\right)$ & $\mathrm{AM} 1.1\left(\mathrm{z}=24.6^{\circ}\right)$ & $\mathrm{AM} 1.5\left(\mathrm{z}=48.2^{\circ}\right)$ & $\mathrm{AM} 2\left(\mathrm{z}=60.0^{\circ}\right)$ \\
\hline horizontal & 10.1 & 10.9 & 14.0 & 17.4 \\
slope 5:12 & 12.0 & 12.1 & 15.3 & 19.0 \\
vertical & 100.0 & 53.6 & 37.2 & 32.1 \\
\hline
\end{tabular}

Table 5: Variation with air mass and tilt of the diffuse fraction $\Phi(\%)$ of global solar irradiance on an axisymmetric surface under a clear sky.

\begin{tabular}{|c|c|c|c|c|}
\hline & $\mathrm{AM} 1\left(\mathrm{z}=0.0^{\circ}\right)$ & $\mathrm{AM} 1.1\left(\mathrm{z}=24.6^{\circ}\right)$ & $\mathrm{AM} 1.5\left(\mathrm{z}=48.2^{\circ}\right)$ & $\mathrm{AM} 2\left(\mathrm{z}=60.0^{\circ}\right)$ \\
\hline horizontal & 48.7 & 48.8 & 49.1 & 49.6 \\
slope 5:12 & 48.8 & 48.8 & 49.1 & 49.6 \\
vertical & 49.8 & 51.0 & 52.2 & 53.6 \\
\hline
\end{tabular}

Table 6: Variation with air mass and tilt of the NIR fraction $f_{\mathrm{g}}(\%)$ of global solar irradiance on an axisymmetric surface under a clear sky. 


\begin{tabular}{|c|c|c|c|c|c|}
\hline & based on & glossy / clear & glossy / hazy & matte / clear & matte / hazy \\
\hline$\Delta R_{1}(z)$ & $R_{\mathrm{E} 891 \mathrm{BN}}$ & -0.08 to +0.30 & -0.08 to +0.20 & -0.08 to +0.22 & -0.10 to +0.13 \\
$\Delta R_{2}(z)$ & $R_{g, 0}$ & +0.00 to +0.30 & +0.00 to +0.22 & -0.00 to +0.30 & -0.01 to +0.21 \\
\hline
\end{tabular}

Table 7: Underestimation $\Delta R_{j}(z)$ of the global solar reflectance of an axisymmetric surface of any tilt when instantaneous global solar reflectance $R_{\mathrm{g}}(z)$ is replaced by (1) E891BN solar reflectance $R_{\mathrm{E} 891 \mathrm{BN}}$ or $(2) \mathrm{AM} 1 \mathrm{GH}$ solar reflectance $R_{\mathrm{g}, 0}$. Results are shown for glossy and matte practical surfaces under clear and hazy skies.

\begin{tabular}{|c|c|c|c|c|c|}
\hline & based on & glossy / clear & glossy / hazy & matte / clear & matte / hazy \\
\hline$\Delta Q_{1}(z)$ & $R_{\mathrm{E} 891 \mathrm{BN}}$ & -84 to +64 & -84 to +60 & -89 to +16 & -94 to +8 \\
$\Delta Q_{2}(z)$ & $R_{g, 0}$ & +0 to +63 & +0 to +58 & -0 to +28 & -5 to +22 \\
\hline
\end{tabular}

Table 8: Overestimation $\Delta Q_{j}(z)$ of the instantaneous solar heat gain $\left(\mathrm{W} \mathrm{m}^{-2}\right)$ of an axisymmetric surface of any tilt when instantaneous global solar reflectance $R_{\mathrm{g}}(z)$ is replaced by (1) E891BN solar reflectance $R_{\mathrm{E} 891 \mathrm{BN}}$ or (2) AM1GH solar reflectance $R_{\mathrm{g}, 0}$. Results are shown for glossy and matte practical surfaces under clear and hazy skies.

\begin{tabular}{|c|c|c|c|c|c|}
\hline & based on & glossy / clear & glossy / hazy & matte / clear & matte / hazy \\
\hline$\Delta Q_{\text {peak }, 1}$ & $R_{\text {E891BN }}$ & -84 to +38 & -84 to +38 & -89 to +0 & -94 to +0 \\
$\Delta Q_{\text {peak }, 2}$ & $R_{g, 0}$ & +0 to +35 & +1 to +35 & +0 to +11 & -5 to +8 \\
\hline
\end{tabular}

Table 9: Overestimation $\Delta Q_{\text {peak }, j}$ of the peak solar heat gain $\left(\mathrm{W} \mathrm{m}^{-2}\right)$ of an axisymmetric surface of any tilt when global solar reflectance $R_{\mathrm{g}}(\tilde{z})$ is replaced by $(1) \mathrm{E} 891 \mathrm{BN}$ solar reflectance $R_{\mathrm{E} 891 \mathrm{BN}}$ or (2) AM1GH solar reflectance $R_{\mathrm{g}, 0}$. Results are shown for glossy and matte practical surfaces under clear and hazy skies.

\begin{tabular}{|c|c|c|c|c|c|}
\hline & based on & glossy / clear & glossy / hazy & matte $/$ clear & matte $/$ hazy \\
\hline$\Delta \bar{R}_{1}$ & $R_{\mathrm{E} 891 \mathrm{BN}}$ & -0.06 to +0.13 & -0.06 to +0.10 & -0.08 to +0.01 & -0.07 to +0.00 \\
$\Delta \bar{R}_{2}$ & $R_{g, 0}$ & +0.00 to +0.12 & +0.00 to +0.10 & -0.00 to +0.09 & -0.00 to +0.08 \\
\hline
\end{tabular}

Table 10: Underestimation $\Delta \bar{R}_{j}$ of the daytime mean solar reflectance of an axisymmetric surface of any tilt when winter, summer or annual daytime mean global solar reflectance $\bar{R}$ at latitude $25^{\circ} \mathrm{N}$, $37^{\circ} \mathrm{N}$ or $49^{\circ} \mathrm{N}$ is replaced by (1) E891BN solar reflectance $R_{\mathrm{E} 891 \mathrm{BN}}$ or (2) AM1GH solar reflectance $R_{\mathrm{g}, 0}$. Results are shown for glossy and matte practical surfaces under clear and hazy skies.

\begin{tabular}{|c|c|c|c|c|c|}
\hline & based on & glossy / clear & glossy / hazy & matte / clear & matte / hazy \\
\hline$\Delta \bar{Q}_{1}$ & $R_{\text {E891BN }}$ & -41 to +29 & -36 to +22 & -50 to +2 & -46 to +0 \\
$\Delta \bar{Q}_{2}$ & $R_{g, 0}$ & +1 to +28 & +1 to +21 & -0 to +21 & -0 to +17 \\
\hline
\end{tabular}

Table 11: Overestimation $\Delta \bar{Q}_{j}$ of the daytime mean solar heat gain $\left(\mathrm{W} \mathrm{m}^{-2}\right)$ of an axisymmetric surface of any tilt when winter, summer or annual daytime mean global solar reflectance $\bar{R}$ at latitude $25^{\circ} \mathrm{N}, 37^{\circ} \mathrm{N}$ or $49^{\circ} \mathrm{N}$ is replaced by (1) E891BN solar reflectance $R_{\mathrm{E} 891 \mathrm{BN}}$ or (2) AM1GH solar reflectance $R_{\mathrm{g}, 0}$. Results are shown for glossy and matte practical surfaces under clear and hazy skies. 


\begin{tabular}{|c|c|c|c|c|c|}
\hline based on & $\Delta Q_{\text {peak }}\left(\mathrm{W} \mathrm{m}^{-2}\right)$ & $\Delta \bar{Q}_{\text {annual }}\left(\mathrm{W} \mathrm{m}{ }^{-2}\right)$ & $F_{\text {summer }}(\%)$ & $F_{\text {winter }}(\%)$ & $\mathcal{F}_{\text {net }}(\%)$ \\
\hline$R_{\mathrm{E} 891 \mathrm{BN}}$ & -84 to 7 & -34 to 22 & 3 to 23 & 5 to 35 & $\leq 23$ \\
$R_{g, 0}$ & 0 to 2 & 2 to 20 & 1 to 3 & 2 to 14 & $\leq 3$ \\
\hline
\end{tabular}

Table 12: Overestimation $\Delta Q_{\text {peak }}$ of the peak solar heat gain, overestimation $\Delta \bar{Q}_{\text {annual }}$ of the annual daytime mean solar heat gain, overestimation $F_{\text {summer }}$ of the cool-roof cooling energy savings $C$, overestimation $F_{\text {winter }}$ of the cool-roof heating energy penalty $H$ and overestimation $\mathcal{F}_{\text {net }}$ of the economic value $N$ of cool-roof net energy savings for practical glossy axisymmetric surfaces at slopes of up to $5: 12\left[23^{\circ}\right]$, such as roofs and pavements, under a clear sky.

\begin{tabular}{|c|c|c|c|c|}
\hline based on & $\Delta Q_{\text {peak }}\left(\mathrm{W} \mathrm{m}^{-2}\right)$ & $\Delta \bar{Q}_{\text {annual }}\left(\mathrm{W} \mathrm{m}^{-2}\right)$ & $F_{\text {summer }}(\%)$ & $F_{\text {winter }}(\%)$ \\
\hline$R_{\mathrm{E} 891 \mathrm{BN}}$ & -89 to 0 & -44 to 0 & 0 to 18 & 0 to 18 \\
$R_{g, 0}$ & 0 to 1 & -0 to 5 & -2 to 0 & -6 to 0 \\
\hline
\end{tabular}

Table 13: Overestimation $\Delta Q_{\text {peak }}$ of the peak solar heat gain, overestimation $\Delta \bar{Q}_{\text {annual }}$ of the annual daytime mean solar heat gain, overestimation $F_{\text {summer }}$ of the cool-roof cooling energy savings $C$ and overestimation $F_{\text {winter }}$ of the cool-roof heating energy penalty $H$ for practical matte axisymmetric surfaces at slopes of up to $5: 12\left[23^{\circ}\right]$, such as roofs and pavements, under a clear sky.

\begin{tabular}{|c|c|c|c|c|}
\hline based on & $\Delta Q_{\text {peak }}\left(\mathrm{W} \mathrm{m}^{-2}\right)$ & $\Delta \bar{Q}_{\text {annual }}\left(\mathrm{W} \mathrm{m}^{-2}\right)$ & $F_{\text {summer }}(\%)$ & $F_{\text {winter }}(\%)$ \\
\hline$R_{\mathrm{E} 891 \mathrm{BN}}$ & -9 to 15 & -2 to 15 & 6 to 15 & 2 to 10 \\
$R_{g, 0}$ & 1 to 18 & 1 to 22 & -5 to 7 & -14 to 4 \\
\hline
\end{tabular}

Table 14: Overestimation $\Delta Q_{\text {peak }}$ of the peak solar heat gain, overestimation $\Delta \bar{Q}_{\text {annual }}$ of the annual daytime mean solar heat gain, overestimation $F_{\text {summer }}$ of the cool-roof cooling energy savings $C$ and overestimation $F_{\text {winter }}$ of the cool-roof heating energy penalty $H$ for practical glossy axisymmetric vertical surfaces, such as walls, under a clear sky.

\begin{tabular}{|c|c|c|c|c|}
\hline based on & $\Delta Q_{\text {peak }}\left(\mathrm{W} \mathrm{m}^{-2}\right)$ & $\Delta \bar{Q}_{\text {annual }}\left(\mathrm{W} \mathrm{m}^{-2}\right)$ & $F_{\text {summer }}(\%)$ & $F_{\text {winter }}(\%)$ \\
\hline$R_{\mathrm{E} 891 \mathrm{BN}}$ & -18 to 0 & -10 to 0 & 0 to 8 & -1 to 6 \\
$R_{g, 0}$ & 0 to 11 & 0 to 17 & -11 to 0 & -17 to 0 \\
\hline
\end{tabular}

Table 15: Overestimation $\Delta Q_{\text {peak }}$ of the peak solar heat gain, overestimation $\Delta \bar{Q}_{\text {annual }}$ of the annual daytime mean solar heat gain, overestimation $F_{\text {summer }}$ of the cool-roof cooling energy savings $C$, and overestimation $F_{\text {winter }}$ of the cool-roof heating energy penalty $H$ for practical matte axisymmetric vertical surfaces, such as walls, under a clear sky.

\begin{tabular}{|c|c|c|c|}
\hline & winter & annual & summer \\
\hline $49^{\circ} \mathrm{N}$ & 71 & 60 & 54 \\
$37^{\circ} \mathrm{N}$ & 64 & 56 & 51 \\
$25^{\circ} \mathrm{N}$ & 58 & 53 & 49 \\
\hline
\end{tabular}

Table 16: Variation with latitude and interval of the solar zenith angle $\hat{z}\left(^{\circ}\right)$ at which $R_{\mathrm{g}}(\hat{z})=\bar{R}$ for a glossy horizontal surface. Values for a matte horizontal surface agree to within $1^{\circ}$ of those for a glossy horizontal surface. 


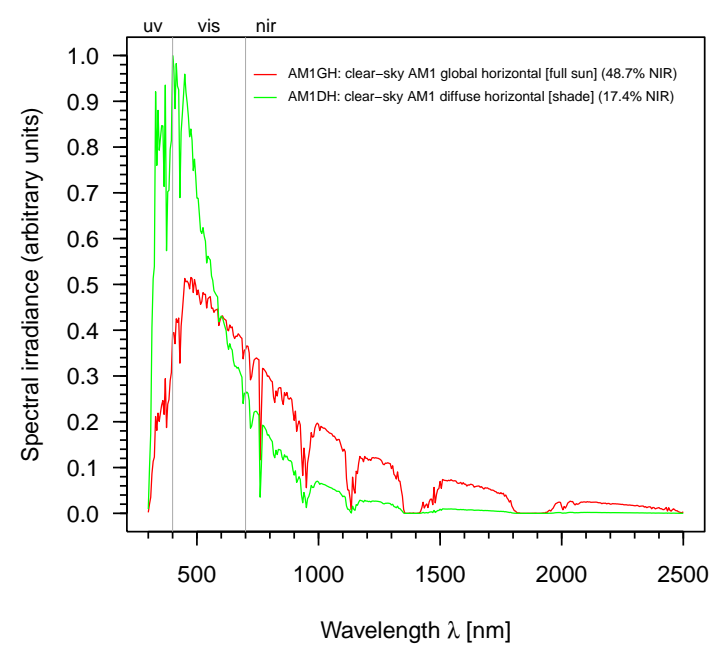

Figure 1: Solar spectral irradiances incident on a horizontal surface in full sun (AM1GH) or in shade $(\mathrm{AM} 1 \mathrm{DH})$.

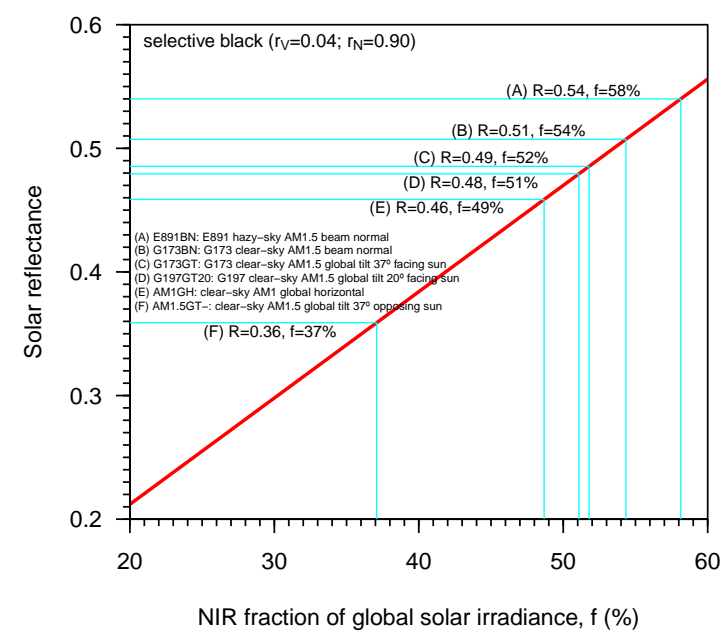

Figure 2: Solar reflectances of a selective black surface computed by weighting its nearnormal beam-hemispherical solar spectral reflectance with various solar spectral irradiances.

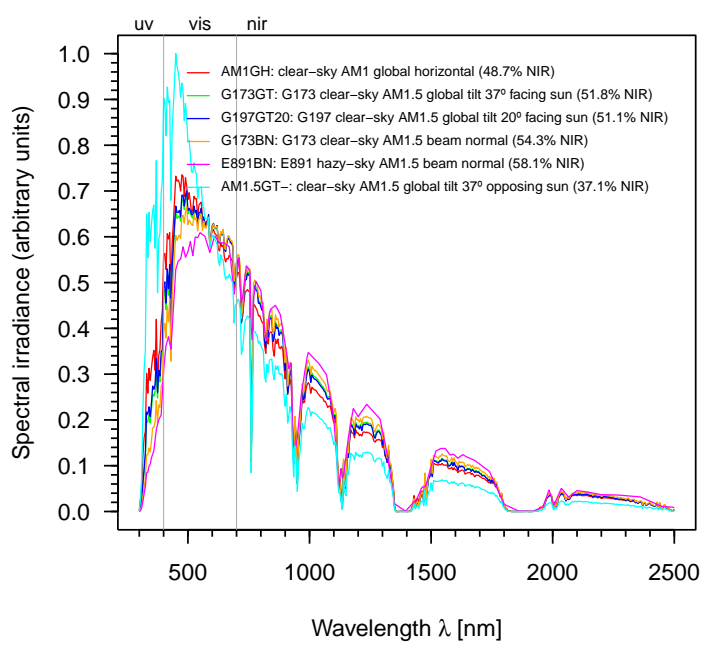

Figure 3: Assorted solar spectral irradiances used to compute selective-black solar reflectances in Figure 2.

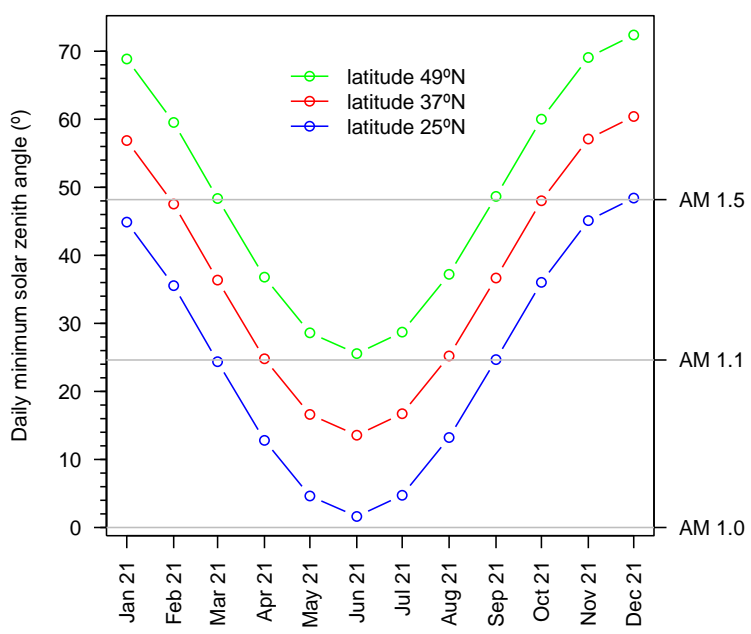

Figure 4: Daily minimum solar zenith angles and air masses on the 21st day of each month at the southernmost, mean and northernmost mainland U.S. latitudes $\left(25^{\circ} \mathrm{N}, 37^{\circ} \mathrm{N}\right.$ and $49^{\circ} \mathrm{N}$, respectively). 


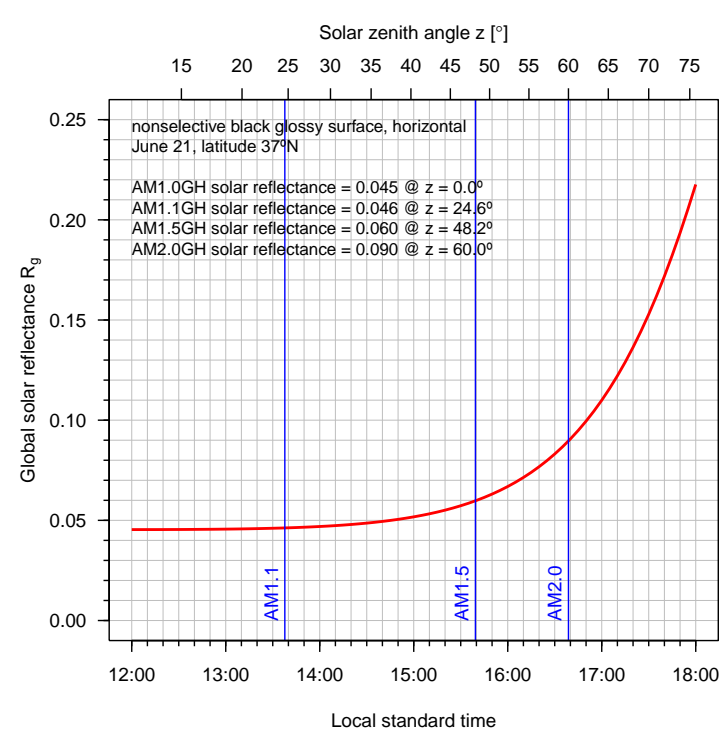

Figure 5: Variation with local standard time and solar zenith angle $z$ of the global solar reflectance $R_{\mathrm{g}}(z)$ of a nonselective black glossy horizontal surface at latitude $37^{\circ} \mathrm{N}$, charted on the afternoon of June 21 (summer solstice).

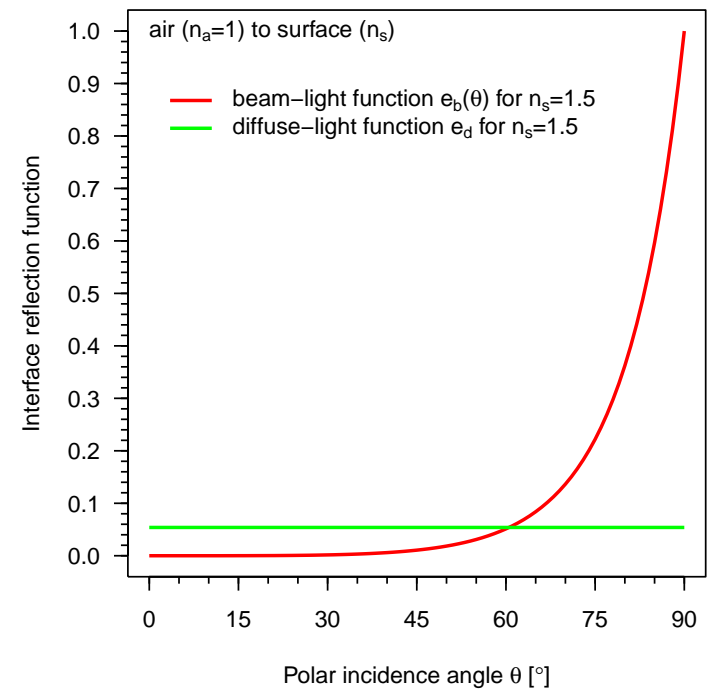

Figure 6: Interface reflection functions $e_{\mathrm{b}}(\theta)$ and $e_{\mathrm{d}}$ for light passing from air $\left(n_{\mathrm{a}}=1\right)$ to a glossy surface of real refractive index $n_{\mathrm{s}}=1.5$.

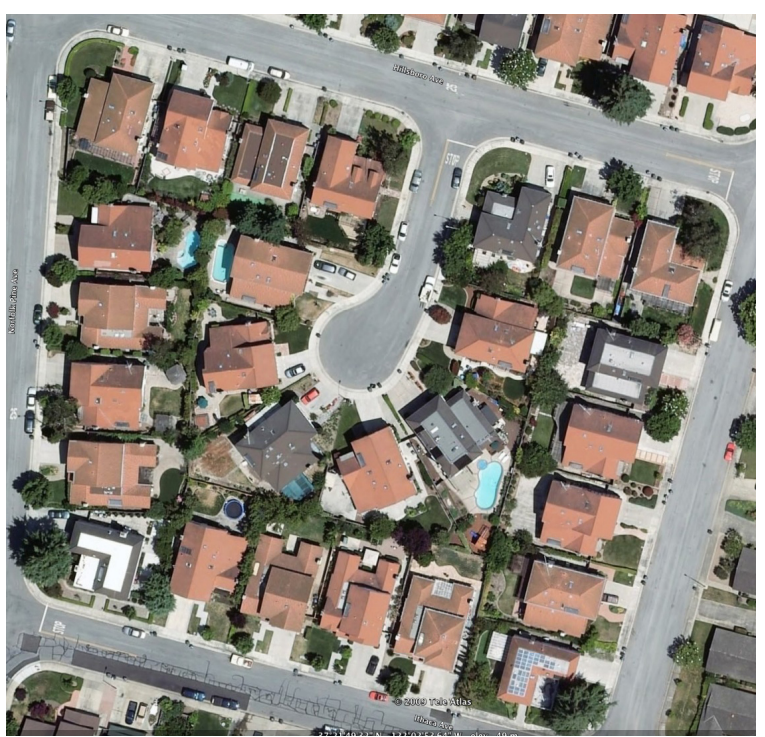

Figure 7: Aerial image of a residential neighborhood in Sunnyvale, California showing roofing planes with well-distributed azimuthal orientations. Source: Google Earth.

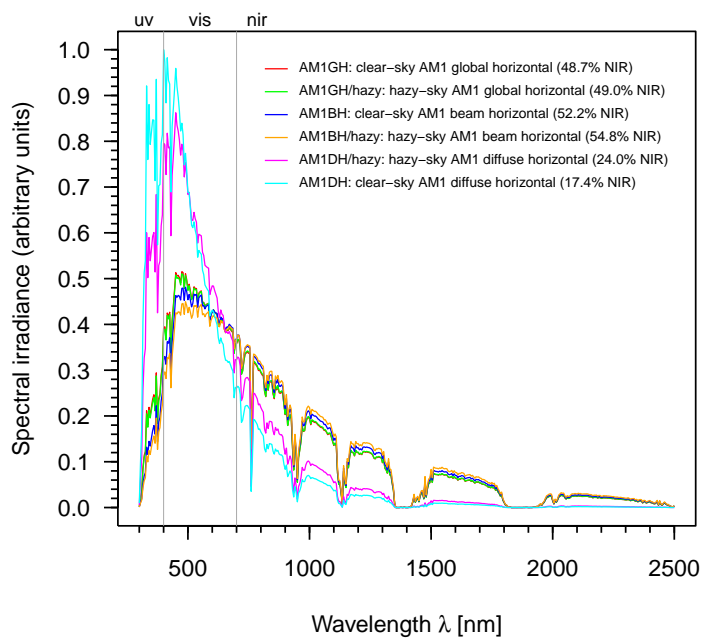

Figure 8: Clear-sky and hazy-sky air mass one horizontal solar spectral irradiances, shown with equal area under each curve to compare shapes. 


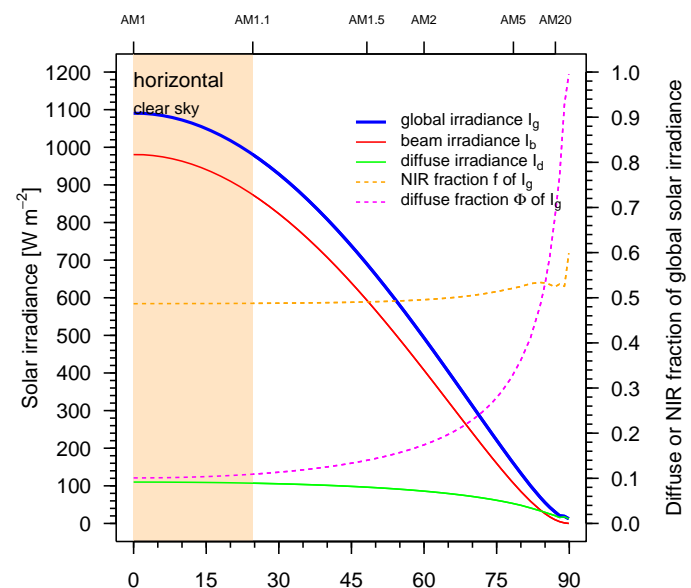

(a)

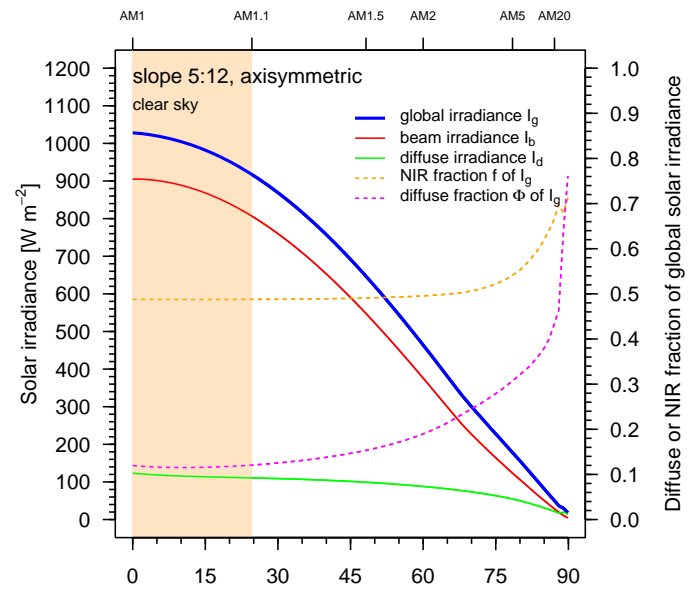

(b)

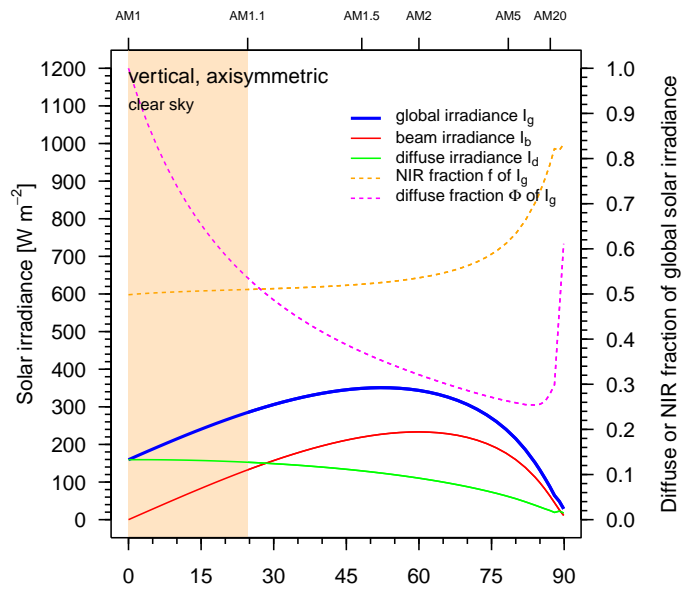

(c)

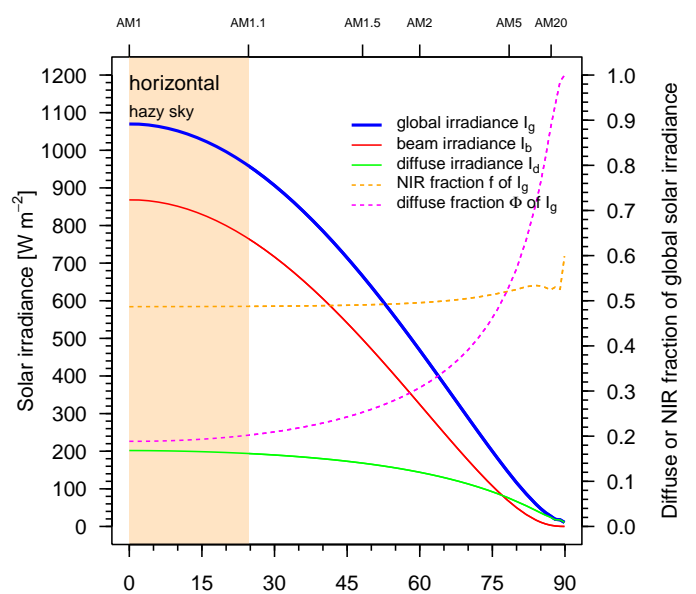

(II) Solar zenith angle $\mathrm{z}\left[{ }^{\circ}\right]$

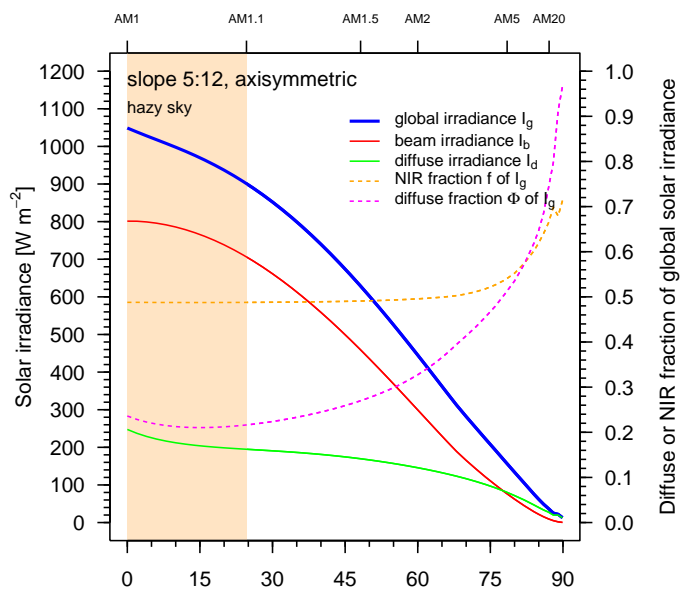

(II) Solar zenith angle $\mathrm{z}\left[{ }^{\circ}\right]$

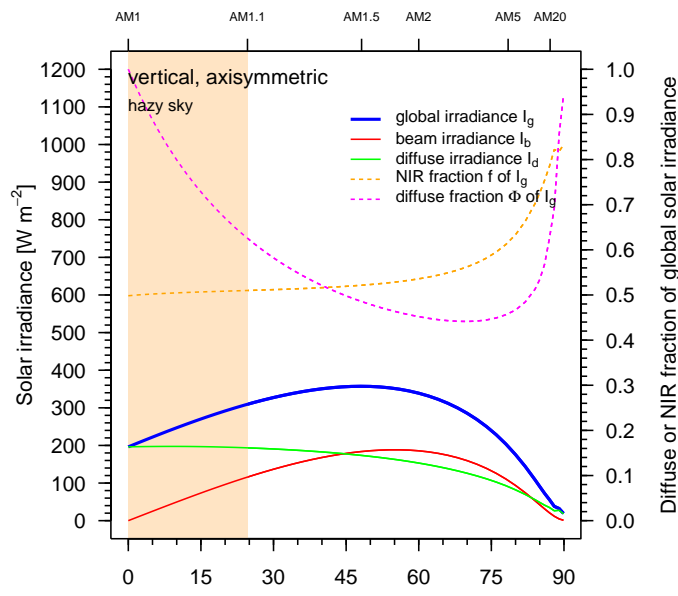

(II) Solar zenith angle $\mathrm{z}\left[^{\circ}\right]$

Figure 9: Variations with surface tilt (a. horizontal, b. slope 5:12 [23] or c. vertical); sky condition (I. clear or II. hazy); and solar zenith angle $z\left(0-90^{\circ}\right)$ of an axisymmetric surface's global solar irradiance $I_{\mathrm{g}}(z)$, beam solar irradiance $I_{\mathrm{b}}(z)$, diffuse solar irradiance $I_{\mathrm{d}}(z)$, diffuse fraction $\Phi(z)$ of $I_{\mathrm{g}}(z)$ and NIR fraction $f_{\mathrm{g}}$ of $I_{\mathrm{g}}(z)$. Air masses up to 1.1 are shaded. 


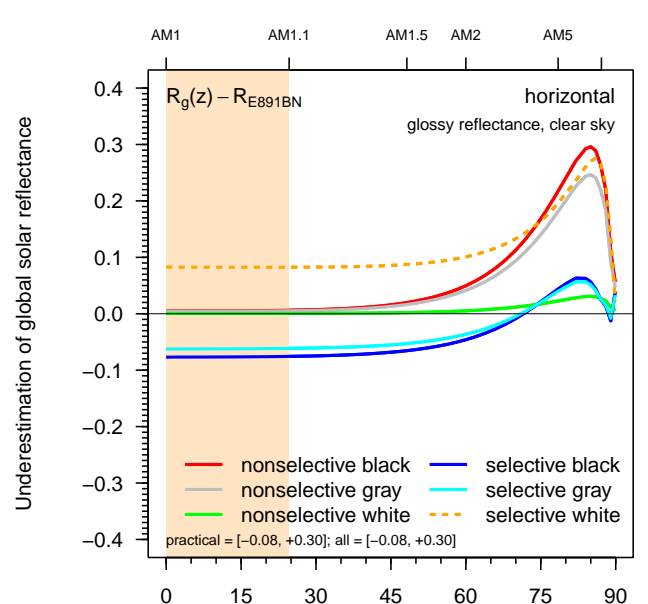

(a)

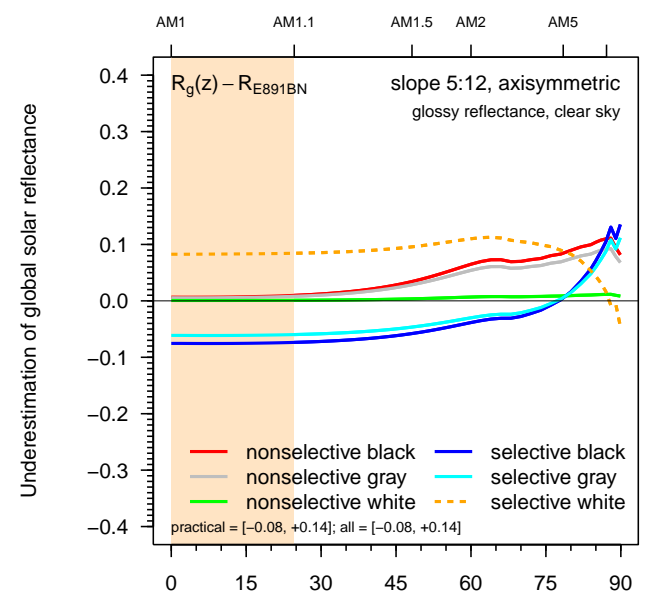

(b)

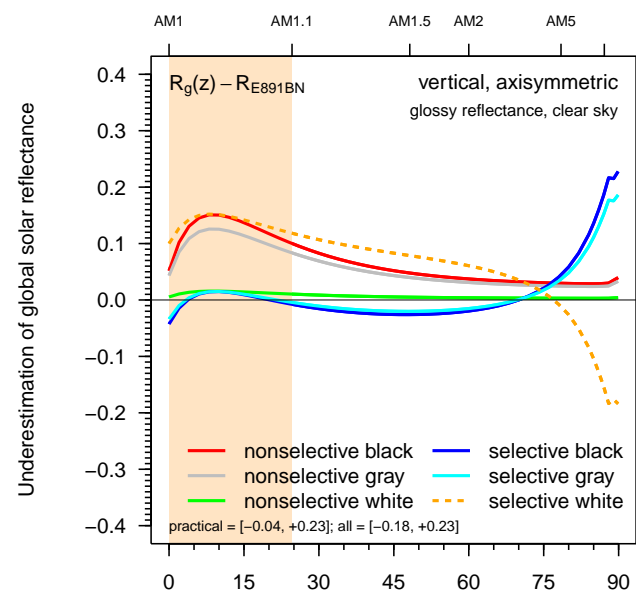

(c)

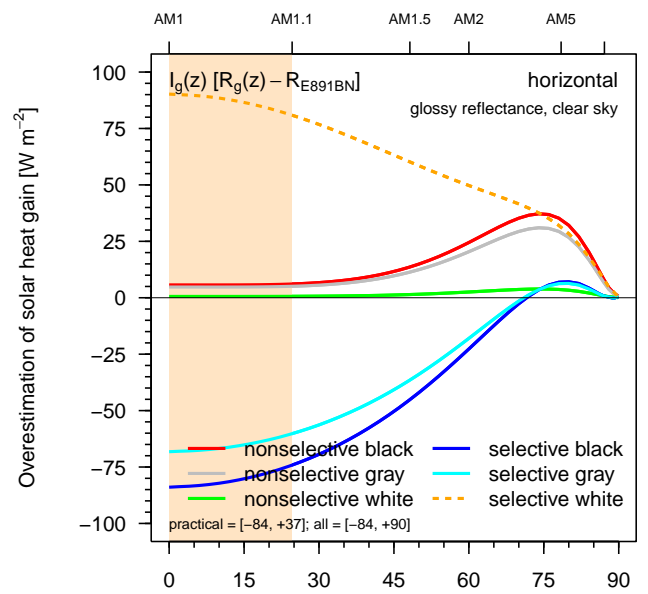

(II) Solar zenith angle $z\left[^{\circ}\right]$

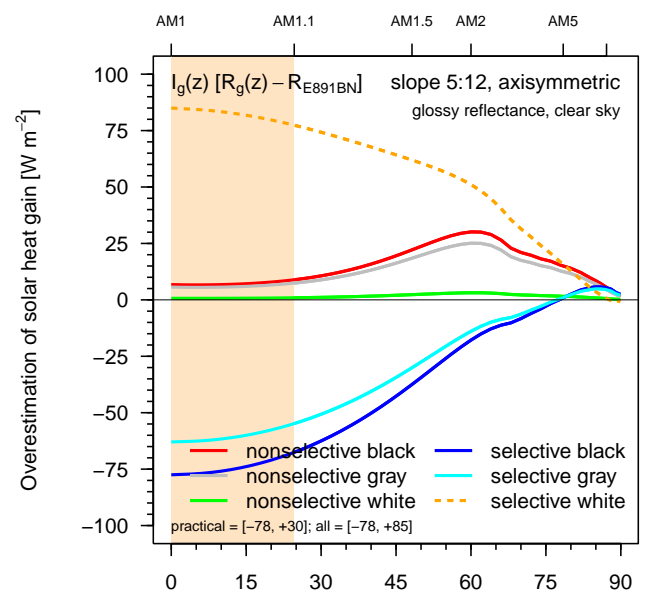

(II) Solar zenith angle $\mathrm{z}\left[{ }^{\circ}\right]$

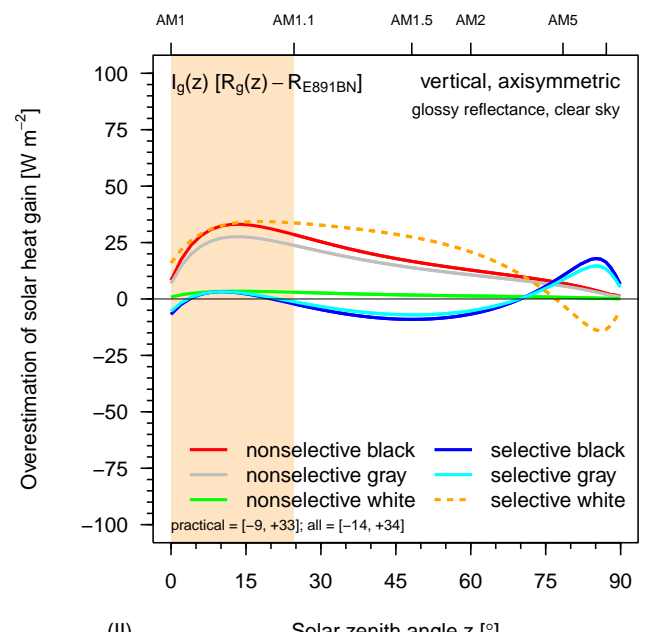

(II) Solar zenith angle $\mathrm{z}\left[{ }^{\circ}\right]$

Figure 10: Variations with surface tilt (a. horizontal, b. slope 5:12 [23] or c. vertical) and solar zenith angle $z\left(0-90^{\circ}\right)$ of the errors in global solar reflectance and solar heat gain of a glossy axisymmetric surface when instantaneous global solar reflectance $R_{\mathrm{g}}(z)$ is replaced by $R_{1}$ $=\mathrm{E} 891 \mathrm{BN}$ solar reflectance $R_{\mathrm{E} 891 \mathrm{BN}}$. Shown for a clear sky are (I) underestimation $\Delta R_{1}(z)$ of global solar reflectance and (II) overestimation $\Delta Q_{1}(z)$ of solar heat gain. Air masses up to 1.1 are Snapress. 


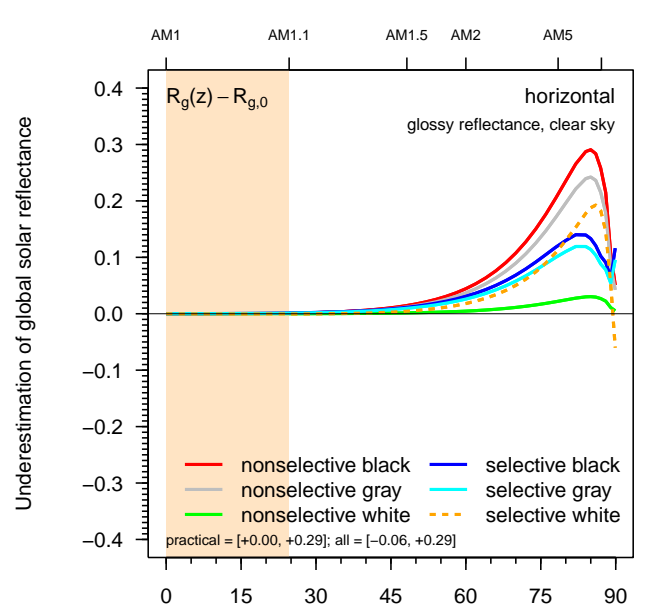

(a)

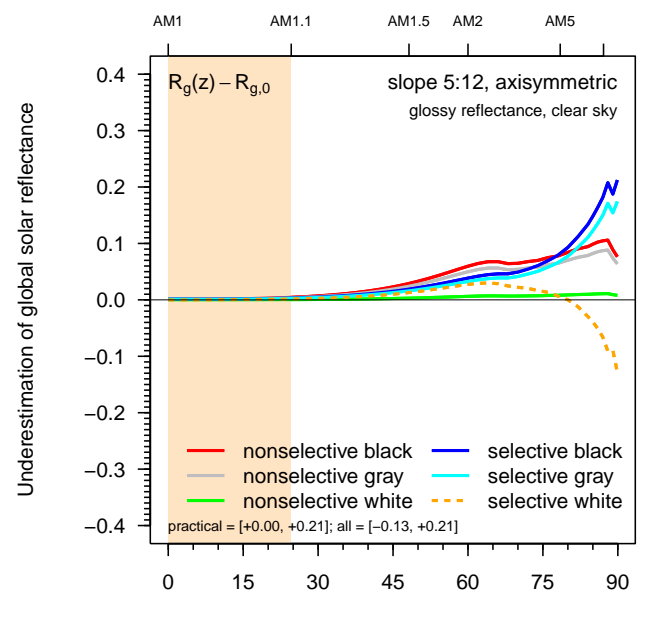

(b)

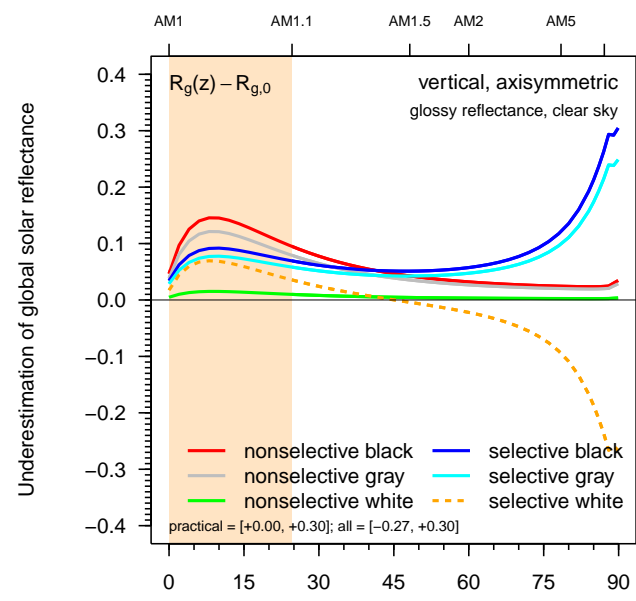

(c)

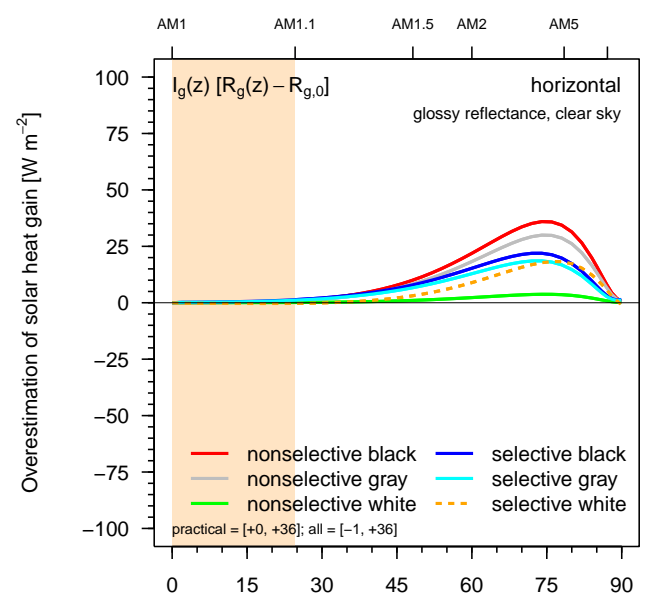

(II) Solar zenith angle $z\left[^{\circ}\right]$

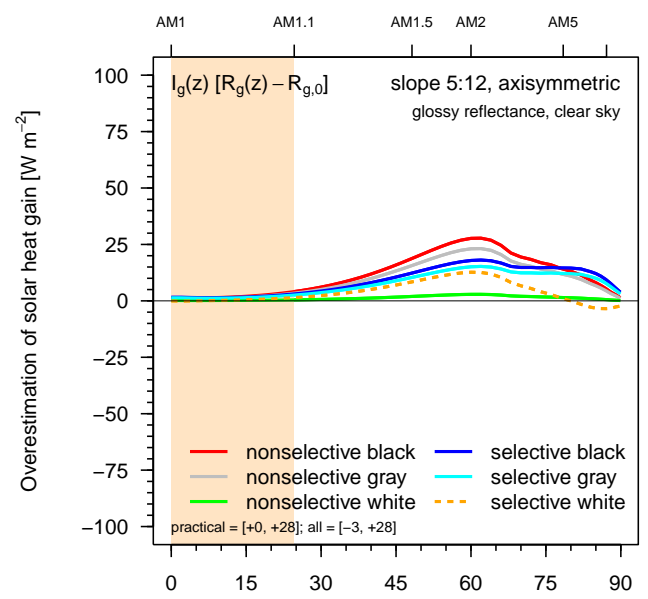

(II) Solar zenith angle $\mathrm{z}\left[{ }^{\circ}\right]$

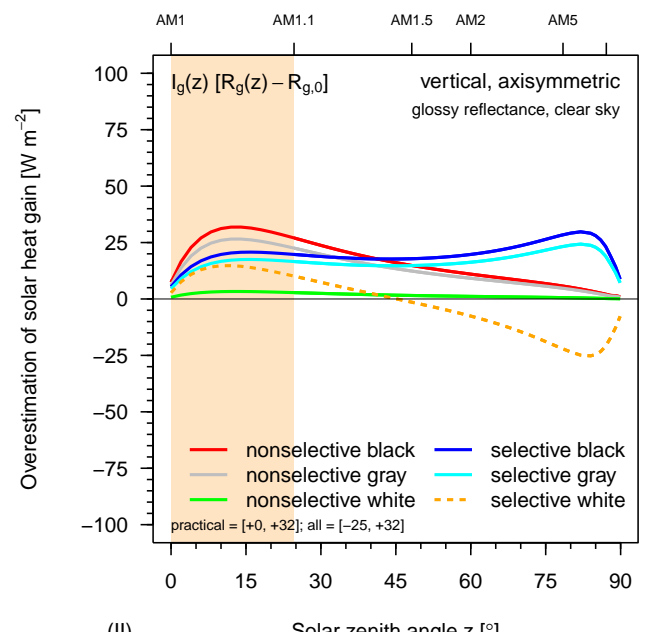

(II) Solar zenith angle $\mathrm{z}\left[{ }^{\circ}\right]$

Figure 11: Variations with surface tilt (a. horizontal, b. slope 5:12 [23] or c. vertical) and solar zenith angle $z\left(0-90^{\circ}\right)$ of the errors in global solar reflectance and solar heat gain of a glossy axisymmetric surface when instantaneous global solar reflectance $R_{\mathrm{g}}(z)$ is replaced by $R_{2}=$ AM1GH solar reflectance $R_{\mathrm{g}, 0}$. Shown for a clear sky are (I) underestimation $\Delta R_{2}(z)$ of global solar reflectance and (II) overestimation $\Delta Q_{2}(z)$ of solar heat gain. Air masses up to 1.1 are shaded. 


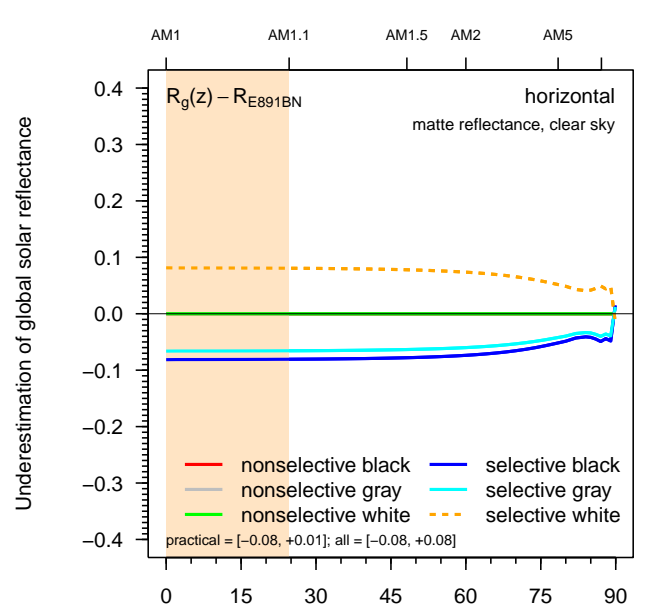

(a)

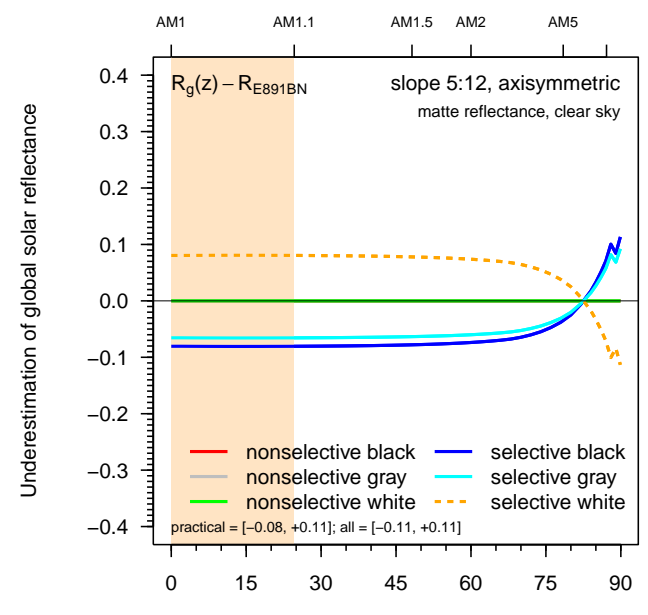

(b)

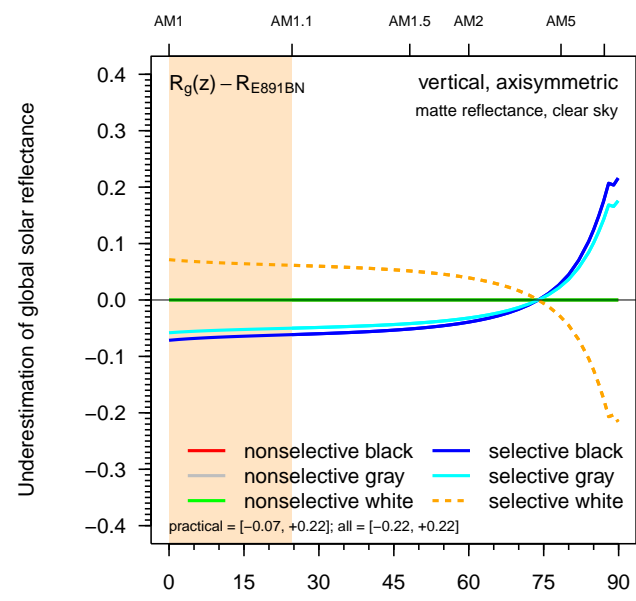

(c)

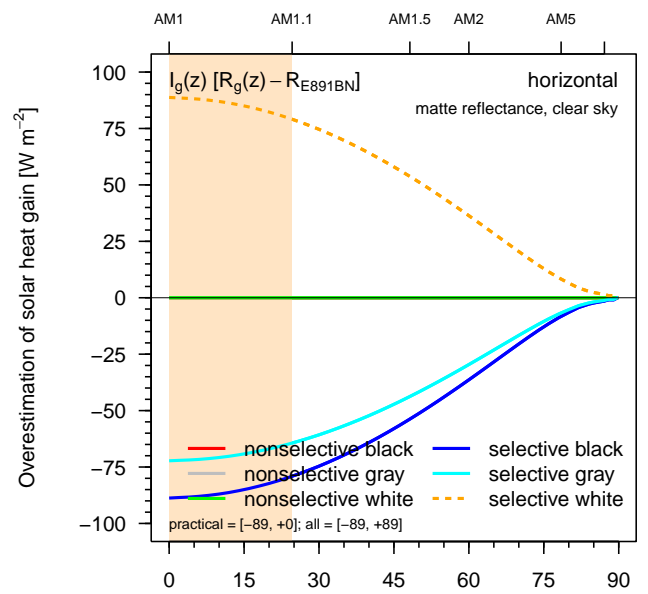

(II) Solar zenith angle $z\left[^{\circ}\right]$

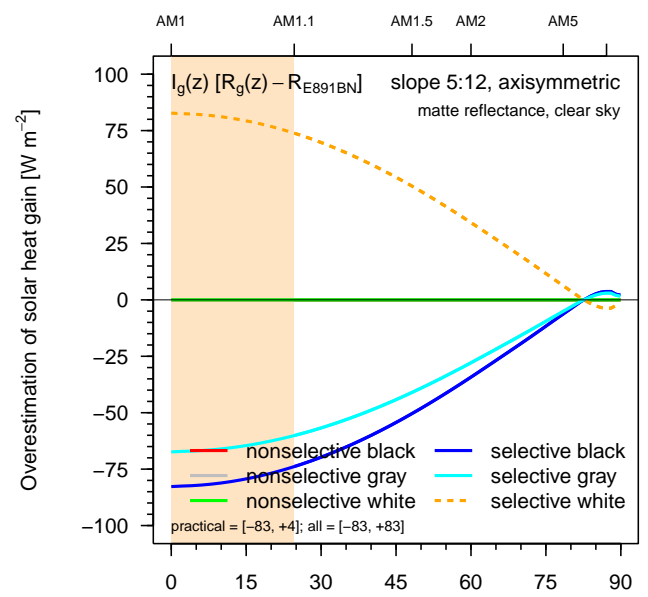

(II) Solar zenith angle $\mathrm{z}\left[{ }^{\circ}\right]$

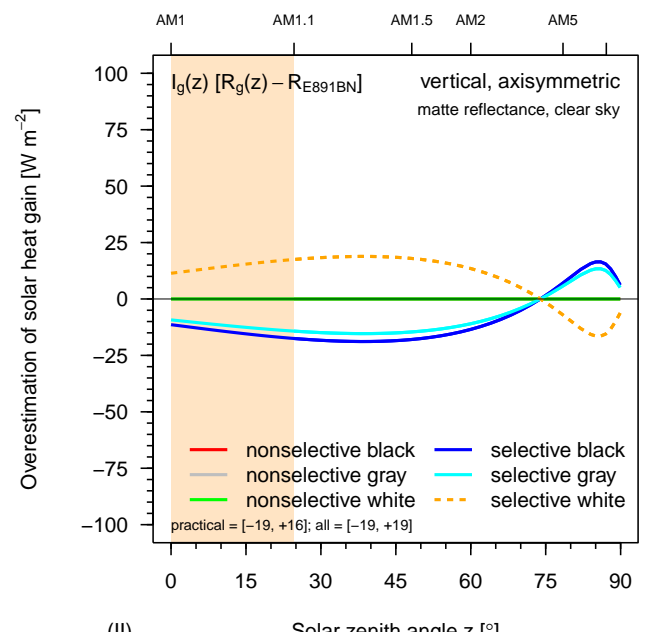

(II) Solar zenith angle $\mathrm{z}\left[{ }^{\circ}\right]$

Figure 12: Variations with surface tilt (a. horizontal, b. slope 5:12 [23] or c. vertical) and solar zenith angle $z\left(0-90^{\circ}\right)$ of the errors in global solar reflectance and solar heat gain of a matte axisymmetric surface when instantaneous global solar reflectance $R_{\mathrm{g}}(z)$ is replaced by $R_{1}$ $=\mathrm{E} 891 \mathrm{BN}$ solar reflectance $R_{\mathrm{E} 891 \mathrm{BN}}$. Shown for a clear sky are (I) underestimation $\Delta R_{1}(z)$ of global solar reflectance and (II) overestimation $\Delta Q_{1}(z)$ of solar heat gain. Air masses up to 1.1 are Inapress 


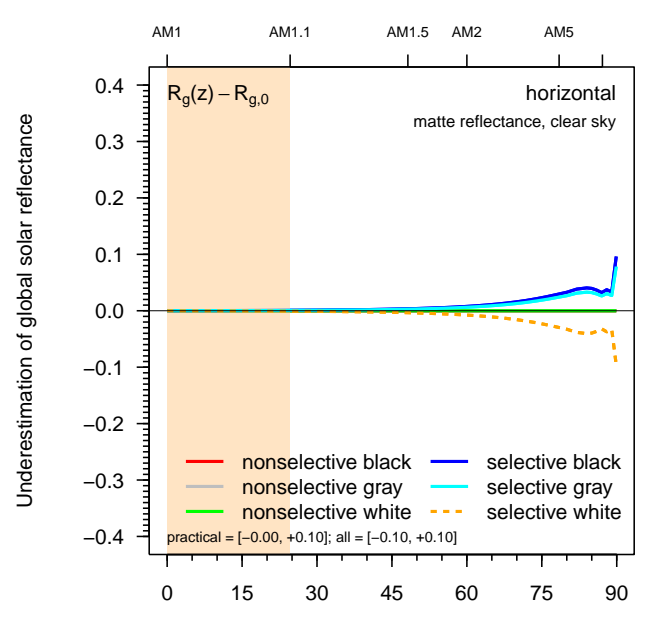

(a)

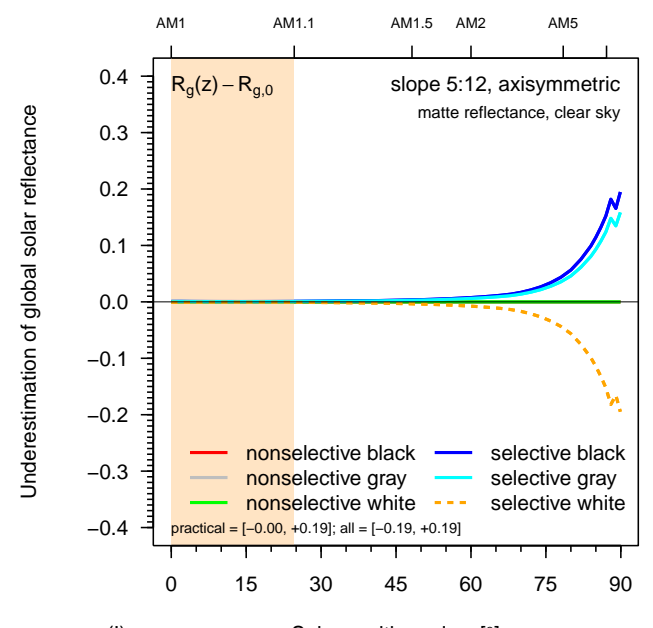

(b)

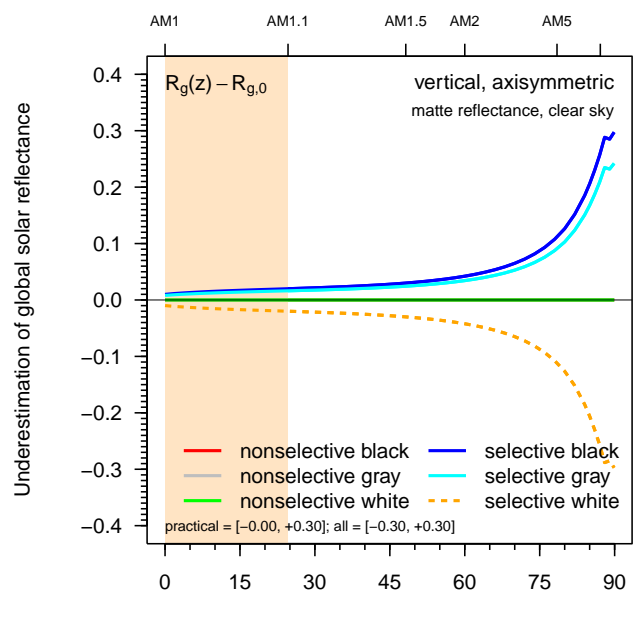

(c)

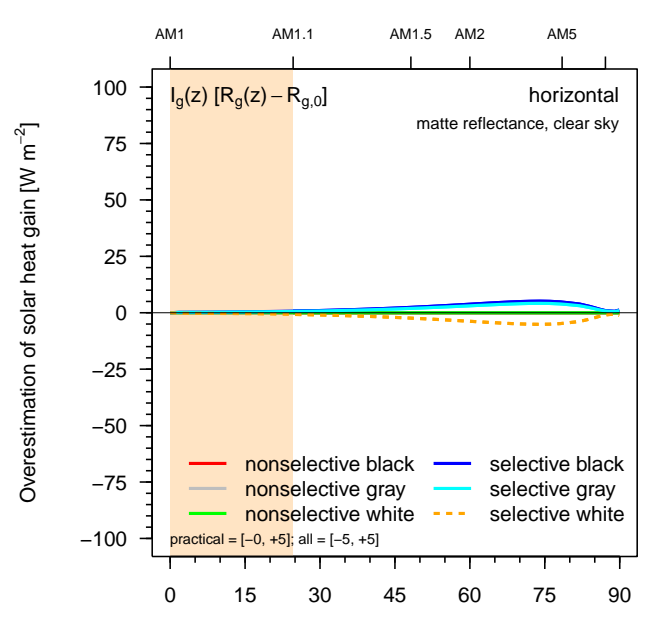

(II) Solar zenith angle $\mathrm{z}\left[{ }^{\circ}\right]$

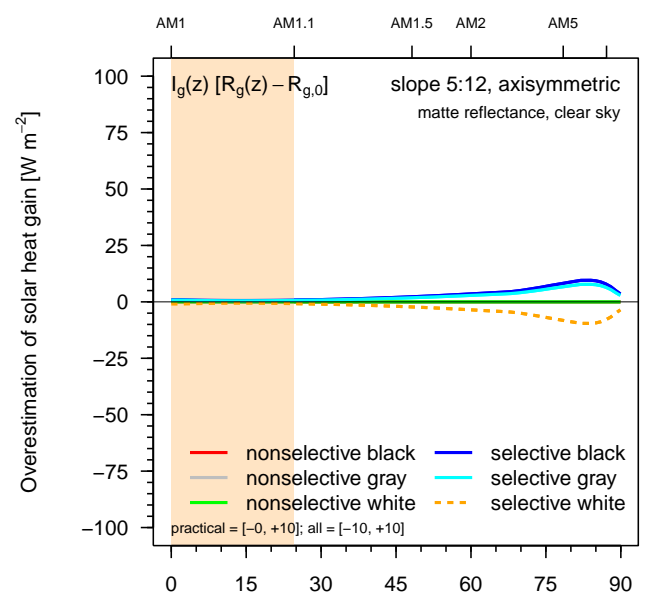

(II) Solar zenith angle $\mathrm{z}\left[{ }^{\circ}\right]$

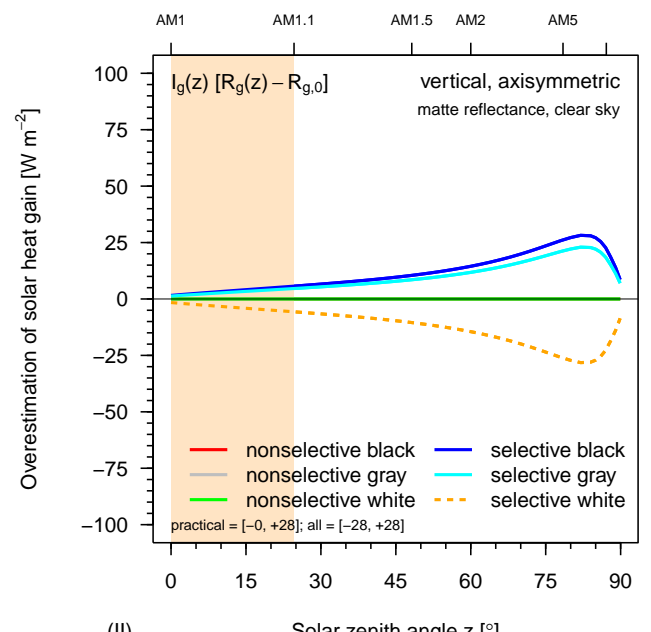

(II) Solar zenith angle $\mathrm{z}\left[{ }^{\circ}\right]$

Figure 13: Variations with surface tilt (a. horizontal, b. slope 5:12 [23] or c. vertical) and solar zenith angle $z\left(0-90^{\circ}\right)$ of the errors in global solar reflectance and solar heat gain of a matte axisymmetric surface when instantaneous global solar reflectance $R_{\mathrm{g}}(z)$ is replaced by $R_{2}=$ AM1GH solar reflectance $R_{\mathrm{g}, 0}$. Shown for a clear sky are (I) underestimation $\Delta R_{2}(z)$ of global solar reflectance and (II) overestimation $\Delta Q_{2}(z)$ of solar heat gain. Air masses up to 1.1 are shaded. 


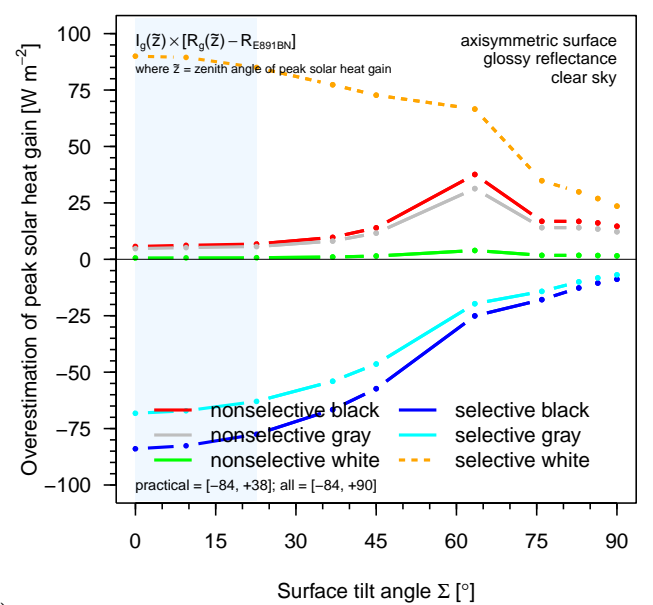

(a)

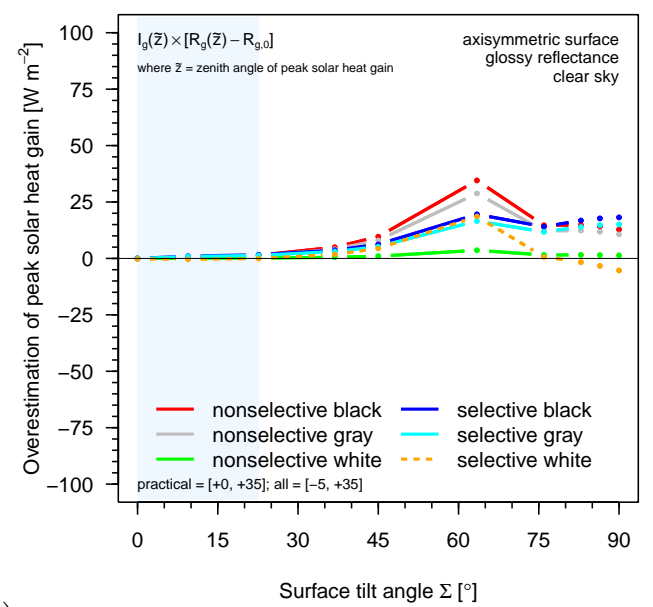

(b)

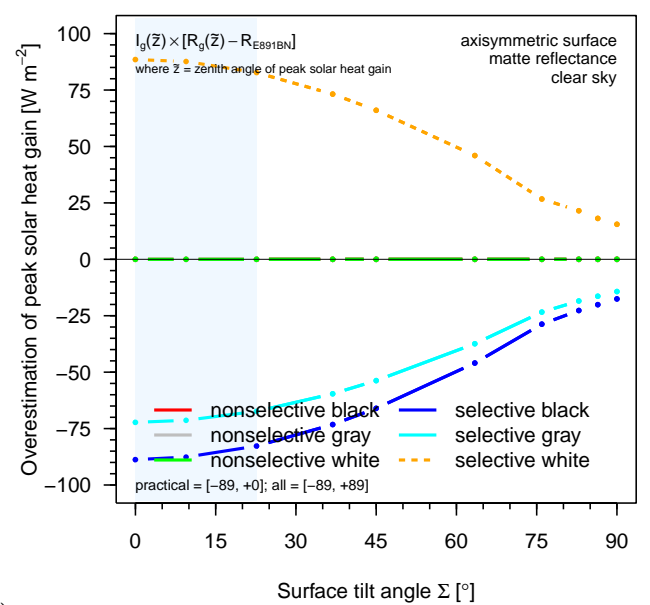

(c)

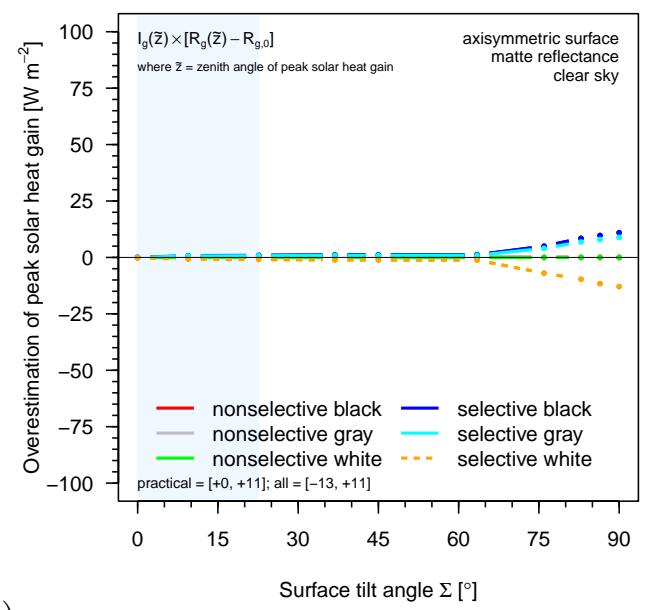

(d)

Figure 14: Variation with surface tilt angle $\Sigma\left(0-90^{\circ}\right)$ of the overestimation $\Delta Q_{\text {peak }, j}$ of peak solar heat gain under a clear sky when the global solar reflectance $R_{\mathrm{g}}(\tilde{z})$ of a glossy surface is replaced by (a) $R_{1}=\mathrm{E} 891 \mathrm{BN}$ solar reflectance $R_{\mathrm{E} 891 \mathrm{BN}}$ or (b) $R_{2}=\mathrm{AM} 1 \mathrm{GH}$ solar reflectance $R_{\mathrm{g}, 0}$; or when $R_{\mathrm{g}}(\tilde{z})$ of a matte surface is replaced by (c) $R_{1}=R_{\mathrm{E} 891 \mathrm{BN}}$ or $(\mathrm{d}) R_{2}=R_{\mathrm{g}, 0}$. Tilts up to $5: 12\left[23^{\circ}\right]$ are shaded. 


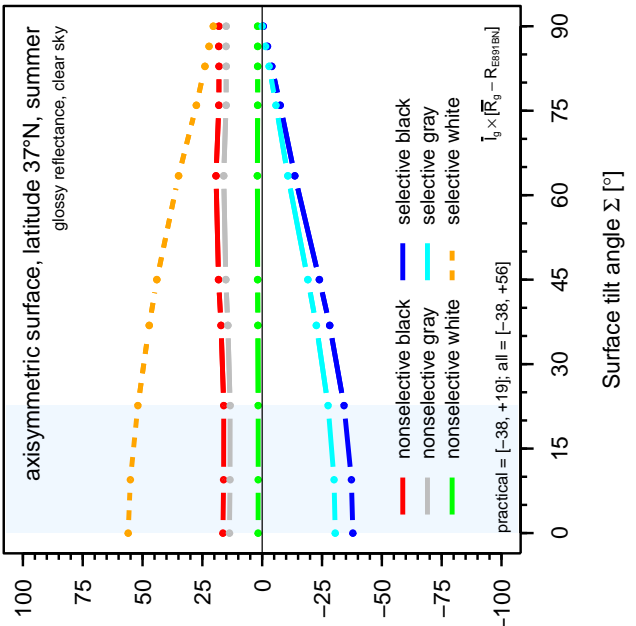

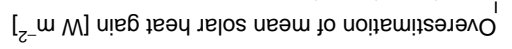
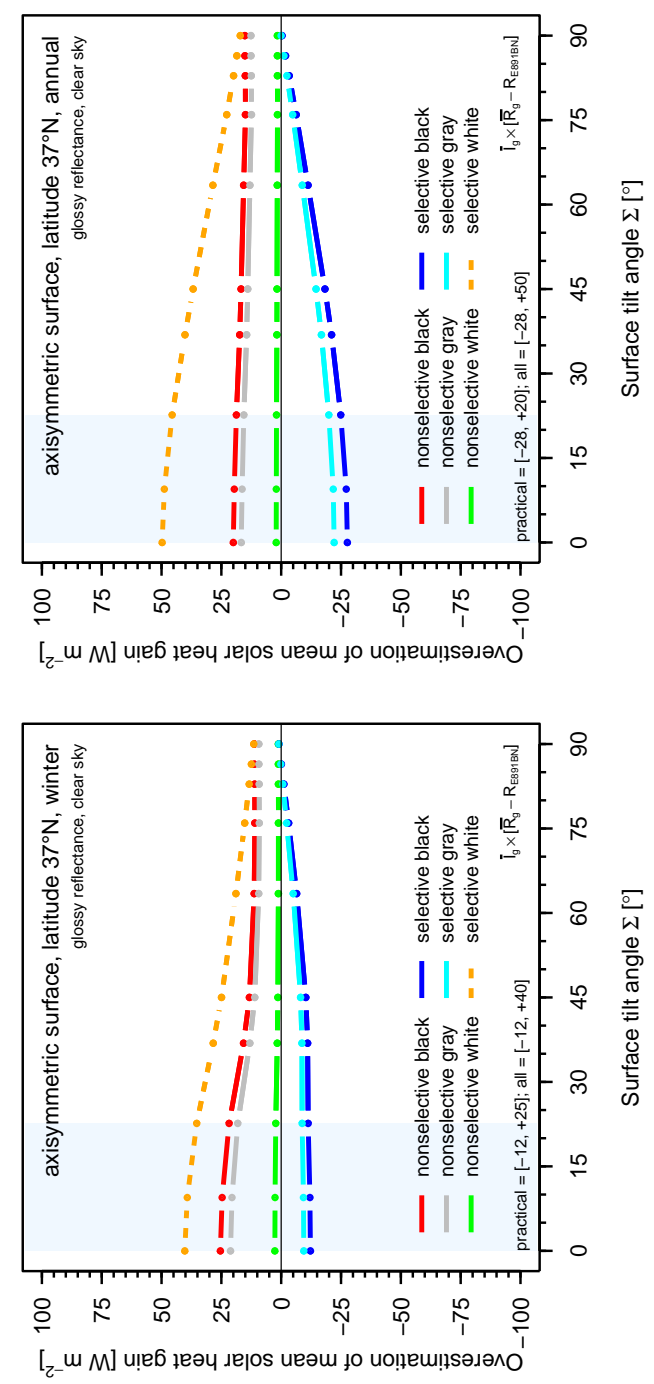

$\overbrace{}^{\pi}$

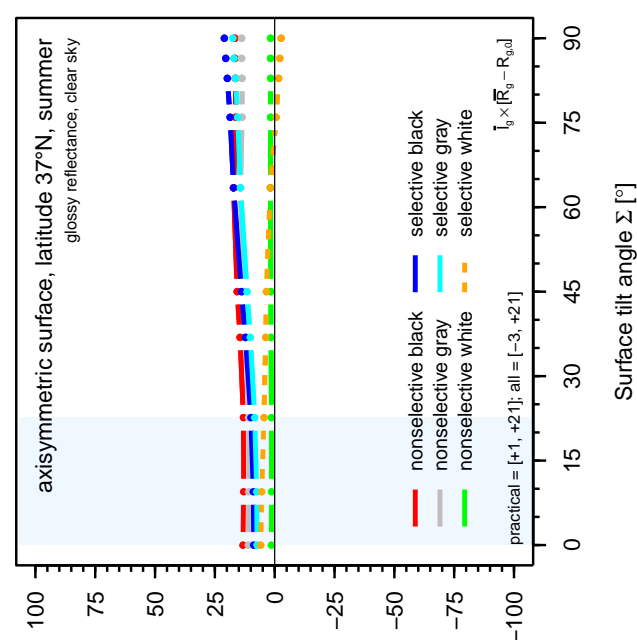

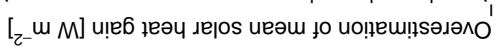
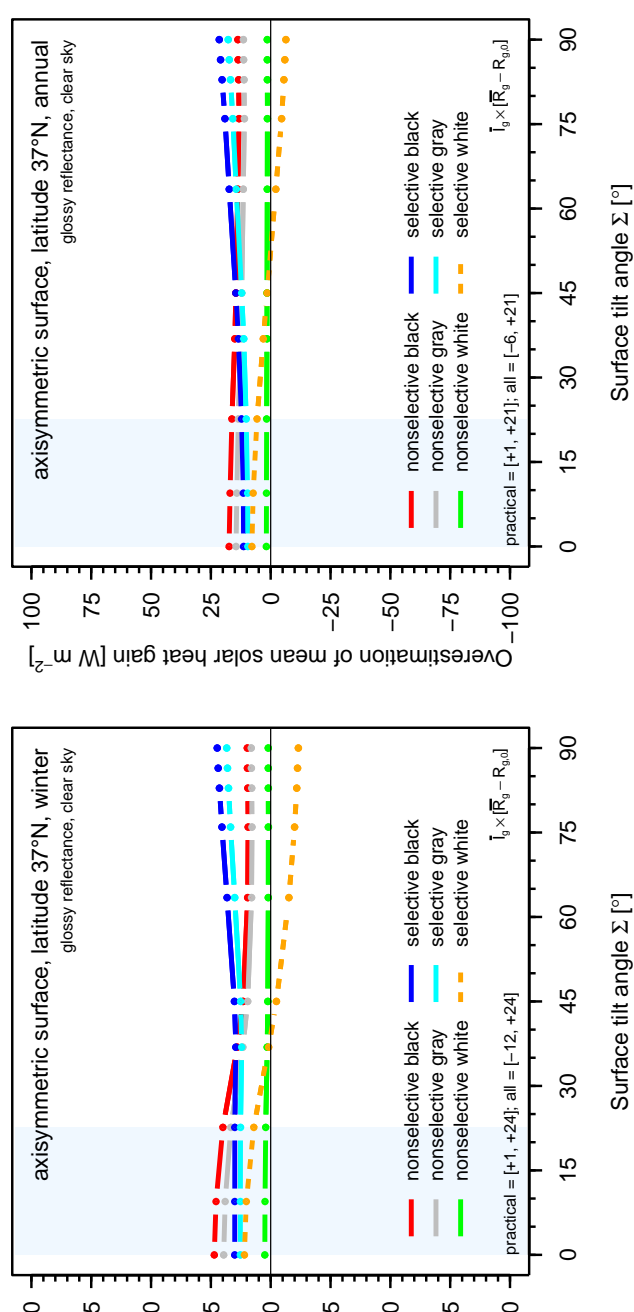

은 요

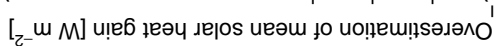

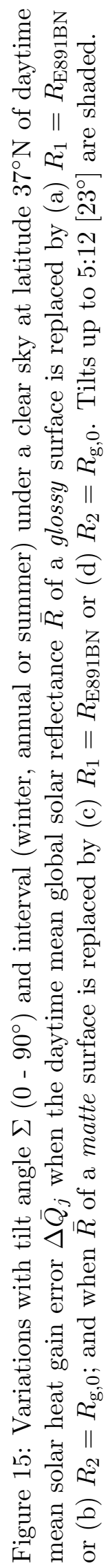




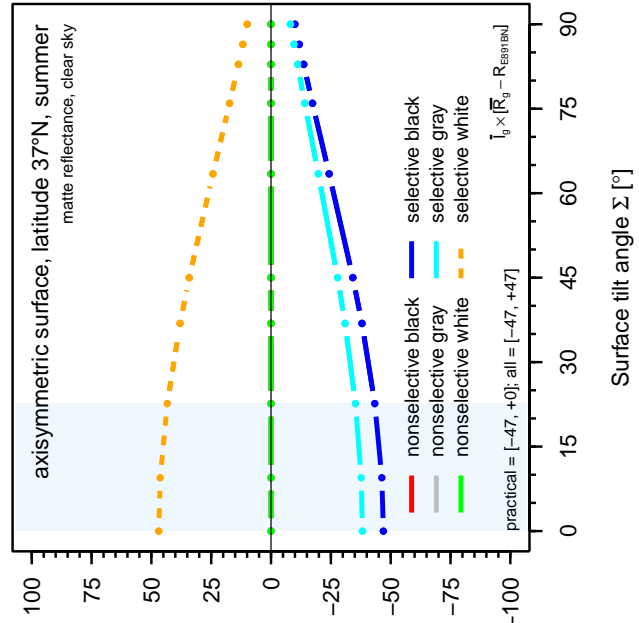

[_-
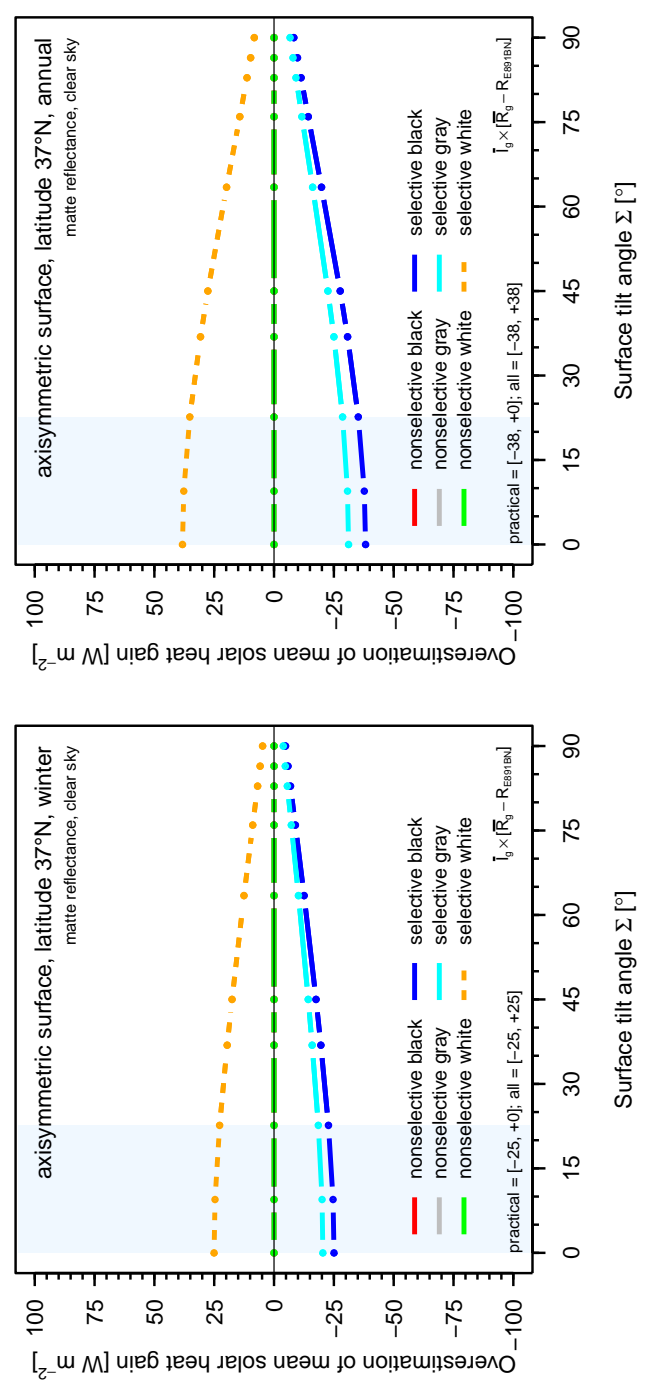
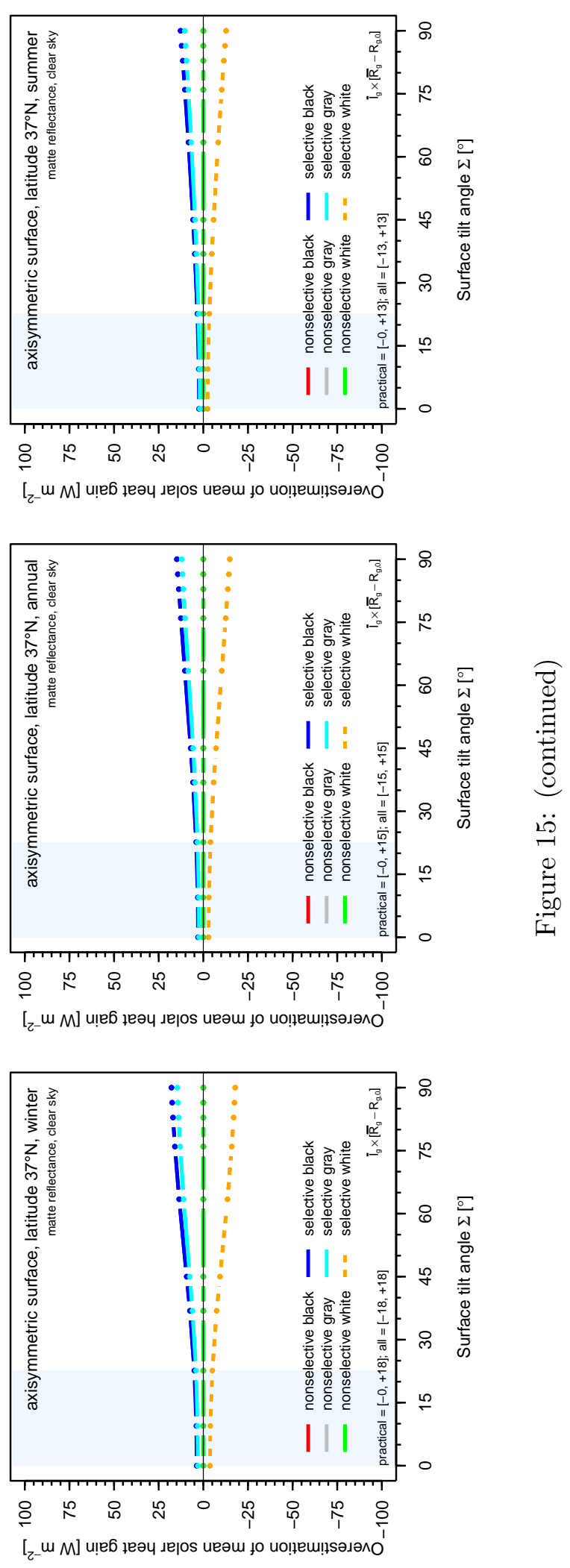

Ә

April 28, 2010 


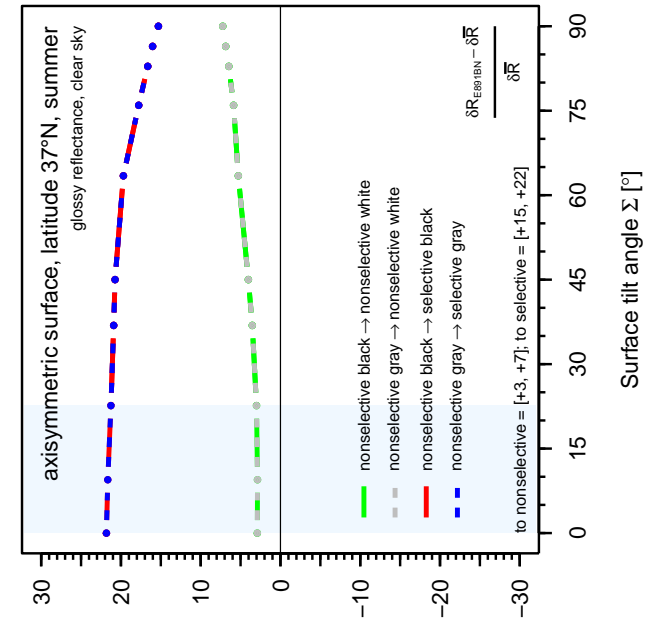

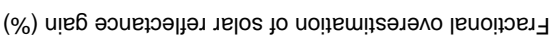

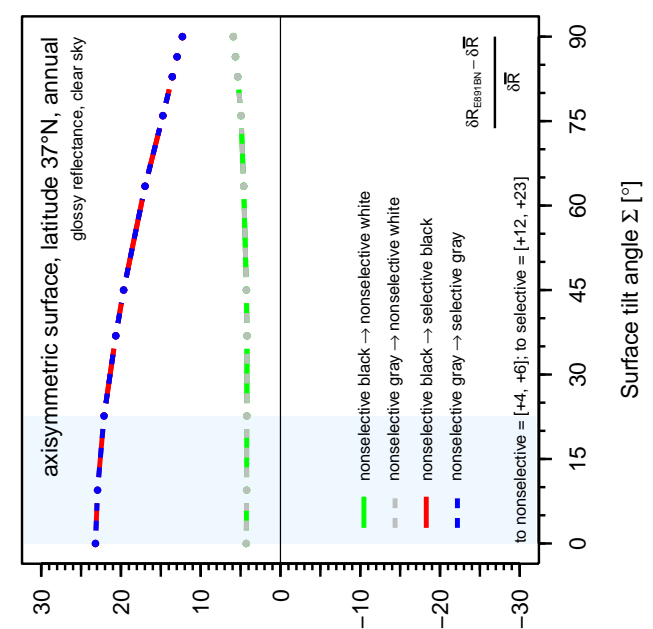

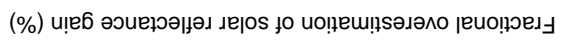

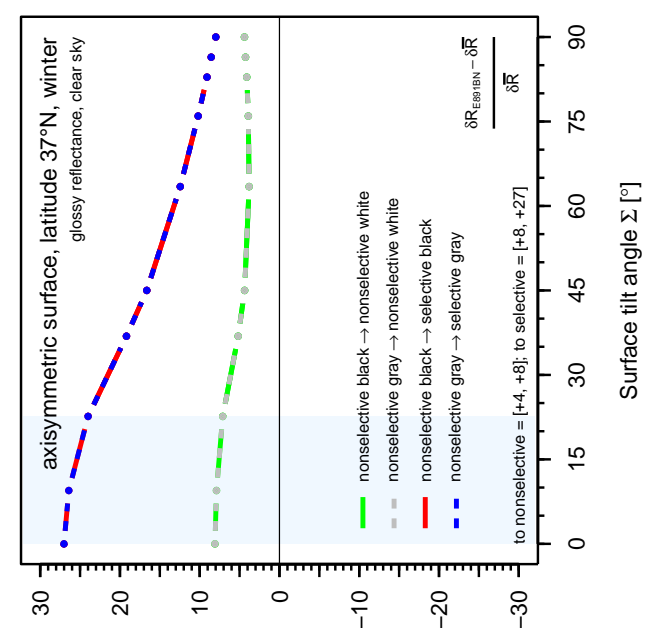

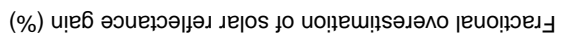

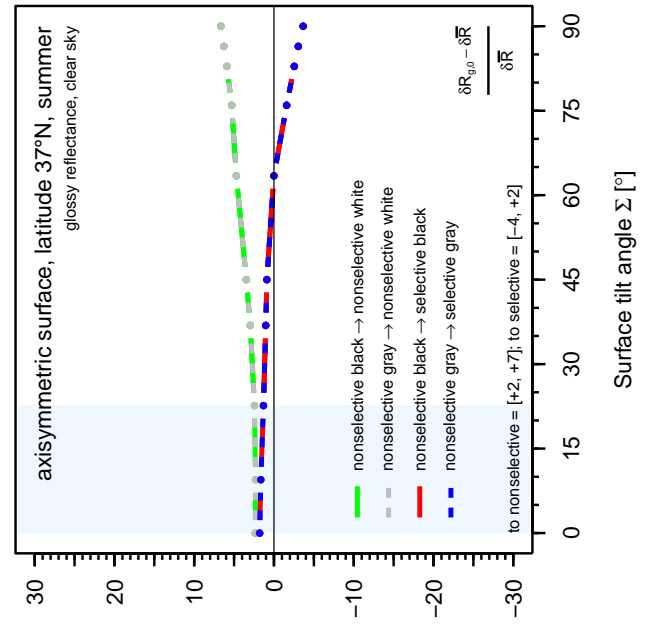

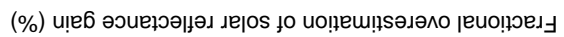

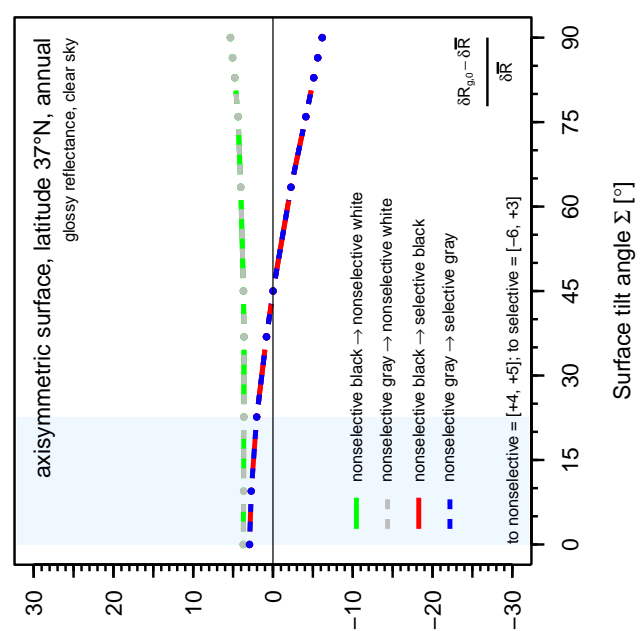

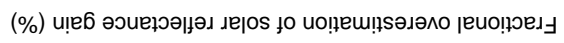

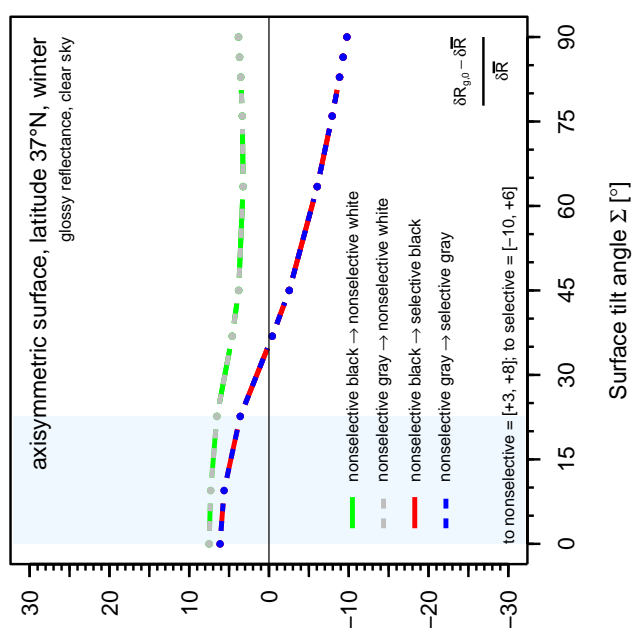

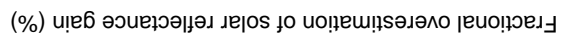

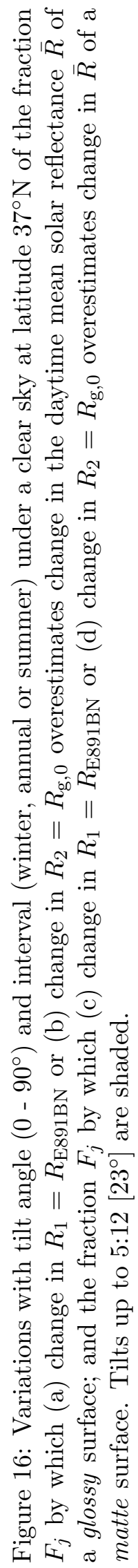

April 28, 2010 


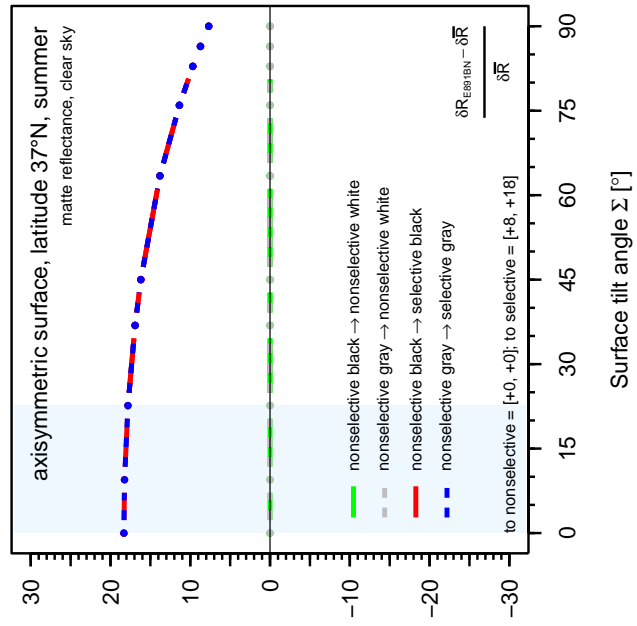

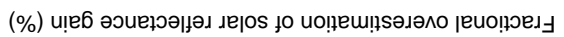

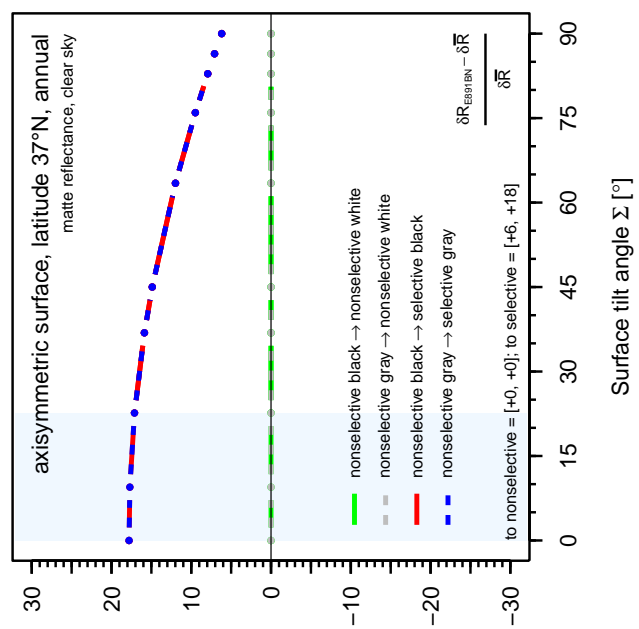

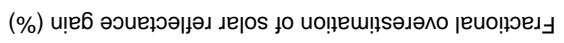

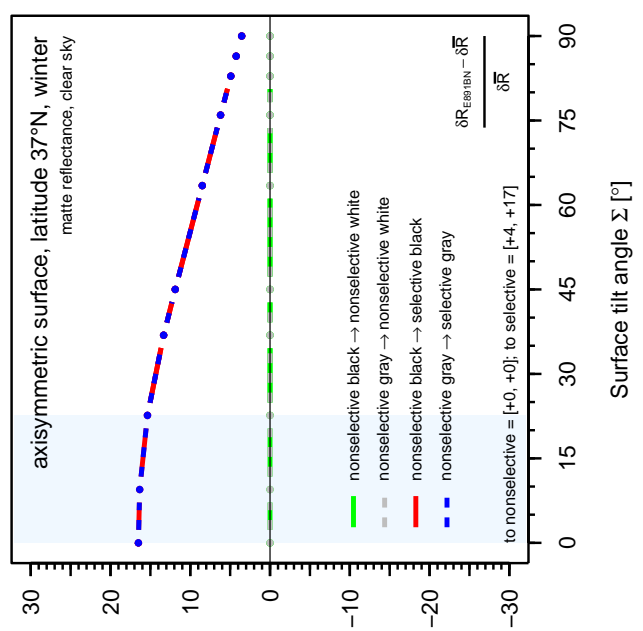

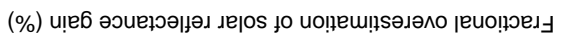

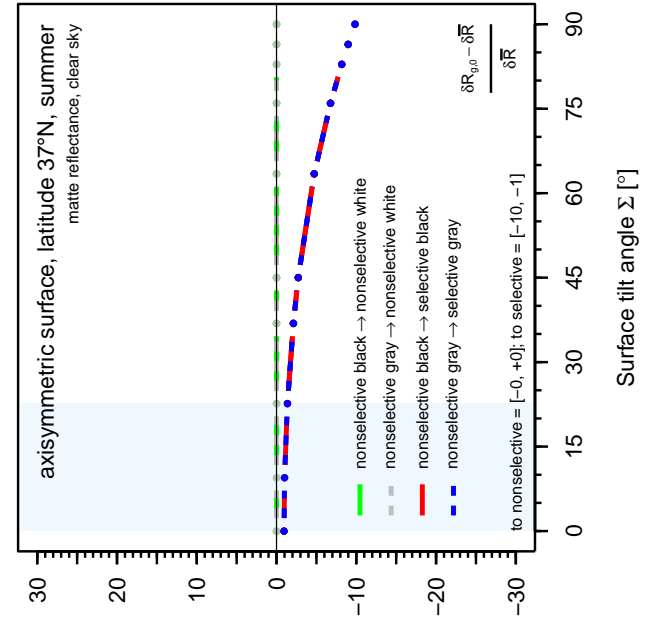

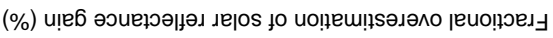

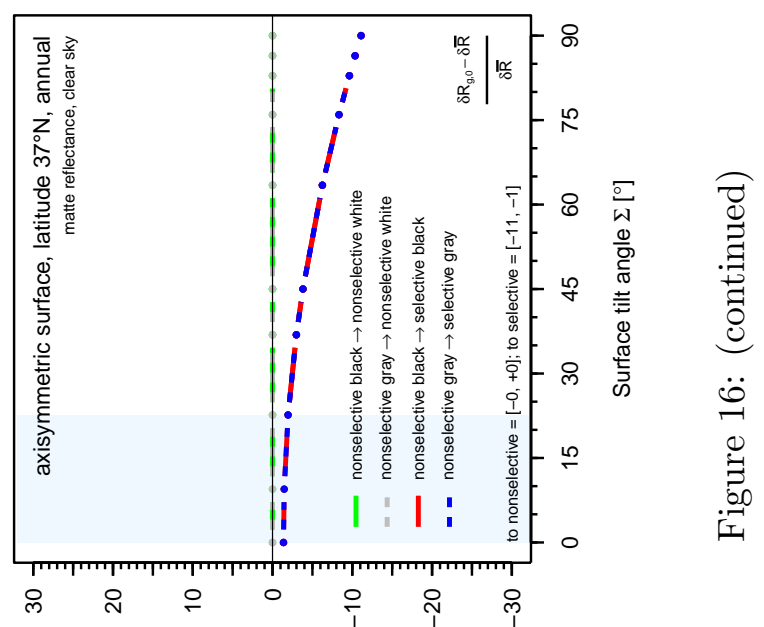

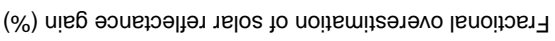

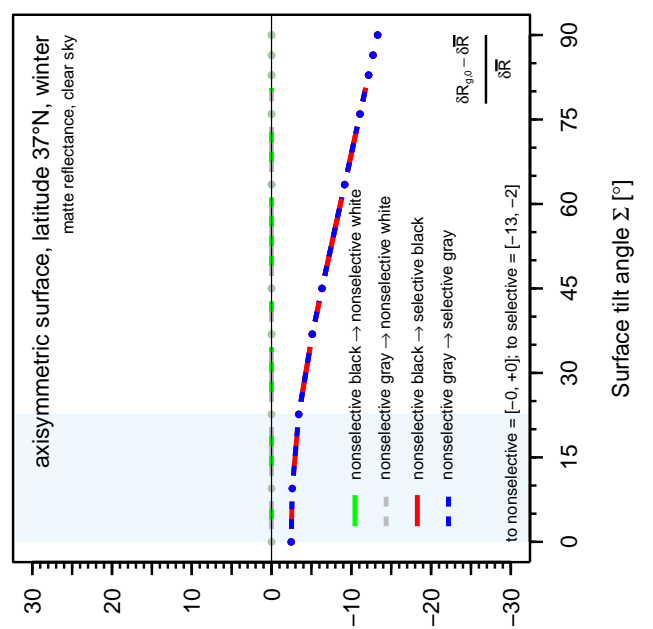

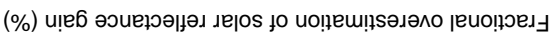




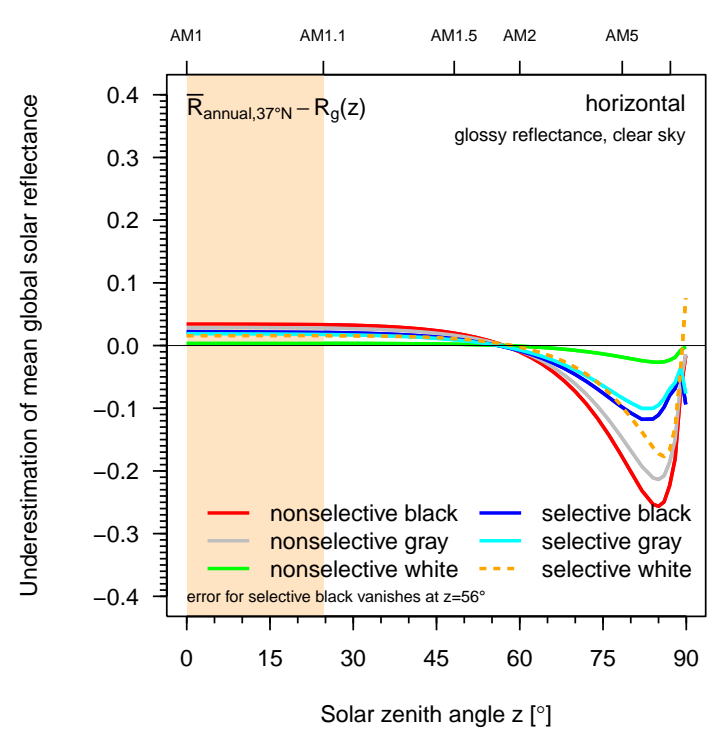

Figure 17: Variation with solar zenith angle $z$ of the amount by which the instantaneous global solar reflectance $R_{\mathrm{g}}(z)$ of a glossy horizontal surface underestimates its annual mean global solar reflectance $\bar{R}_{\text {annual }}$ at latitude $37^{\circ} \mathrm{N}$. 